\title{
The Sub-Lethal and Density-Dependent Effects of an Invasive Wasp on an Endemic Ant
}

By

Allan Burne

A thesis submitted to the

Victoria University of Wellington

in fulfilment of the requirements for the degree of

Doctor of Philosophy in Ecology and Biodiversity

Victoria University of Wellington

2012

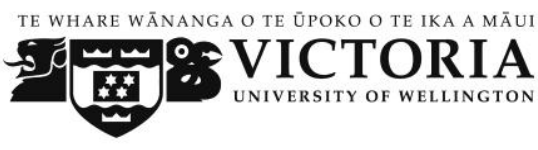





\section{Abstract}

The detrimental effects of invasive species on recipient taxa are most frequently reported in terms of displacement or extinction. However, there may be other less obvious effects. For example, a reduction in resource availability mediated by a novel competitor may affect growth and development in recipient species. The cost of aggressive competitive interactions with invasives may promote niche shifts or altered spatial distribution to minimise competition, and intense predation by exotic species may result in a reduced effective population size with a concomitant reduction in genetic diversity. In this thesis I examined the sub-lethal effects of varying densities of the invasive competitor and predator Vespula vulgaris on the morphology, behaviour, population genetics and spatial distribution of the New Zealand endemic ant Prolasius advenus.

The restriction of food resources can result in reduced worker size and altered scaling relationships of adult body parts in ants. Measurements of nine morphological characters from $P$. advenus worker ants collected from sites of varying wasp density revealed that workers were significantly smaller where there were more wasps. I also found evidence of allometric scaling relationships among body parts, which varied between areas of high and low wasp density. In particular the scaling relationships between the abdominal segments and overall size were found to be weaker where there were more wasps. This scaling variation resulted in ant workers with proportionally smaller abdomens in areas where wasps were most abundant, which might reduce their resource gathering and defensive efficiency.

I tested the hypothesis that tasks performed by workers would be size correlated. In the presence of high densities of wasps, honeydew collection and brood care was undertaken by larger workers, whereas foraging in leaf litter was undertaken by smaller workers. In contrast, no relationship was found between task and worker size where wasp densities were lower. I suggest that in addition to increased efficiency in the collection of liquid carbohydrate resources larger workers may also serve a defensive role. I also tested the hypothesis that where the exclusively diurnal wasps were most abundant $P$. advenus workers would minimise potential competitive interactions by foraging predominantly at night. However, $P$. advenus were found to forage as much or more by day in the presence of high densities of wasps and to forage more nocturnally where wasps were sparse. Increasing the number of foragers by day may improve $P$. advenus' competitive ability with wasps, but has the potential to come at the cost of other nest functions, energetic gains and increased worker mortality. 
Competitive mechanisms might influence ant population genetics, but wasps have also been shown to prey on dispersing ant queens. Analysis of microsatellite DNA markers revealed evidence of a genetic bottleneck in $P$. advenus populations where invasive predatory wasps have persisted at high population densities for more than twenty years. Ant populations at all wasp densities displayed significant heterozygote deficit, which may indicate that even at comparatively low densities predation by wasps has a detrimental effect on $P$. advenus genetic diversity. Alternatively, the observed heterozygote deficit may be the result of limited dispersal, population substructure or the peculiarities of the ant species' mating system. An examination of the broader population genetic structure of $P$. advenus from the seven sites sampled indicated that they were derived from two distinct populations. However, no individual assigned entirely to either population suggesting either some remaining admixture between the two populations or that they are derived from a common ancestral population.

Finally I examined the effects of increasing wasp density, honeydew availability and habitat diversity on the distribution of $P$. advenus. Prolasius advenus nests tended to be smaller and populations displayed less variation in nest size where wasp densities were highest, which could indicate reduced longevity. Nest distribution was overdispersed relative to both conand hetero-specific neighbours in high wasp density sites, but apparently randomly distributed in low wasp density sites. Both wasp and ant nest densities were greatest where honeydew was most abundant and plant diversity was lowest. These results suggest that intraand inter-specific competition in combination with resource and nest site availability influences $P$. advenus nest distribution.

Competition and predation by invasive species may influence recipient species' morphology, behaviour, genetic diversity and spatial distribution over a comparatively short period of time. These effects are much more subtle than under situations of direct predation. Such effects may not be immediately obvious in terms of abundance, but have potential long-term implications for the fitness and persistence of $P$. advenus in the presence of high densities of wasps. 


\section{Acknowledgments}

I am greatly indebted to many people without whom the completion of this dissertation would not have been possible. Firstly, I would like to thank my supervisor Associate Professor Phil Lester for his guidance, support and patience throughout this degree. I am also grateful to my secondary supervisor Dr Pete Ritchie whose help in the preparation of chapter four in particular was invaluable. Cath Duthie, Monica Gruber and Julien Grangier have been a tremendous source of support to me throughout. I have learned a great deal from them and it has been fantastic to have had them around to discuss ideas, seek advice and drink coffee with.

I would also like to thank Cat Jones, Laura Bass, Megumi Ogo, Simon Morse, and Evan Brenton-Rule for all their assistance in the field and lab and to express my gratitude to the staff of DOC St. Arnaud, DOC Pelorus Bridge and Blair Tilley of Nelson Pine Industries for their assistance at my study sites. My thanks also go to Richard Toft and Jo Rees formerly of Landcare Research Nelson, for allowing me access to their wasp density data and for all their help while I was in Nelson and to Suzanne Ryder of the Natural History Museum, London for allowing me access to $P$. advenus types and specimens in the collection. I am also grateful to the Allan Wilson Centre.

I am fortunate. The School of Biological Sciences at Victoria University is full of friendly and helpful people. I would like to express my gratitude to the administrators and technicians whose doors I have knocked on so frequently with last minute requests or in search of advice or obscure equipment. Mary Murray, Sandra Taylor, Delwyn Carter-Jarrett, Paul Marsden, Patricia Stein, Neville Higgins, Cameron Jack, Craig Dooney, Chris Thorne, Lesley Milicich and Sue Keall - thank you. The members of Bug Club, Ant Club and The Peter Ritchie Labgroup have provided helpful comments on various drafts and proposals and Sébastien Rioux-Paquette, Monica Gruber, Elizabeth Heeg, Andrew Martin, Stephen Hartley, Joe Zuccarello, John Haywood, Phil Sirvid and Phil Taylor have given me valuable and much appreciated advice along the way. My officemates Cath Duthie, Heidi Kikillus, Dan Logan and Gaius Wilson have been great too. Thanks to them all.

I would like to thank the Royal Society of New Zealand Marsden Fund for their generous financial support throughout this degree without which this project would not have been possible. 
I would also like to thank my examiners Ken Ryan, Maria (Masha) Minor and Ben Hoffmann for their helpful comments and suggestions.

Finally, I would like to thank my family. I thank my mother Carmen Pittaway for her support and encouragement throughout this degree and in all the years leading up to it. Her faith in me has always surpassed my own and has encouraged me in all my endeavours. I am grateful too to my brother Mic for his encouragement and for many interesting discussions along the way.

I also thank my wife Kyleigh who has put up with a lot and helped a great deal, and my sons Buster who has been there and enthusiastic throughout this degree and Leo who showed up half way through, they have helped me keep things in perspective and made it all worthwhile. 


\section{Table of Contents}

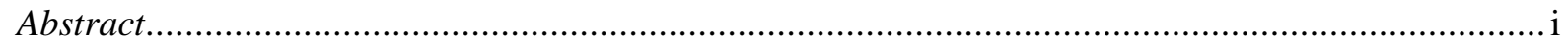

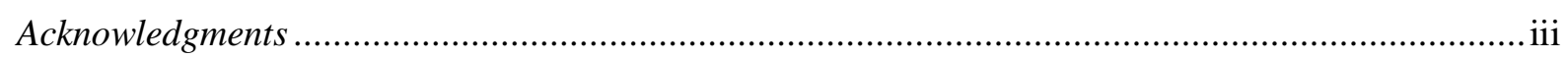

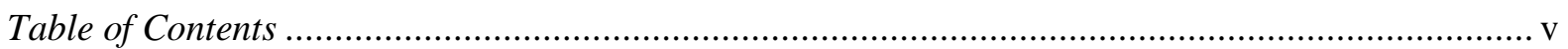

Table of Figures ............................................................................................................... viii

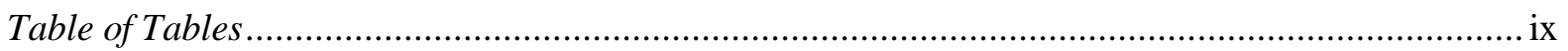

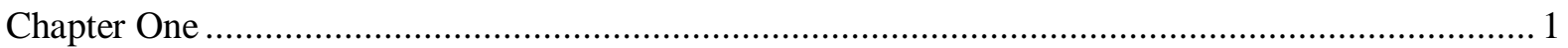

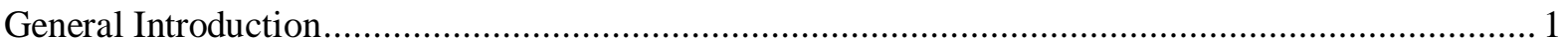

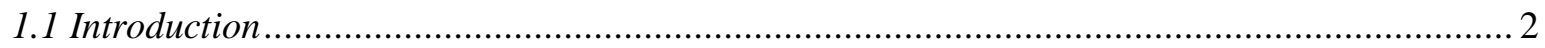

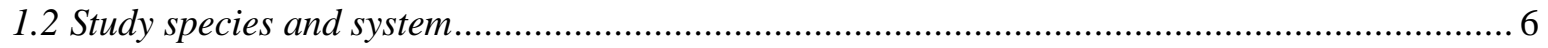

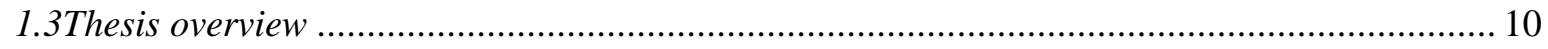

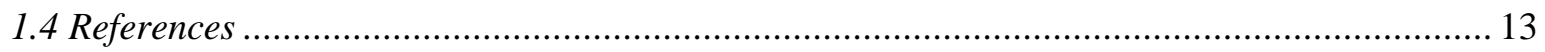

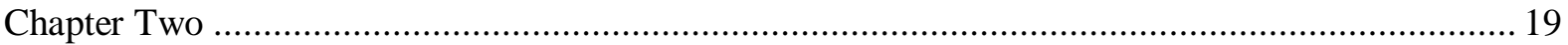

Density-dependent effects of the invasive wasp Vespula vulgaris (L.) (Hymenoptera) on worker size and morphology in the endemic New Zealand ant Prolasius advenus (Fr. Smith) (Hymenoptera)..... 19

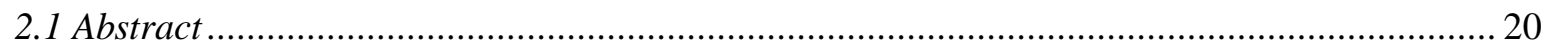

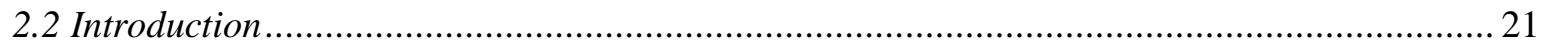

2.3 Methods

2.3.1 Study sites and specimen collection ........................................................................ 24

2.3.2 Effects of increasing wasp density on worker size ………………………………… 25

2.3.3 Effects of increasing wasp density on worker morphology ........................................... 26

2.3.4 Scaling relationships in P. advenus and the effect of high wasp densities ........................ 26

2.3.5 Comparison of $P$. advenus worker size prior to wasp invasion with post-wasp workers.... 27

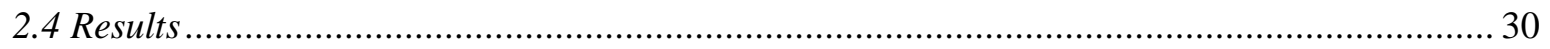

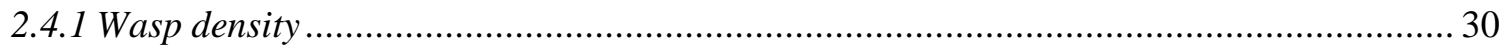

2.4.2 Effects of increasing wasp density on worker size …………………………………....... 30

2.4.3 Effects of increasing wasp density on worker morphology …………………………....... 32

2.4.4 Scaling relationships in P. advenus and the effect of high wasp densities......................... 33

2.4.5 Comparison of P. advenus worker size prior to wasp invasion with post-wasp workers.... 33

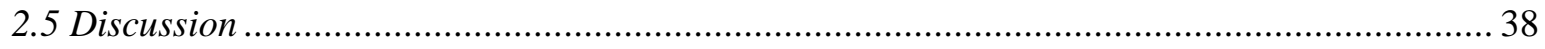

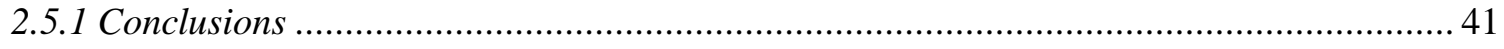

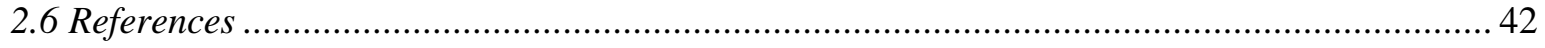


Chapter Three.

Behavioural plasticity and size correlated task allocation in the New Zealand bush ant Prolasius advenus (Fr. Smith) in the presence of high densities of the invasive common wasp Vespula vulgaris (L.)

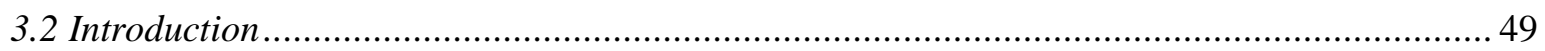

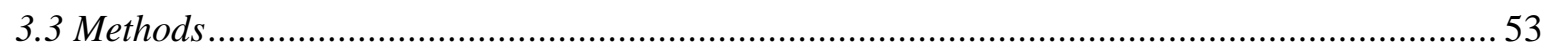

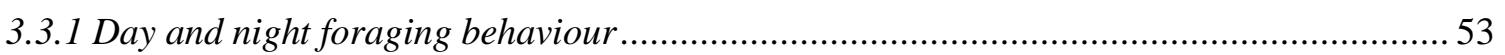

3.3.2 Size correlated division of labour at high and low wasp density ........................................ 55

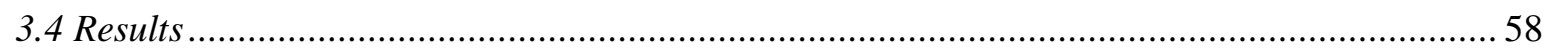

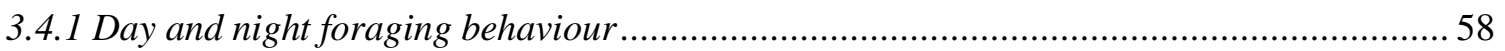

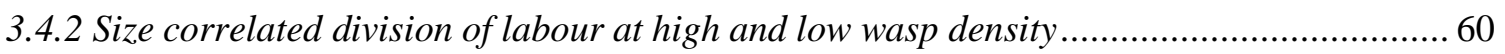

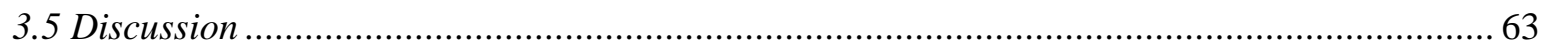

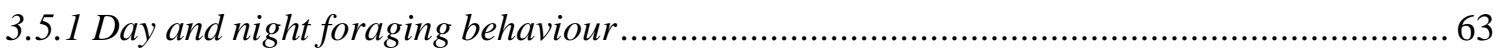

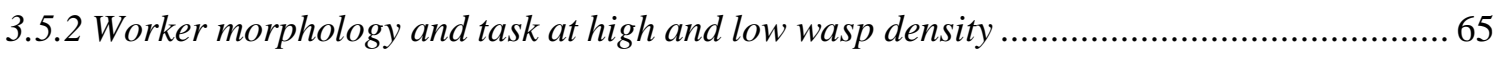

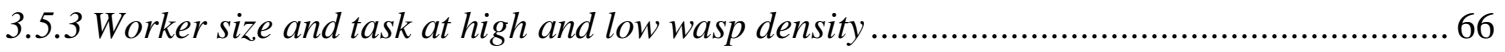

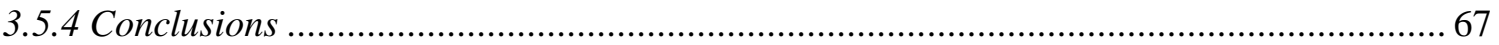

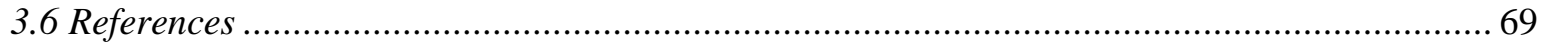

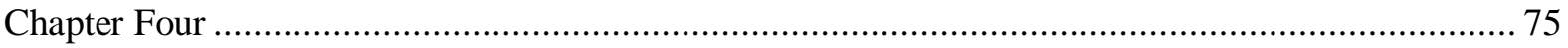

Evidence of a genetic bottleneck in populations of the endemic New Zealand bush ant Prolasius advenus (Fr. Smith) subject to intense predation by the invasive wasp Vespula vulgaris (L.)........... 75

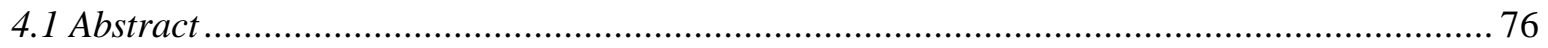

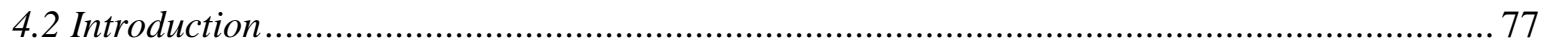

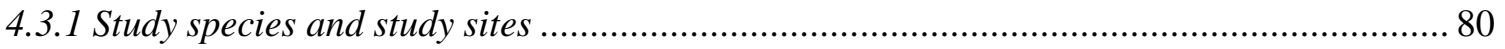

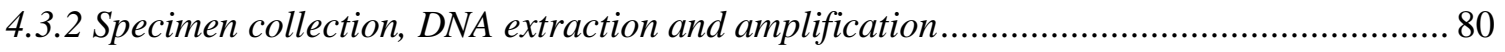

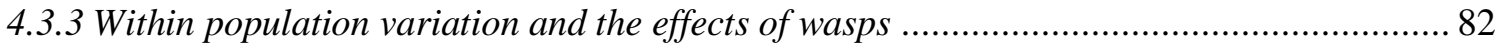

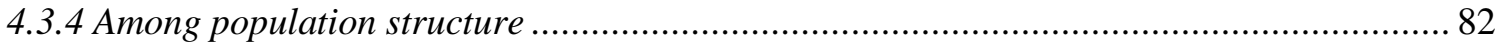

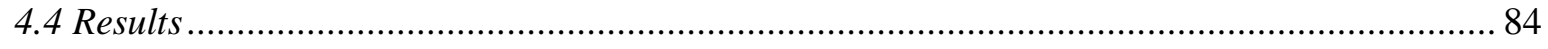

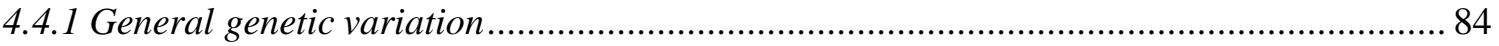

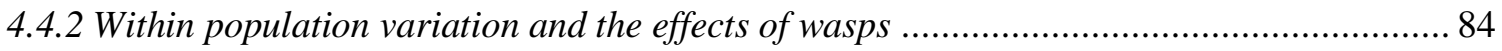

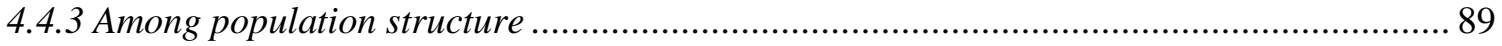

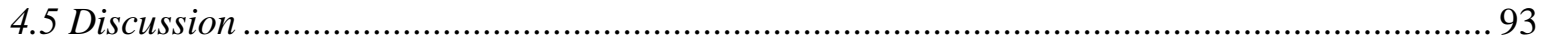

4.5.1 Within Population variation and the effects of wasps ...................................................... 93

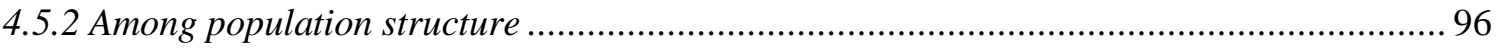

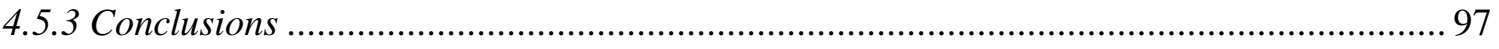

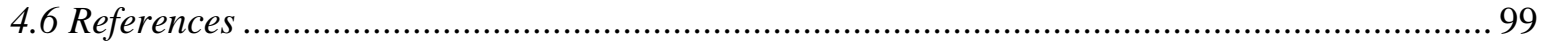


Chapter Five

Nest size, spatial distribution and density of the New Zealand endemic ant Prolasius advenus (Fr.

Smith) in the presence of varying densities of the invasive wasp Vespula vulgaris (L.)

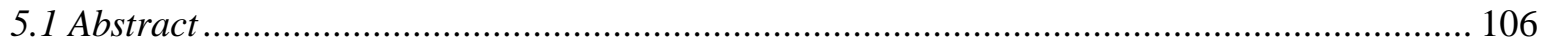

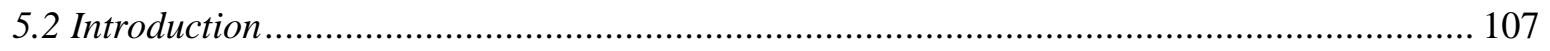

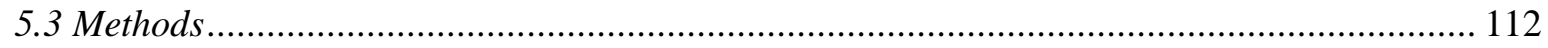

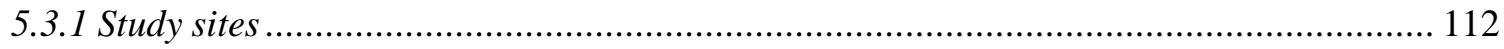

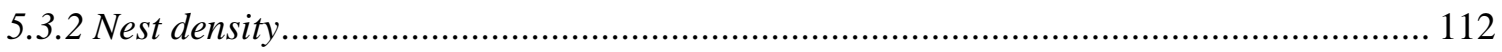

5.3.3 Nest distribution and distance to nearest neighbour...................................................... 113

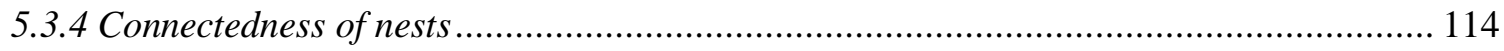

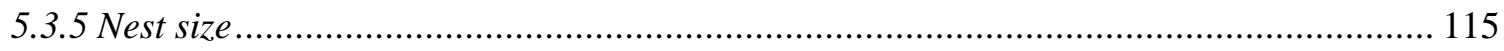

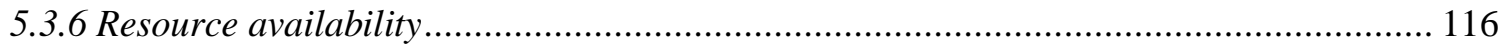

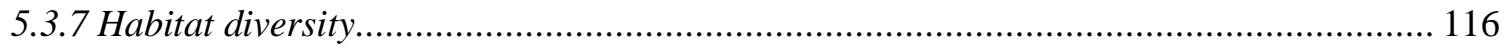

5.3.8 Correlation between nest density, size and distribution and habitat ............................. 117

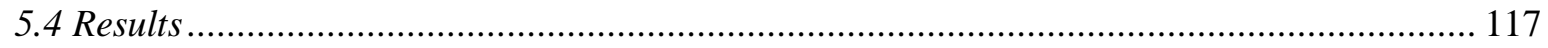

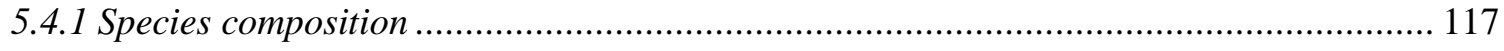

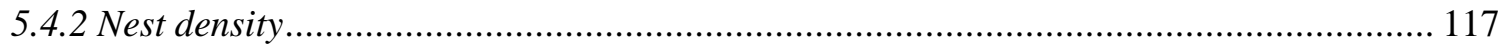

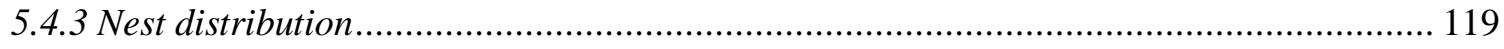

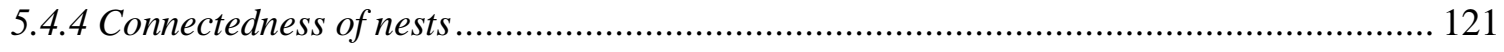

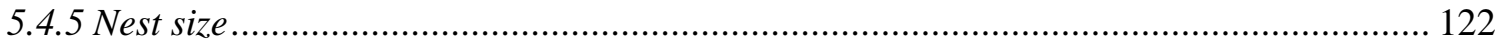

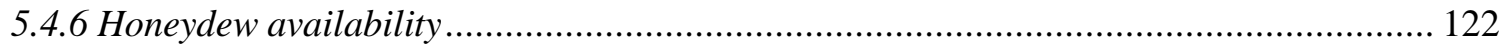

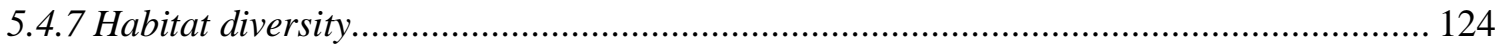

5.4.8 Correlation between nest density size and distribution and habitat .............................. 127

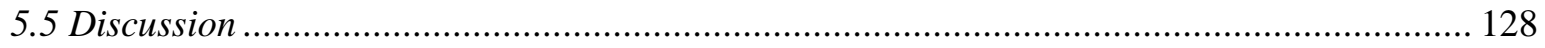

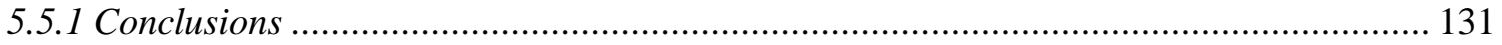

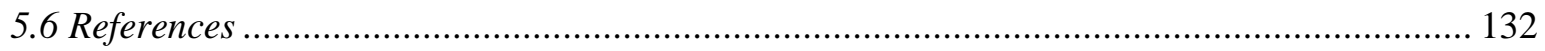

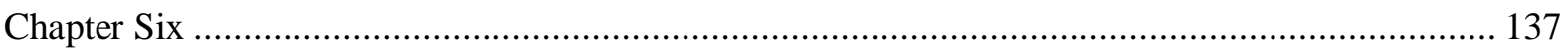

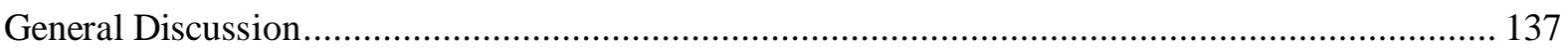

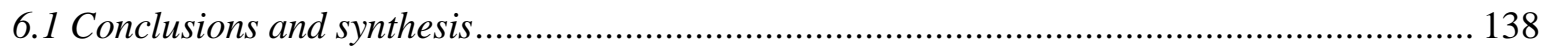

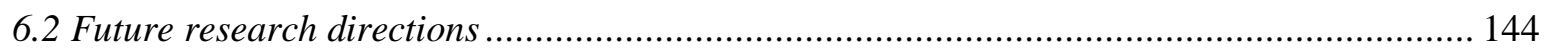

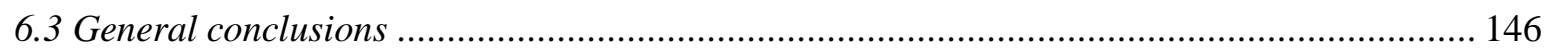

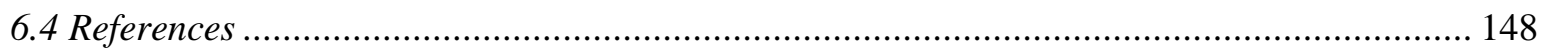

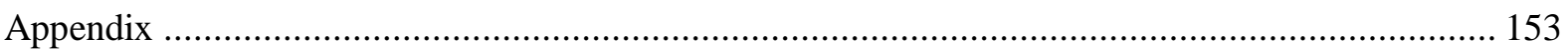




\section{Table of Figures}

Figure 1.1 Seven New Zealand Nothofagus beech forest sites experiencing varying levels of wasp infestation

Figure 2.1 Annual wasp density and mean wasp density at seven Nothofagus beech forest sites between 1988 and 2010.

Figure 2.2 Nine morphological characters measured on Prolasius advenus workers.

Figure 2.3 The negative relationship between increasing wasp density and P. advenus worker size..31

Figure 2.4 The non-continuous scaling relationship between gaster and petiole size. . .34

Figure 2.5 A comparison of $P$. advenus worker size prior to the arrival of V. vulgaris with post invasion workers with and without wasp removal.

Figure 3.1 Annual wasp density and mean wasp density at four Nothofagus beech forest sites between 1988 and 2010.

Figure 3.2 The relative proportion of diurnal and nocturnal $P$. advenus workers foraging at five

Nothofagus beech forest sites in order of increasing wasp density. .59

Figure 3.3 A comparison of the relative contribution of four morphological characters to P. advenus worker total length.

Figure 3.4 A comparison of the relationship between P. advenus worker size and the task they perform in populations from high and low wasp density areas......

Figure 4.1 The mean common wasp nest density at seven Nothofagus beech forest sites between 1988 and 2010 ......

Figure 4.2 The mean proportion of workers assigned to the nest they were collected from based on relatedness at each of seven New Zealand South Island Nothofagus beech forest sites.

Figure 4.3 The mean allelic diversity and heterozygosity across six microsatellite loci of seven $P$. advenus populations in order of increasing wasp density.

Figure 4.4 The population genetic structure of Prolasius advenus at seven Nothofagus beech forest sites.

Figure 4.5 Genetic isolation by distance of seven Prolasius advenus populations.

Figure 5.1 Annual wasp density and mean wasp density at four Nothofagus beech forest sites between 1988 and 2010.

Figure 5.2 Prolasius advenus nest density distributions at five Nothofagus beech forest sites arranged in order of increasing wasp density.

Figure 5.3 Prolasius advenus inter-nest distances at five New Zealand South Island Nothofagus beech forest sites arranged in order of increasing wasp nest density.

Figure 5.4 Prolasius advenus nest size distribution and coefficient of nest size variation in five Nothofagus beech forest sites arranged in order of increasing wasp nest density..... 
Figure 5.5 Index of honeydew abundance at five Nothofagus beech forest sites arranged in increasing order of wasp nest density.

Figure 5.6 Index of plant species diversity at five Nothofagus beech forest sites arranged in increasing order of wasp nest density.....

Figure 5.7 The relative proportion of honeydew rich and honeydew poor Nothofagus species comprising the canopy of five sites varying in wasp infestation.

Figure A.1 Allele frequency distributions for locus Pad2 in seven Prolasius advenus populations...154

Figure A.2 Allele frequency distributions for locus Pad4 in seven Prolasius advenus populations...155

Figure A.3 Allele frequency distributions for locus Pad5 in seven Prolasius advenus populations...156

Figure A.4 Allele frequency distributions for locus Pad9 in seven Prolasius advenus populations...157

Figure A.5 Allele frequency distributions for locus Pad10 in seven Prolasius advenus populations. 158

Figure A.6 Allele frequency distributions for locus Pad15 in seven Prolasius advenus populations.159

\section{Table of Tables}

Table 2.1 MANCOVA results showing the effects of site differences and wasp density on the size of $P$. advenus morphological characters.

Table 2.2 Results of reduced major axis regression showing the scaling relationships between $P$. advenus body parts.

Table2.3 Result of segmented regression analysis showing continuous and non-continuous scaling relationships among $P$. advenus body parts.

Table 2.4 Comparison of scaling relationships among P. advenus body parts in high and low wasp density populations.

Table 4.1 Primer sequences and specifications of size microsatellite markers developed for Prolasius advenus.

Table 4.2 Allelic diversity, heterozygosity and probability of genetic bottleneck in seven populations of Prolasius advenus from sites of varying wasp density......

Table 4.3 Genetic differentiation among seven P. advenus populations from sites of varying wasp density

Table 5.1 Nearest neighbour analysis of Prolasius advenus nest dispersion at five sites with varying wasp infestation.

Table 5.2 Plant species richness, evenness and diversity at five Nothofagus beech forest sites. 

Chapter One

\section{General Introduction}




\subsection{Introduction}

\section{Invasive species}

The detrimental effects invasive predators and competitors have on native species are frequently density-dependent. When released from their own competitors and predators, invasive species frequently attain higher population densities in the invaded environment than they do in their native range (Carlton, 1990). Exotic predators generally have a greater impact on native prey communities than their local equivalents (Salo et al., 2007) and are frequently cited as the major contributing factor to the extinction, displacement or population thinning of native taxa (MacDonald and Harrington, 2003; Patankar et al., 2006). Predation appears to be the primary mechanism of extinction and the findings of numerous recent studies suggest the effects of competition with invasive species are less severe (Sagoff, 2005). Davis (2003) suggests the sub-lethal impact of competition with invasive species affords recipient taxa sufficient time to modify their niche use or behaviour to promote coexistence with the invader. The effects of invasive species on recipient communities are predominantly reported in terms of displacement and extinction.

\section{Competition in general}

The Gause (1932) competitive exclusion principle states that two species cannot coexist if they use the same limited resources in exactly the same manner. Where two species compete for limiting food resources the superior competitor may ultimately displace or reduce the growth, abundance or fitness of the other. This may be the result of a direct reduction in the availability of the limiting resource by the superior competitor, interference with the inferior competitor's ability to secure the resource or by depleting the energy gained from it by aggressive interaction (Schoener, 1974a). At the population level, the impacts of competitive interactions may be apparent in terms of reduced abundance and altered spatial distribution. At the individual level competition may result in reduced growth and fitness.

Growth in some insect species can be directly affected by resource restrictions imposed by competitors. In holometabolous insects reduction in the quality or quantity of food resources available during larval development has been demonstrated to result in a reduction in adult body size (Thomas, 1993; Wheeler and Buck, 1992; Emlen and Nijhout, 2000; Mirth and Riddiford, 2007; Sorvari and Hakkarainen, 2009). Overall growth in holometabolous insects occurs during larval (feeding) stages and is dependent on complex interactions between genotypic and environmental factors, perhaps foremost of which is the availability of high 
quality food (Emlen and Nijhout, 2000). It is generally at the stage of the final larval instar that adult size is ultimately determined and no further increase in body size occurs thereafter.

Development of adult body parts, such as the structures of the head, thorax and appendages, from the imaginal discs occurs by cell proliferation and changes in cell size (Emlen and Allen, 2004). The process begins in a closed system during the pre-pupal and pupal stages, when feeding has ceased (Nijhout and Wheeler, 1996). Development of each disc is independent and growth of one may come at the expense of another where resources prior to pupation are limiting (Emlen, 2001). Trait variation may be size dependent (isometric) or size independent (allometric) (Huxley, 1931) and the latter is common in many ant subfamilies (Breed, 2002). Variation in the relative size of organs in conspecific individuals at the same developmental stage is termed static allometry. This may further be subdivided into: 1. environmental static allometry (also referred to as a reaction norm), where a single genotype results in different phenotypes under different environmental conditions, and 2. genotypic static allometry, where different genotypes produce different phenotypes in the same environment (Shingleton et al., 2007). Plotting trait size for a single genotype against an environmental variable may reveal phenotypic variation in response to a range of environmental conditions. Reaction norms may also exist where phenotypic scaling is a response to body size (Emlen and Nijhout, 2000).

\section{Altered foraging behaviour may reduce the effects of competition}

When sympatric species' resource use overlaps, competition may drive directional selection for altered phenotypes that minimise competition or modify resource use (Rice and Pfennig, 2006). Character displacement has been observed in a wide variety of taxa including snails, beetles, fishes, amphibians, reptiles, birds and mammals (Schluter, 2001), and is most prevalent in species that display wide phenotypic variation (Pfennig and Murphy, 2000). In allopatry, different selective pressures may apply resulting in divergence, particularly where gene flow is restricted (Rice and Pfennig, 2010).

Coexistence between competing species can occur as a result of altered resource use and spatial and temporal partitioning. According to optimal foraging theory (MacArthur and Pianka, 1966) the reduction of food availability in an area as a result of exploitive competition may lower its value to a point where it is excluded from an individual's foraging itinerary. The quality of temporal habitat, such as a particular time of day when temperature is optimal for foraging, may also be reduced by competition. Such a reduction in temporal 
habitat quality may promote temporal partitioning of resource use by an alteration of the inferior competitor's diel foraging cycle (Schoener, 1974b). However, temporal partitioning of resources is only viable as a form of niche partitioning if the resource is renewed between the two feeding times (MacArthur and Levins, 1967).

\section{Competition and spatial distribution}

Central place foraging theory (Orians and Pearson, 1979; Schoener, 1979) describes the costs incurred by species that do not consume resources where they are secured, but rather travel from a central point, such as a nest or colony, to find resources and take them back to the point where they started. The costs of competitive interactions for central place foragers are high, however, competing species may minimise these interactions by altering their spatial distribution in a homogenous environment.

The spatial distribution of organisms may be broadly described as aggregated, random or overdispersed (Clark and Evans, 1954). Based on the assumption of random distribution within a given area the ratio of the observed distance between two neighbouring individuals or nests and the expected distance can be used to classify spatial distribution of nearest neighbours.

Competition with invasive species may result in reduced species richness and abundance of native species (Roura Pascual et al., 2010). Competition also shapes spatial distribution and may result in overdispersal particularly among sessile organisms where interactions are primarily between nearest neighbours. Thus, an individual's growth and fitness may be influenced by the number, size and position of its nearest neighbours (Stoll and Bergius, 2005). Overdispersion in seemingly suitable habitats may reflect defence of territory including food and spatial resources from neighbouring con- or hetero-specifics. Regular spacing may also serve to facilitate more efficient exploitation of stable food resources (Johnson et al., 1987). The distance between ant nests may be a function of foraging radius. Where two colonies foraging radii and resource use overlap regular spacing of con- and hetero-specific neighbours can serve to minimise competitive interactions (Levins and Traniello, 1981; Gordon and Kulig, 1996).

\section{Predation and spatial distribution}

By contrast, the effect of predation on spatial distribution may result in an aggregated distribution. Prey animals may reduce the probability of being eaten by staying close to 
others (Hamilton, 1971). Aggregation also serves to reduce encounter rates between predators and prey groups. When prey species aggregate into fewer large groups (as opposed to many small groups) encounter rates reduce and prey are more difficult for predators to locate (Ioannou et al., 2011). Predation can be a major cause of increased dispersal cost (Rosengren and Pamilo, 1983). Where there is a high cost of dispersal some ant species adopt an aggregated distribution on two scales: multiple queens aggregate per nest (polygyny) (Bourke and Franks, 1995) and colonies are formed that comprise an aggregation of multiple nests with exchange of workers among nests (Debout et al., 2007).

\section{Predation by exotic species}

Predation by invasive species has been linked to extinction (Savidge, 1987; Blackburn et al., 2004) and population decline (Wanless et al., 2007; Hilton and Cuthbert, 2010) in native species. The arrival of exotic predators has been suggested to lead to extinctions of native taxa, which have evolved in their absence and lack appropriate anti predator responses (Blackburn et al., 2004). Social wasps have been identified as a major threat to endemic invertebrates due to their highly generalised predacious nature (USFWS, 2001).

\section{Predation may result in reduced effective population size}

Intense predation by invasive species may ultimately lead to a reduction in the effective population size of a native species, increasing the strength of genetic drift and cause a loss of allelic diversity and a reduction in heterozygotes (Gasc et al., 2010). Smaller populations are more likely to be affected by stochastic processes, such as genetic drift. Gene flow is perhaps of foremost importance as a force that can counteract the effects of drift and maintain levels of population genetic diversity. The detrimental effects of invasive predators may be compounded by habitat fragmentation, which can further reduce population size (Suarez and Case, 2003). The long term implications of such loss in genetic diversity may include reduced resistance to pathogens and reduced adaptive potential to environmental changes.

Invasive competitors and predators may have short term sub-lethal effects on the growth, behaviour, population genetics and spatial distribution of native taxa. These effects may have potential long term implications for the fitness and persistence of recipient species that are not immediately apparent when measured in terms of abundance or displacement. In this dissertation I aimed to examine the sub-lethal effects of increasing population densities of the invasive common wasp Vespula vulgaris (L.) on the morphology, behaviour, population 
genetics and spatial distribution of the New Zealand endemic small brown bush ant Prolasius advenus (Fr. Smith)1862. Wasps and ants clearly compete (Grangier and Lester, 2011), but wasps are also major predators of the ant's dispersing queens (Harris, 1991).

\subsection{Study species and system}

The common wasp V. vulgaris (L.) is an invasive species in New Zealand. The first evidence of the species' arrival is a specimen collected from Wairarapa in 1921 (Donovan, 1984). Further single specimens were collected in 1923 and 1945 from Masterton and Auckland respectively but it was not until 1983 that it was confirmed that the species had become established, with large populations reported in Dunedin, Christchurch, Nelson, Wellington and Auckland (Donovan, 1984; Clapperton et al., 1989). The wasp continued its colonization of both the North and South Islands inhabiting "about half of the country" by 1989 (Clapperton et al., 1989). By this time $V$. vulgaris had driven another invasive species, the German wasp $V$. germanica to localized extinction in the honeydew beech forests of the Nelson Lakes area (Sandlant and Moller, 1989). The common wasp has subsequently been recorded at extremely high densities (up to 30 nests $\mathrm{Ha}^{-1}$ ) in the beech forests of the upper South Island (Barlow et al., 2002), where it continues to be a pest species posing a threat to local biodiversity and public health to the present day. An annual monitoring program of wasp densities in seven sites in the Nelson Lakes Nothofagus honeydew beech forests was conducted between 1988 and 2008 (Barlow et al., 2002; Beggs et al., 1998). I conducted a reduced survey of four of the sites described below in 2009 and 2010.

The wasp feeds on honeydew excreted by the larval instars of the native scale insect Ultracoelostoma assimile (Maskell) (Moller and Tilley, 1989). The scale primarily infests the trunks and branches of the beech species Nothofagus fusca, N. solandri var cliffortiodes and var solandri and N. truncata, (but seldom N. menziesii), where it penetrates the phloem vessels of the tree with its stylet and feeds on sap (Morales et al., 1988). The carbohydrate content of the sap is modified in the insect's gut and honeydew, a sugary residue containing metabolic products, is then excreted through its waxy anal filament (Grant and Beggs, 1989). High performance liquid chromatography (HPLC) analysis of the sugar composition of beech honeydew found it contains fructose, sucrose, glucose and numerous oligosaccharides, and as such represents a valuable high energy food source to both vertebrates and invertebrates in this system (Grant and Beggs, 1989). Indeed, it has been suggested that there are no comparable alternative carbohydrate sources in beech forest (Moller et al., 1991). A comparative study of honeydew composition in Queensland rainforest indicated that it 
contained a broader profile of sugars than those available in other carbohydrate sources such as nectar or wound-sap and also represents a source of several amino acids at high concentration (Bluthgen et al., 2004).

Consumption of honeydew by wasps disrupts the diets of several native birds and insects that rely on the resource for carbohydrate (Moller and Tilley, 1989). The number of anal filaments carrying a drop of honeydew, drop size and sugar concentration was found to be lowest during periods of peak wasp abundance (Moller and Tilley, 1989). When a droplet of honeydew is removed from the anal filament of a scale insect by a feeding bird or insect it is replaced in a matter of minutes. As the droplet grows in size water evaporates from it, increasing the sugar concentration. It has been suggested that the frequency with which the common wasp revisits a filament prevents the droplet from reaching its maximum size or sugar concentration (Moller et al., 1991). The wasps have also been observed cropping anal filaments, which may ultimately result in complete loss of the tube further reducing honeydew availability (Moller and Tilley, 1989). Indeed it has been estimated that V. vulgaris reduces the standing crop of honeydew by as much as $92 \%$ in the five months when these wasps are most active (Beggs et al., 1998).

Vespula vulgaris is also a predator of several invertebrate orders, which they generally feed to their developing larvae (Harris, 1989; Harris, 1991; Harris and Oliver, 1993; Toft and Beggs, 1995, Toft and Rees, 1998). A survey of prey consumption in the beech forests of the North Western South Island found that more than one third of the invertebrates caught by wasps belonged to the order Hymenoptera and of those $83 \%$ were winged reproductive ants (Harris, 1991). The most abundant ant species in the beech forests of the Nelson Lakes area is P. advenus (McColl, 1975).

Commonly known as the small brown bush ant, $P$. advenus is an abundant New Zealand endemic that has a broad distribution in beech and podocarp forest and occasionally open plains throughout the North, South and Stewart Islands (Don, 2007). It is the only New Zealand representative of the genus Prolasius Forel, which comprises 19 species, seventeen of which have a solely Australian distribution and only one species that occurs in Australia and New Guinea (Taylor, 1992). The genus belongs to the subfamily Formicinae, which is one of the higher ant subfamilies believed to have diverged approximately 100 million years ago (Moreau et al., 2006). Despite the species' abundance very little is known of its life history, behaviour or diet. Its taxonomic status however, is well resolved, which in 
conjunction with a recent molecular phylogeny of the Formicidae (Moreau et al., 2006) makes it possible to make cautious inferences about its biology based on closely related taxa.

Prolasius advenus has two morphologically distinct female castes; reproductive queens and workers. The latter have recently been found to produce males in queenless colonies (Grangier, unpublished.). The common wasp preys on the winged queens and males of $P$. advenus during their nuptial flight (pers. obs.). In the higher subfamilies of the Formicidae male aggregation syndrome is the more common of the two broadly identified mating strategies (Peeters and Ito, 2001). The alternative, female-calling syndrome, usually involves wingless queens from small colonies often in species with poor caste differentiation (Hölldobler and Wilson, 1990). As small brown bush ant castes are well differentiated and queens are winged it is probable that $P$. advenus employs male aggregation as its reproductive strategy. In this mode of reproduction alate queens and males are simultaneously released from their natal nests and undergo a nuptial flight during which they mate either in flight or on the ground (Hölldobler and Wilson 1990). Smith, (1896) immediately follows his observations on the behaviour of $P$. advenus with a report of large swarms of winged reproductives in flight between February and March, but it is unclear whether this included $P$. advenus. However, malaise traps set in March 2008 contained multiple winged $P$. advenus queens and up to two-hundred males (Duthie, pers. com.) suggesting large scale synchronized dispersal. This would coincide with the period when $V$. vulgaris are at peak abundance in the Nelson beech forest (Harris, 1991) and it is common for winged ants to be among the prey items at this time (Harris, pers. com.).

Winged queens carry stored food resources to aid in colony foundation and therefore represent a high yield prey item to wasps. In many of the "higher" ant families (including the Formicinae, to which the genus Prolasius belongs) the maiden flight is followed by independent colony foundation. Claustral colony founders, the most common mode of colony foundation, do not forage but rather seal themselves in a chamber, lay eggs and rely on internal reserves to raise the first cohort of workers (Hölldobler and Wilson, 1990). The alate queen's thorax is modified to store metabolic reserves that increase her chance of successful colony establishment (Peeters and Ito, 2001). Wings are lost and the wing muscles are histolysised to provide proteins for oogenesis. When these are exhausted, storage proteins, accumulated from eclosion to the nuptial flight in the fat bodies of the queen's gaster are utilised (Martinez and Wheeler, 1994). Resource investment in alate queens is significantly higher than in males, with the mass increasing fourfold between eclosion and nuptial flight 
(Boomsma and Isaaks, 1985). Winged females also carry large quantities of carbohydrates in the form of glycogen and free sugars, that are used to fuel their maiden flight, and lipids which are later depleted during colony formation (Keller and Passera, 1989; Passera and Keller, 1990). Larger queens have larger reserves and are more likely to successfully found new colonies than smaller queens (Wiernasz and Cole, 2003) and as such may also represent a preferred prey item for wasps.

The small brown bush ant's diet displays significant overlap with that of $V$. vulgaris (Duthie, 2011) consisting of small invertebrates, which it actively hunts, and scale honeydew.

Although other potential sources of carbohydrate have been described, such as the honeydewlike products of rhizophagous Homoptera (Smith, 1896) and wound-sap (Grehan, 1979), scale honeydew is the most important carbohydrate source in the beech forests of the Nelson Lakes area (Moller et al., 1989). The consumption of honeydew by wasps is detrimental to both native birds and insects (Beggs et al., 1998; Moller and Tilley, 1989). In addition to its exploitation of the honeydew resource the common wasp has been shown to interfere with $P$. advenus ability to secure resources by actively removing workers from baits (Grangier and Lester, 2011). The wasp then is clearly an exploitive and interference competitor with $P$. advenus for food as well as a significant predator of its dispersing queens and males and as such may exert considerable detrimental influence on the growth, abundance and spatial distribution of this ant. However, it is possible that $P$. advenus may mitigate these effects by altering its behaviour and or niche use to either minimise competitive interactions with the wasp or to maximise its competitive ability.

\section{Study sites}

Between 1988 and 2008 annual wasp nest density surveys were conducted by Landcare Research Nelson (For methods see: Beggs et al., 1998 and Barlow et al., 2002) in seven Nelson Lakes honeydew beech forest sites: Pelorus Bridge ( $\left.41^{\circ} 18^{\prime} \mathrm{S}, 173^{\circ} 34^{\prime} \mathrm{E}\right)$; Graham Valley $\left(41^{\circ} 09^{\prime} \mathrm{S}, 173^{\circ}, 31^{\prime} \mathrm{E}\right)$; Spooner's Range ( $\left.41^{\circ} 27^{\prime} \mathrm{S}, 172^{\circ} 55^{\prime} \mathrm{E}\right)$; Lake Rotoiti (41 ${ }^{\circ}$ $\left.49^{\prime} \mathrm{S}, 172^{\circ} 50^{\prime} \mathrm{E}\right)$; Mt. Misery ( $\left.41^{\circ} 54^{\prime} \mathrm{S}, 172^{\circ}, 39^{\prime} \mathrm{E}\right)$; Tiraumea Saddle $\left(41^{\circ} 54^{\prime} \mathrm{S}, 172^{\circ}, 37^{\prime}\right.$ E ) and Matakitaki $\left(42^{\circ} 58^{\prime} \mathrm{S}, 172^{\circ}, 20^{\prime} \mathrm{E}\right)$ (Figure 1.1). A reduced survey was conducted in 2009 and 2010 measuring densities at only four of the sites: Pelorus Bridge, Spooner's Range, Mt. Misery and Lake Rotoiti. The data collected provide a historical record of annual variation in wasp density and delineates sites with consistently higher and consistently lower levels of wasp infestation (see Beggs et al., 1998 and Barlow et al., 2002). 


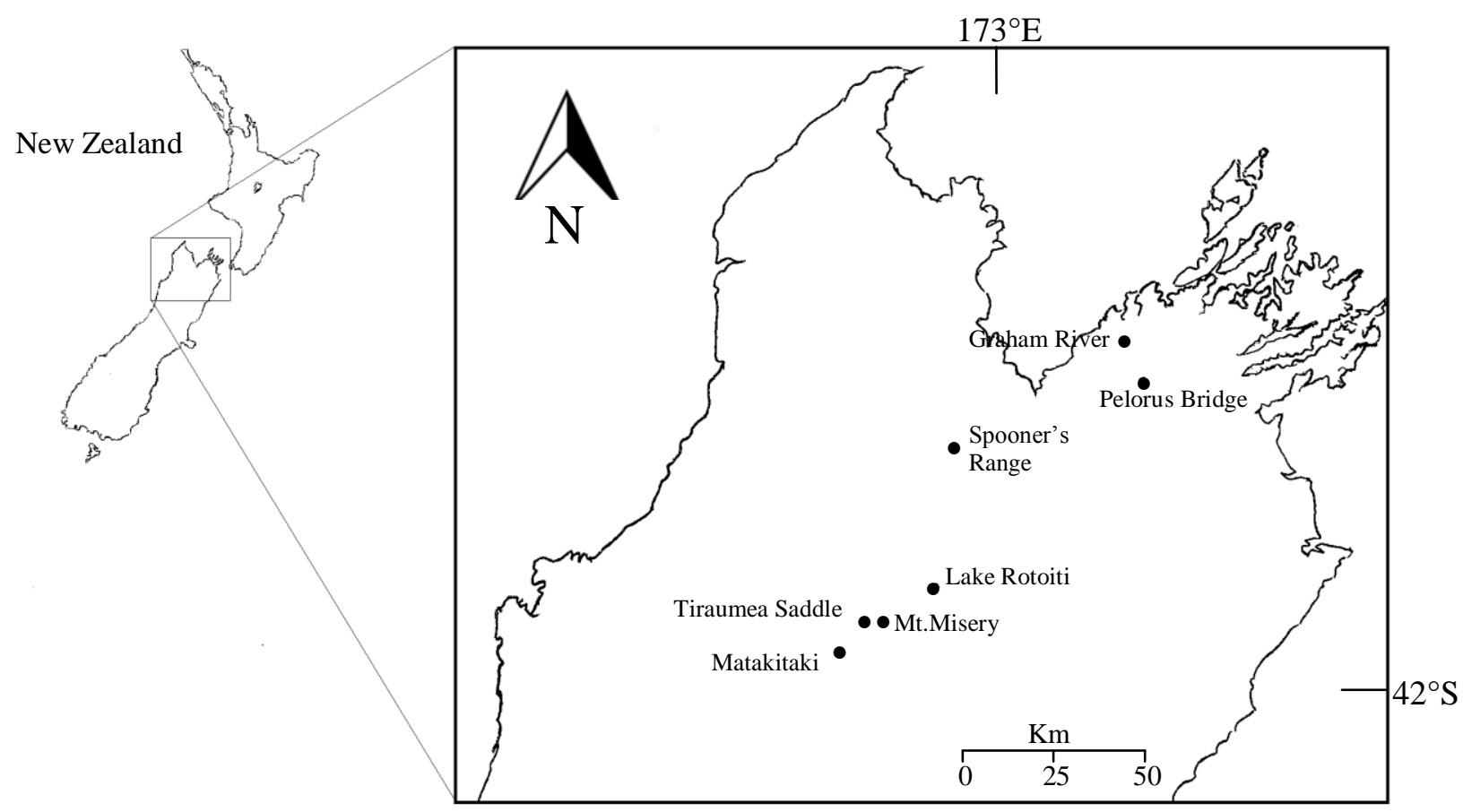

Figure 1.1 Seven Nothofagus beech forest sites of varying wasp infestation in New Zealand's northern South Island. These sites were chosen based on the availability of long term wasp density data collected between 1988 and 2010.

The canopy at each site is dominated by Nothofagus spp. The understory is simple comprising Nothofagus spp. saplings, Pseudopanax spp. and Coprosma spp. Pelorus Bridge and Spooner's Range also include tree ferns (Cyathea dealbata and Dicksonia squarosa) in their understory. Ground cover is predominantly leaf litter with fallen branches covered in moss; crown ferns (Blechnum discolor) are common at some sites. Sooty mould (Capnodium, Tricopeltheca and Capnocybe spp.), which grows where honeydew has fallen, covers the bark and roots of trees as well as areas of ground cover.

\subsection{Thesis overview}

Chapter 2

In chapter two I investigated the effects of varying densities of the common wasp $V$. vulgaris on morphological variation in P. advenus. A reduction in the quality and quantity of food resources has been found to result in decreased worker size in other ant species. Previous studies show the common wasp reduces the quality and quantity of honeydew available in Nothofagus forests and competes with P. advenus for protein resources; therefore I predicted that $P$. advenus workers would be smaller in areas where wasps were more abundant compared with areas where there were fewer wasps. I also examined the scaling relationships 
among worker body parts. Because development of adult body parts occurs in a closed system after feeding has ceased, growth of one imaginal structure may come at the expense of another. Where food resources are limited at the time of pupation altered allometric scaling relationships may result.

\section{Chapter 3}

Here I examined the effect of invasive wasps at high and low density on the foraging behaviour and temporal niche use of the endemic bush ant $P$. advenus. The invasive common wasp is a competitor for protein and carbohydrate resources with the endemic bush ant $P$. advenus. However, the wasp is an exclusively diurnal forager while ants may forage throughout both day and night. As honeydew is produced throughout the diel cycle I predicted that $P$. advenus in areas of high wasp density would alter its temporal niche to forage more at night when the wasps were absent.

Based on the results of Chapter 2, I predicted that $P$. advenus would display size correlated division of labour where wasps were least abundant and that larger workers, with disproportionately larger gasters, would forage for honeydew, that intermediate sized workers would forage for protein resources and smaller workers would tend brood.

\section{Chapter 4}

Exotic predators are often more efficient than their native equivalents and can result in rapid decline in the effective population size of recipient taxa. This may result in increased genetic drift and loss of genetic variation. Dispersing alate queens comprise more than $25 \%$ of the diet of V. vulgaris in Nothofagus forests of the Nelson Lakes area when the wasp is at peak abundance in March and April. In this chapter I examined the population genetic structure of $P$. advenus to establish whether the seven populations used in the study were genetically discrete or form a large panmictic population. I predicted that high levels of predation by invasive wasps at high density would result in a population genetic bottleneck in $P$. advenus.

\section{Chapter 5}

Invasive species may reduce the abundance and alter the distribution of native species by means of predation and competition. Patterns of spatial distribution may be broadly categorised as aggregated, random or overdispersed. Competition and predation can result in 
opposing spatial distributions as overdispersal has been hypothesised to mitigate the effects of competition by reducing forager overlap and aggregation can reduce the individual's probability of being preyed upon. In this chapter I predicted that $P$. advenus nest densities would be lower where wasps were more abundant and that nests would be smaller and would vary less in size. I also predicted that competition with wasps would promote an overdispersed distribution of nests and examined the effects of honeydew availability and vegetation structure on the spatial distribution and abundance of $P$. advenus

\section{Chapter 6}

This chapter is a general discussion of the results of the previous four chapters. I also speculate on the long term implications of my findings and suggest possibilities for future research.

This dissertation is written in the form of manuscripts for publication. Consequently there is some repetition between chapters in some introductory or other material. 


\subsection{References}

Barlow, N.D., Beggs, J.R. and Barron, M.C. (2002) Dynamics of common wasps in New Zealand beech forests: a model with density dependence and weather. Journal of Animal Ecology 71: 663-671

Beggs, J.R., Toft, R.J., Malham, J.P., Rees, J.S., Tilley, J.A.V., Moller, H. and Alspach, P. (1998) The difficulty of reducing introduced wasp (Vespula vulgaris) populations for conservation gains. New Zealand Journal of Ecology 22(1): 55-63

Blackburn, T.M., Cassey, P., Duncan, R.P., Evans, K.L. and Gaston, K.J. (2004) Avian extinctions and mammalian introductions on oceanic islands. Science 305(5692): 1955-1958

Blüthgen, N., Gottsberger, G. and Fielder, K. (2004) Sugar and amino acid composition of ant-attended nectar and honeydew sources from an Australian rainforest. Austral Ecology 29: 418-429

Boomsma, J.J. and Isaaks, J.A.(1985) Energy investment and respiration in queens and males of Lasius niger (Hymenoptera: Formicidae). Behavioural Ecology and Sociobiology 18: 1927

Bourke, A. F. G. and Franks, N. R. (1995) Social evolution in ants. Princeton University Press, Princeton, New Jersey: 529pp

Breed, M.D. (2002) Allometry in the giant tropical ant Paraponera clavata. Insectes Sociaux 49: $125-128$

Carlton, J.T., Thompson, J.K., Schemel, L.E. and Nichols, F.H. (1990) Remarkable invasion of San Francisco Bay (California, USA) by Asian clam Potamocorbula amurensis. I. Introduction and dispersal. Marine Ecology Progress Series 66: 81-94

Clapperton, B.K., Moller, H. and Sandlant, G.R. (1989) Distribution of social wasps (Hymenoptera:Vespidae) in New Zealand in 1987. New Zealand Journal of Zoology 16: 315323

Clark, P. J. and Evans F.C. (1954) Distance to nearest neighbour as a measure of spatial relationships in Populations. Ecology 35(4): 445-453.

Davis, M.A. (2003) Biotic globalization: does competition from introduced species threaten biodiversity? Bioscience 53(5): 481-489

Debout, G., Schatz, B., Elias, M. and McKey, D. (2007) Polydomy in ants: what we know, what we think we know and what remains to be done. Biological Journal of the Linnaean Society 90: 319-348

Don, W. (2007) Ants of New Zealand. Otago University Press, Dunedin, New Zealand: $239 \mathrm{pp}$

Donovan, B.J. (1984) Occurrence of the common wasp, Vespula vulgaris (L.) (Hymenoptera: Vespidae) in New Zealand. New Zealand Journal of Zoology 11: 417-427

Duthie, C. (2011) Factors promoting coexistence between endemic ants and invasive wasps. Unpublished $\mathrm{PhD}$ thesis. Victoria University Wellington. 
Emlen, D.J. (2001) Costs and the diversification of animal structures. Science 291: 15341536

Emlen, D.J. and Allen, C.E. (2004) Genotype to Phenotype: physiological control of trait size and scaling in insects. Integrative and Comparative Biology 43: 617-674

Emlen, D.J. and Nijhout, H.F. (2000) The development and evolution of exaggerated morphologies in insects. Annual Review of Entomology 45: 661-708

Gasc, A., Duryea, M.C., Cox, R.M., Kern, A. and Calsbeek, R. (2010) Invasive predators deplete genetic diversity of island lizards. PloS One 5(8): 1-4

Gause, G.F. (1932) Experimental studies on the struggle for existence I. Mixed population of two species of Yeast. Journal of Experimental Biology 9: 389-402

Gordon, D.M. and Kulig, A.W. (1996) Founding, foraging, and fighting: colony size and the spatial distribution of harvester ant nests. Ecology 77(8): 2393-2409

Grangier, J. and Lester, P.J. (2011) A novel interference behaviour: invasive wasps remove ants from resources and drop them from a height. Biology Letters 7(5): 664-667

Grant, W.D., and Beggs, J.R. (1989) Carbohydrate analysis of beech honeydew. New Zealand Journal of Zoology 16: 283-288

Grehan, J. (1979) Ants around the entrances of puriri moth tunnels-a note. The Weta News Bulletin of the Entomological Society of New Zealand Inc. 3(1): 5

Hamilton, W. D. (1971). Geometry for the selfish herd. Journal of Theoretical Biology 31: 295-311

Harris, R. (1989) An entrance trap to sample foods of social wasps (Hymenoptera: Vespidae). New Zealand Journal of Zoology 16: 369-371

Harris, R. (1991) Diet of the wasps Vespula vulgaris and V. germanica in honeydew beech forest of the South Island, New Zealand). New Zealand Journal of Zoology 18: 159-169

Harris, R.J. and Oliver, E.H. (1993) Prey diets and population densities of wasps Vespula vulgaris and Vespula germanica in a scrubland-pasture. New Zealand Journal of Ecology 15: $5-12$

Hilton, G.M. and Cuthbert, R.J. (2010) The catastrophic impact of mammalian predators of birds of the UK overseas territories: a review and synthesis. Ibis 152: 443-458

Hölldobler, B. and Wilson, E.O. (1990) The Ants. Harvard University Press, Cambridge, MA: $732 \mathrm{pp}$

Huxley, J.F. (1931) Notes on differential growth. The American Naturalist 65(699): 289-315

Ioannou, C.C., Bartumeus, F., Krause, J. and Ruxton, G.D. (2011) Unified effects of aggregation reveal larger prey groups take longer to find. Proceedings of the Royal Society $B$ (Biological Sciences) 278: 2985-2990

Johnson, L.K., Hubbell, S.P. and Feener Jnr., D.H. (1987) Defence of food supplies by eusocial colonies. American Zoologist 27: 347-358 
Keller, L. and Passera, L. (1989) Size and fat content of gynes in relation to the mode of colony founding in ants. Oecologia 80 : 236-240

Levins, S. and Traniello, J. E. A. (1981). Territoriality, nest dispersion, and community structure in ants. Psyche 88: 265-319

MacArthur, R.H. and Levins R. (1967) The limiting similarity, convergence, and divergence of coexisting species. The American Naturalist 101(921): 377-385

MacArthur, R.H. and Pianka, E. R. (1966) On optimal use of a patchy environment. American Naturalist 100: 603-609

MacDonald, D.W. and Harrington, L.A. (2003) The American mink: the triumph and tragedy of adaptation out of context. New Zealand Journal of Zoology 30: 421-441

Martinez, T. and Wheeler, D.E. (1994) Storage proteins in adult ants (Camponotus festinatus): Roles in colony founding by queens and in larval rearing by workers. Journal of Insect Physiology 40(8): 723-729

McColl, H.P. (1975) The invertebrate fauna of the litter surface of a Nothofagus truncata forest floor, and the effect of microclimate on activity. New Zealand Journal of Zoology 2(1): $15-34$

Mirth, C.K. and Riddiford, L.M. (2007) Size assessment and growth control: how adult size is determined in insects. Bioessays 29(4): 344-355

Moller, H. and Tilley, J.A.V. (1989) Beech honeydew: seasonal variation and use by wasps, honey bees, and other insects. New Zealand Journal of Zoology 16: 289-302

Moller, H., Tilley, J.A.V., Thomas, B.W. and Gaze, P.D. (1991) Effect of introduced social wasps on standing crop of honeydew in New Zealand beech forests. New Zealand Journal of Zoology 18: 171-179

Morales, C.F., Hill, M.G. and Walker, A.K. (1988) Life history of the sooty beech scale (Ultracoelostoma assimile) (Maskell), (Hemiptera:Margarodidae) in New Zealand Nothofagus forests. New Zealand Entomologist 11: 24-38

Moreau, C.S., Bell, C.D., Vila, R., Archibald, S.B. and Pierce, N.E (2006) Phylogeny of the ants: diversification in the age of angiosperms. Science 312: 101-104

Nijhout, H.F. and Wheeler, D.E. (1996) Growth models of complex allometries in holometabolous insects. The American Naturalist 148(1): 40-56

Orians, G.H. and Pearson, N.E. (1979) On the theory of central place foraging. PP 155-177. In Horn E.M., Stairs, G.R. and Mitchell, R.D., editors. Analysis of Ecological Systems. Ohio State University Press, Columbus, Ohio, USA: 312pp

Passera, L. and Keller, L. (1990) Loss of mating flight and shift in the pattern of carbohydrate storage in sexuals of ants (Hymenoptera: Formicidae). Journal of Comparative Physiology B 160: $207-211$

Patankar, R., von Hippel, F.A. and Bell, M.A. (2006) Extinction of a weakly armoured threespine stickleback (Gasterosteus aculeatus) population in Prator Lake, Alaska. Ecology of Freshwater Fish 15: 482-487 
Peeters, C. and Ito, F. (2001) Colony dispersal and evolution of the queen morphology in social Hymenoptera. Annual Review of Entomology 46: 601-630

Pfennig, D.W. and Murphy, P.J. (2000) Character displacement in polyphenic tadpoles. Evolution 54(5): 1738-1749

Rice, A.M. and Pfennig, D.W. (2006) Character displacement: in situ evolution of novel phenotypes or sorting of pre-existing variation? Journal of Evolutionary Biology 20(2): 448459

Rice, A.M. and Pfennig, D.W. (2010) Does character displacement initiate speciation? Evidence of reduced gene flow between populations experiencing divergent selection. Journal of Evolutionary Biology 23: 854-865

Rosengren, R. and Pamilo, P. (1983) The evolution of polygyny and polydomy in mound building Formica ants. Acta Entomologica Fennica 42: 65-77

Roura-Pascual, N., Bas, J.M. and Hui, C. (2010) The spread of the Argentine ant: enivironmental determinants and impacts on native ant communities. Biological Invasions 12: 2399-2412

Sagoff, M. (2005) Do non-native species threaten the natural environment? Journal of Agricultural and Environmental Ethics 18: 215-236

Salo, P., Korpimäki, E., Banks, P.B., Nordström, M. and Dickman, C.R. (2007) Alien predators are more dangerous than native predators to prey populations. Proceedings of the Royal Society B: Biological Sciences 274: 1237-1243

Sandlant, G.R. and Moller, H. (1989) Abundance of common and German wasps (Hymenoptera:Vespidae) in honeydew beech forests of New Zealand in 1987. New Zealand Journal of Zoology 16: 333-343

Savidge, J.A. (1987) Extinction of an island forest avifauna by an introduced snake. Ecology 68(3): 660-668

Schluter, D. (2000) Ecological character displacement in adaptive radiation. The American Naturalist 156(S4): 4-16

Schoener, T.W. (a) (1974) Resource partitioning in ecological communities. Science 185 (4145): 27-39

Schoener, T.W. (b) (1974) The compression hypothesis and temporal resource partitioning. Proceedings of the National Academy of Sciences U.S.A. 71(10): 4169-4172

Schoener, T.W. (1979) Generality of the size-distance relation in models of optimal feeding. American Naturalist 114: 902-914.

Shingleton, A.W., Frankino, W.A., Flatt, T., Nijhout, H.F. and Emlen, D.J. (2007) Size and shape: the developmental regulation of static allometry in insects. Bioessays 29(6): 536-548

Smith, W.W. (1896) On the habits of New Zealand ants. Transactions and Proceedings of the New Zealand Institute 29: 468-479 
Sorvari, J. and Hakkarainen, H. (2009) Forest clear-cutting causes small workers in the polydomous wood ant Formica aquilonia. Annales Zoologici Fennici 46: 431-438

Stoll, P. and Bergius, E. (2005) Pattern and process: competition causes regular spacing of individuals within plant populations. Journal of Ecology 93(2): 395-403

Suarez, A.V. and Case, T.J. (2003) The ecological consequences of a fragmentation mediated invasion: the Argentine ant, Linepithema humile, in southern California. Ecological Studies 162: $161-180$

Thomas, R.H. (1993) Ecology of body size in Drosophilla buzzatii untangling the effects of temperature and nutrition. Ecological Entomology 18(1): 84-90

Toft, R.J. and Beggs, J.R. (1995) Seasonality of crane flies (Diptera:Tipulidae) in South Island beech forest in relation to the abundance of Vespula wasps (Hymenoptera: Vespidae). New Zealand Entomologist 18: 37-43.

Toft, R.J. and Rees, J.S. (1998) Reducing predation of orb-web spiders by controlling common wasps (Vespula vulgaris) in a New Zealand beech forest. Ecological Entomology 23(1): $90-95$

United States Fish and Wildlife Service (USFWS) (2001). Endangered and threatened wildlife and plants; proposed endangered status for 12 species of picture-winged flies from the Hawaiian Islands. Federal Register 66(11): 3964-3976

Wanless, R.M., Angel, A., Cuthbert, R.J., Hilton, G.M. and Ryan, P.G. (2007) Can predation by invasive mice drive seabird extinctions? Biology Letters 3: 241-244

Wheeler D.E. and Buck, N.A. (1992) Protein lipid and carbohydrate use during metamorphosis in the ant Solenopsis xyloni. Physiological Entomology 17(4): 397-403

Wiernasz, D.C. and Cole, B.J. (2003) Queen size mediates survival and colony fitness in harvester ants. Evolution 57(9): 2179-2183 
Chapter Two

Density-dependent effects of the invasive

wasp Vespula vulgaris (L.) (Hymenoptera) on

worker size and morphology in the endemic

New Zealand ant Prolasius advenus (Fr.

Smith) (Hymenoptera). 


\subsection{Abstract}

In ants, adult worker size and shape are the result of separate developmental processes. However, both are strongly affected by the quality and quantity of food available during larval development. In the honeydew beech forests of New Zealand the invasive wasp Vespula vulgaris attains some of the highest nest densities in the world. It competes with the endemic ant Prolasius advenus for both protein and carbohydrate resources. I tested the hypothesis that $P$. advenus worker size would be reduced in areas of high wasp density. My results indicate much intraspecific variation in size, and a significant reduction in worker size with increasing wasp density.

I also examined scaling relationships in $P$. advenus and tested the hypothesis that scaling would vary between ants from areas differing in wasp densities. Growth of some structures was found to be allometric; heads became proportionally shorter and wider with increasing body size, while the gaster and petiole became proportionally larger. Legs were found to scale isometrically. A comparison of scaling relationships against Weber's length in populations at high and low wasp densities indicated no significant difference in any combinations except with petiole and gaster size, which were proportionally greater in populations at low wasp densities. Similarly when scaled against total length, the length of the scape was found to be proportionally shorter where wasps were more abundant. I also used a combination of museum specimens collected prior to $V$. vulgaris establishment with samples collected from the same sites after the wasp's arrival to test the hypothesis that $P$. advenus workers were larger before this invasive competitor arrived. I found no difference in size of pre- and post-invasion workers, but suggest this result is because of insufficient samples. I suggest these results indicate that invasive wasps reduce growth and alter scaling relationships in ants by limiting resource availability during larval development. 


\subsection{Introduction}

The detrimental impact of invasive species on native biota is widely viewed as being second in magnitude only to habitat destruction (Vitousek, 1996). While predation by introduced organisms is often associated with extinction, the effects of competition on recipient taxa are typically sub-lethal (Davis, 2003). Resource exploitation or interference competition by exotic species frequently results in a reduction in fitness, survival or growth in native species (Begon $e t$ al., 1996). For example, competition between tadpoles of the invasive coastal plain toad Incilius nebulifer and the native Fowler's toad Anaxyrus fowleri was found to result in a reduction in body size and survivorship to metamorphosis in A. fowleri tadpoles (Vogel and Pechmann, 2010). Furthermore, the effect of interspecific competition on larval size was found to be density dependent in a study of four anuran species. Increasing larval density was accompanied by a reduction in larval size at metamorphosis. However, decreases in anuran size were not associated with a decrease in survivorship (Boone, 2005).

The quantity and quality of food resources available during larval development has been shown to be a major contributing factor to adult size in holometabolous insects (Emlen and Nijhout, 2000; Mirth and Riddiford, 2007). The size of the final larval instar prior to pupation is directly correlated with adult size (Wheeler, 1991). Numerous studies have indicated that a reduction in the availability of food resources results in the production of smaller offspring in holometabolous insects (Thomas, 1993; Wheeler and Buck, 1992; Emlen and Nijhout, 2000; Mirth and Riddiford, 2007; Sorvari and Hakkarainen, 2009). By contrast, adult shape, the relative proportion of one body part to another, is dictated after pupation has been initiated. An individual's body parts, such as the structures of the head, thorax and the appendages, develop from the imaginal discs (Emlen and Allen, 2004). The process occurs in a closed system during the pre-pupal and pupal stages, when feeding has ceased (Nijhout and Wheeler, 1996) and is entirely reliant on reserves accumulated by the larva. Up to $40 \%$ of protein, $45 \%$ of lipid and $75 \%$ of sugar reserves are utilised after pupation (Wheeler and Buck, 1992). Development of each disc is independent and, where resources within the pupa are limiting, growth of one may come at the expense of another resulting in altered scaling relationships (Nijhout and Wheeler, 1996; Emlen, 2001).

Scaling relationships among body parts are typically visualised using bivariate plots of log transformed measurements of the body part under examination against a similarly transformed 
measure of overall body size. Trait variation may be size dependent (isometric) where the slope of the line is equal to 1.0 or size independent (allometric), where the allometric coefficient $k$ differs significantly from 1.0 (Huxley, 1931). When $k>1.0$ it is said to be positive allometry reflecting a disproportionate increase in size of an organ relative to overall body size. Conversely, when $k<1.0$ it is referred to as negative allometry indicating a decrease in the relative proportion of a body part with overall size. Allometric scaling is common in many ant subfamilies (Breed, 2002). The majority of these relationships can be described with a single regression line; however, non-continuous relationships are frequently described in holometabolous insects (Knell, 2008). In ants these may reflect switch-points in development resulting in caste differentiation and task specialisation (Diniz-Fihlo et al., 1994). Such variation may allow ant species to persist in a variety of environmental conditions and to adapt rapidly to novel environmental stressors.

According to caste ratio theory (Oster and Wilson, 1978) ant colonies should be able to alter the proportion of each morph produced in response to environmental change. Allometries in holometabolous insects have been shown to develop rapidly (Emlen and Nijhout, 2000). For example increased competition upregulate soldier production in Pheidole pallidula (Passera et al., 1996) and variation in the availability of food increases colonies' relative investment in soldiers (McGlynn and Owen, 2002), alates (Sorvari and Hakkarainen, 2009) and workers (Ode and Rissing, 2002) in other ant species.

The common Wasp Vespula vulgaris is an invasive species in New Zealand's upper South Island. Since its establishment in late 1980s the species has been recorded at global peak population densities in the Nothofagus beech forests of the Nelson Lakes area (Thomas et al., 1990; Barlow et al., 2002). Its success has been attributed to the presence of abundant honeydew resources (Barlow et al., 2002), a sugary exudate excreted from the anal filament of the juvenile scale insect Ultracoelastoma assimile (Maskell) that infests the Nothofagus beech forest (Morales et al., 1988). The wasps' consumption of honeydew is so great that it has been found to reduce both the quality and quantity of the resource to the detriment of native bird species (Moller and Tilley, 1989; Moller et al., 1991; Beggs and Wilson, 1991) and insects (Moller and Tilley, 1989). In addition, V. vulgaris is a voracious predator of many invertebrate orders (Harris, 1991; Harris and Oliver, 1993; Toft and Beggs, 1995) and potentially competes with insectivorous birds (Moller and Tilley 1989) and predatory invertebrates (Thomas et al., 1990). 
The endemic small brown bush ant Prolasius advenus (Fr. Smith) is the most abundant ant species in these forests (McColl, 1975; Grangier and Lester, 2011; Chapter 5). It feeds on macroinvertebrate prey and is dependent on honeydew as a source of carbohydrate (Smith, 1896; Smith, 1969; Don, 2007). The diet of the common wasp displays significant overlap with that of $P$. advenus (Duthie, 2011). The wasp therefore represents a significant competitor that appears to exert a density dependent restriction of both carbohydrate (Moller and Tilley, 1989) and protein (Harris, 1991) resource availability to the ants.

Prolasius advenus is the most abundant ant species in Nothofagus forest (McColl, 1975) where it has been observed feeding on honeydew (Smith, 1896; Duthie, 2011; Grangier and Lester, 2011; pers. obs.). The ant is also a voracious predator of other invertebrates (Don, 2007; pers. obs.). The invasive wasp $V$. vulgaris significantly reduces both carbohydrate and protein availability in the southern beech forests (Moller et al., 1991; Harris, 1991). Worker size has been found to decrease with resource quality in other ant species (Wheeler and Buck, 1992; Mirth and Riddiford, 2007; Sorvari and Hakkarainen, 2009). Here I use a combination of individual and combined measurements of morphological characters to test the hypothesis that $P$. advenus workers are smaller in areas where wasps maintain high population densities compared to areas where wasps are less abundant. I also compared measures of museum specimens collected prior to wasp invasion with specimens collected from the same localities after wasps became established to test the hypothesis that in the absence of wasps $P$. advenus were historically larger. Finally, as caste ratio theory (Oster and Wilson, 1978) posits that colonies should be able to increase the relative abundance of particular worker morphs according to environmental pressure, I examine scaling relationships in $P$. advenus across all population and compare scaling relationships at high and low wasp density to test the hypothesis that morphological development will alter where wasps are most abundant. 


\subsection{Methods}

\subsubsection{Study sites and specimen collection}

Between 1988 and 2008 annual wasp nest density surveys were conducted by Landcare Research Nelson (For methods see: Beggs et al., 1998 and Barlow et al., 2002) in seven Nelson Lakes honeydew beech forest sites: Pelorus Bridge ( $\left.41^{\circ} 18^{\prime} \mathrm{S}, 173^{\circ} 34^{\prime} \mathrm{E}\right)$; Graham Valley $\left(41^{\circ} 09^{\prime} \mathrm{S}\right.$, $\left.173^{\circ} 31^{\prime} \mathrm{E}\right)$; Spooner's Range ( $\left.41^{\circ} 27^{\prime} \mathrm{S}, 172^{\circ} 55^{\prime} \mathrm{E}\right)$; Lake Rotoiti (41 $\left.49^{\prime} \mathrm{S}, 172^{\circ} 50^{\prime} \mathrm{E}\right)$; Mt. Misery $\left(41^{\circ} 54^{\prime} \mathrm{S}, 172^{\circ} 39^{\prime} \mathrm{E}\right)$; Tiraumea Saddle $\left(41^{\circ} 54^{\prime} \mathrm{S}, 172^{\circ} 37^{\prime} \mathrm{E}\right)$ and Matakitaki $\left(42^{\circ} 58^{\prime}\right.$ $\left.\mathrm{S}, 172^{\circ} 20^{\prime} \mathrm{E}\right)$. A reduced survey was conducted in 2009 and 2010 measuring densities at only four of the sites: Pelorus Bridge, Spooner's Range, Mt. Misery and Lake Rotoiti. The data collected provide a historical record of annual variation in wasp density and delineates sites with consistently higher and consistently lower levels of wasp infestation (see Beggs et al., 1998 and Barlow et al., 2002) (Figure 2.1). Ants were collected from all of these sites. Additional specimens were collected from Maitai Valley northwest of Nelson city (41 $\left.18^{\prime} \mathrm{S}, 173^{\circ} 22^{\prime} \mathrm{E}\right)$, a site now heavily infested with $V$. vulgaris, for comparison with specimens in the Natural History Museum London that were collected by E.B. Britton in 1949 prior to the wasps' arrival. Ants were also collected from another area of Maitai Valley $\left(41^{\circ} 17^{\prime} \mathrm{S}, 173^{\circ} 21^{\prime} \mathrm{E}\right)$ that has an ongoing wasp poisoning programme.

Prolasius advenus worker specimens were collected between summer 2008 and 2010 from the seven sites monitored for wasp density. Samples collected in 2008 were taken from four nests collected in toto along the Landcare transect line at each of the seven long term survey sites with the exception of Graham River and Tiraumea where only two nests each were collected. Approximately 30 workers were then haphazardly sampled from each nest. A further 30 workers were sampled haphazardly by mouth aspirator from each of three nests per site opened along the transect lines at Pelorus Bridge, Mt. Misery, Lake Rotoiti, and Spooner's Range in 2009. In addition between 23 and 152 specimens per site were collected from pitfall traps. The traps were haphazardly placed in three $10 \times 10$ m quadrats set at all sites except Graham Valley and Tiraumea, which were omitted due to the logistical problems associated with reaching the sites. Approximately 90 ants were haphazardly collected by mouth aspirator from epigaeic, terrestrial 
and arboreal substrates at each of four sites in 2010: Pelorus Bridge, Spooner's Range, Mt. Misery and Lake Rotoiti.

\subsubsection{Effects of increasing wasp density on worker size}

Measurements were taken from a total of 1731 workers collected from the seven long term wasp density survey sites described above to test the hypothesis that worker size will decrease with increasing wasp density. Total length was used as an estimator of worker size based on the sum of four longitudinal measurements: head length (measured dorsally from the anterior tip of the clypeus to the occiput); Weber's length, (viewed laterally; the diagonal distance between the anterior margin of the pronotum to the posterior margin of the metapleural bulla); petiole length (viewed ventrally; the distance from the anterior to the posterior margin of the petiole); the first gaster segment (viewed laterally; the distance from the anterior-most point of the first gaster segment to its posterior margin) (Figure 2.2). It should be noted that because an ant's gaster tends to vary in length depending on how much it has ingested, only the first segment, which cannot expand, was measured in this study. This measurement is a commonly used proxy for total length of the abdomen (Tschinkel et al., 2003). All these and the measurements below were taken using a Nikon SMZ1500 compound microscope at $112.5 \times$ magnification with a lens graticule except Weber's length which was measured at $80 \times$ magnification in order to fit the thorax into the field of view in its entirety.

The measurements were analysed using ANCOVA with mean worker total length as the dependent variable, site as the independent variable and wasp density as a covariate using PASW 18.0.0 statistical software (SPSS Inc., 2010). The dataset was assessed for normality and homoscedasticity. The results of a Levene's Test of Equality of Error Variances indicated a significant $(\mathrm{P}<0.001)$ deviation from the null hypothesis of equal variance across groups. For this reason data were analysed in PRIMER v6 (Clarke and Gorley, 2006) using PERMANOVA+ (Anderson et al., 2008), which generates P (perm) values by permutation without assumptions of normality or homoscedasticity. A resemblance matrix was first constructed based on Euclidian distance. A main effects permutational ANCOVA analysis was then performed based on Type 1 Sums of Squares with 9999 unrestricted permutations of raw data. Mean worker total length was the dependent variable. Site was the independent variable and wasp density a covariate. 


\subsubsection{Effects of increasing wasp density on worker morphology}

To test the hypothesis that relative growth will vary with increasing wasp density a subsample of 1068 of the specimens above were measured for five additional characters: head width (measured dorsally immediately posterior to the eyes); scape length (measured the margin of the basal condyle to the margin of the first antennal segment); femur length (linear distance from the margin with the trochanter to margin of the tibia); tibia length (linear distance from the junction with the femur to the junction with the first tarsal segment); tarsus length (linear distance from the firsts tarsal segment to the tip of the tarsal claw). All leg measures were taken from the right rear leg.

Nine $P$. advenus worker character measurements; head length; head width; scape length; Weber's length; petiole length; the length of the first gaster segment; femur length; tibia length and tarsus length) from 1068 individuals collected across seven sites of known wasp density between 2008 and 2010 were treated as dependent variables in a MANCOVA analysis with site as the independent variable and wasp density at the time of collection as a covariate. Again the data did not satisfy the assumption of homoscedasticity and data were rerun with the same parameters using PERMANOVA+ (Anderson et al., 2008).

\subsubsection{Scaling relationships in P. advenus and the effect of high wasp densities}

To assess whether scaling relationships among body parts are isometric or allometric the relationships between the nine character measurements above were examined in all 1068 specimens measured using Reduced Major Axis regression (RMA) run on RMA for Java statistical software (Bohonak and van der Linde, 2004). RMA was used in preference to type 1 linear regression to accommodate error in the $\mathrm{x}$-axis data. Prior to analysis data were $\log$ transformed to counteract the multiplicative relationship between characters.

To investigate the possibility that scaling relationships in $P$. advenus workers are not continuous, which would indicate distinct sub-castes; data were reanalysed using segmented regression. Raw measurement data were used to avoid the possibility of spurious breakpoints generated by log transformed data (Burns et al., 2009). Data were analysed using SegReg statistical software (Oosterbaan, 1994). 
To examine the effects of high wasp density on scaling relationships the above samples of $P$. advenus workers were separated based on whether they were collected from high wasp density (> 20 nests $\left.\mathrm{Ha}^{-1}\right)$ or low wasp density $\left(<20\right.$ nests $\left.\mathrm{Ha}^{-1}\right)$ sites and re-analysed using RMA. Confidence intervals of the slope $\beta$ were then compared. Where no overlap of the confidence intervals of the two slopes was observed the scaling relationships were considered to be significantly different.

\subsubsection{Comparison of P. advenus worker size prior to wasp invasion with post-wasp workers}

To test the hypothesis that in the absence of competition by the common wasp, $P$. advenus workers would be larger than workers from the same area after wasp invasion I used historical specimens of $P$. advenus collected from areas now infested by wasps. I used 30 dry mounted specimens of $P$. advenus workers in the collection of the Natural History Museum London for the four characters used to establish total length (head length, Weber's length petiole length and the length of the first gaster segment) at $80 \times$ magnification. The specimens, 22 from Upper Maitai Valley collected on the $5^{\text {th }}$ of September 1949 by E.B. Britton and 8 from Lake Rotoiti collected on the $25^{\text {th }}$ of December 1983 by B.M. Hammond, all originated from beech forest in the Nelson lakes area which has subsequently become infested with wasps. Shrinkage of specimens in dried insect collections typically manifests itself as shrivelling of soft tissues, rather than linear shrinkage. However good collection management practice ensures specimens are maintained in an appropriate temperature and humidity regime to avoid this. For this reason it is assumed that little shrinkage of the chitinous exoskeleton has occurred since the time of collection in the Natural History Museum London specimens.

As both the Maitai Valley and Rotoiti sites currently have areas with ongoing wasp control eight and twenty two specimens respectively were collected in January 2008 by pitfall trapping from areas with a wasp poisoning scheme in place (hereafter wasps removed) and without (hereafter wasp maintained) and preserved in $70 \%$ ethanol. These specimens were then oven-dried at $50^{\circ} \mathrm{C}$ for 24 hours to bring them to a comparable condition to the dry mounted specimens in then Natural History Museum London. They were then measured at $80 \times$ magnification for the four characters that comprise total length. 
The limited availability of $P$. advenus museum specimens which satisfied the criteria of: 1.being collected before $V$. vulgaris became established in New Zealand and 2.being collected from sites that are now infested by the wasp, resulted in a comparatively small sample size. For this reason samples from the Maitai and Rotoiti sites were pooled. A one way ANOVA was then conducted with mean worker total length as the dependent variable and wasp presence as the independent variable with three levels: pre-wasps; wasps maintained and wasps controlled. Data were checked for and conformed to the assumptions of normal distribution and equal variances and effect size and observed power were estimated. The analysis was run using PASW 18.0.0 statistical software (SPSS Inc., 2010).

A power analysis was conducted using G*Power 3.1.2 (Faul et al., 2007). Parameters were set for “medium" (Cohen's $f=0.25$ ) and small (Cohen's $f=0.1$ ) effect sizes with $\alpha$ error probability $=0.05 ;$ Power $(1-\beta$ error probability $)=0.95$ for 3 groups . 


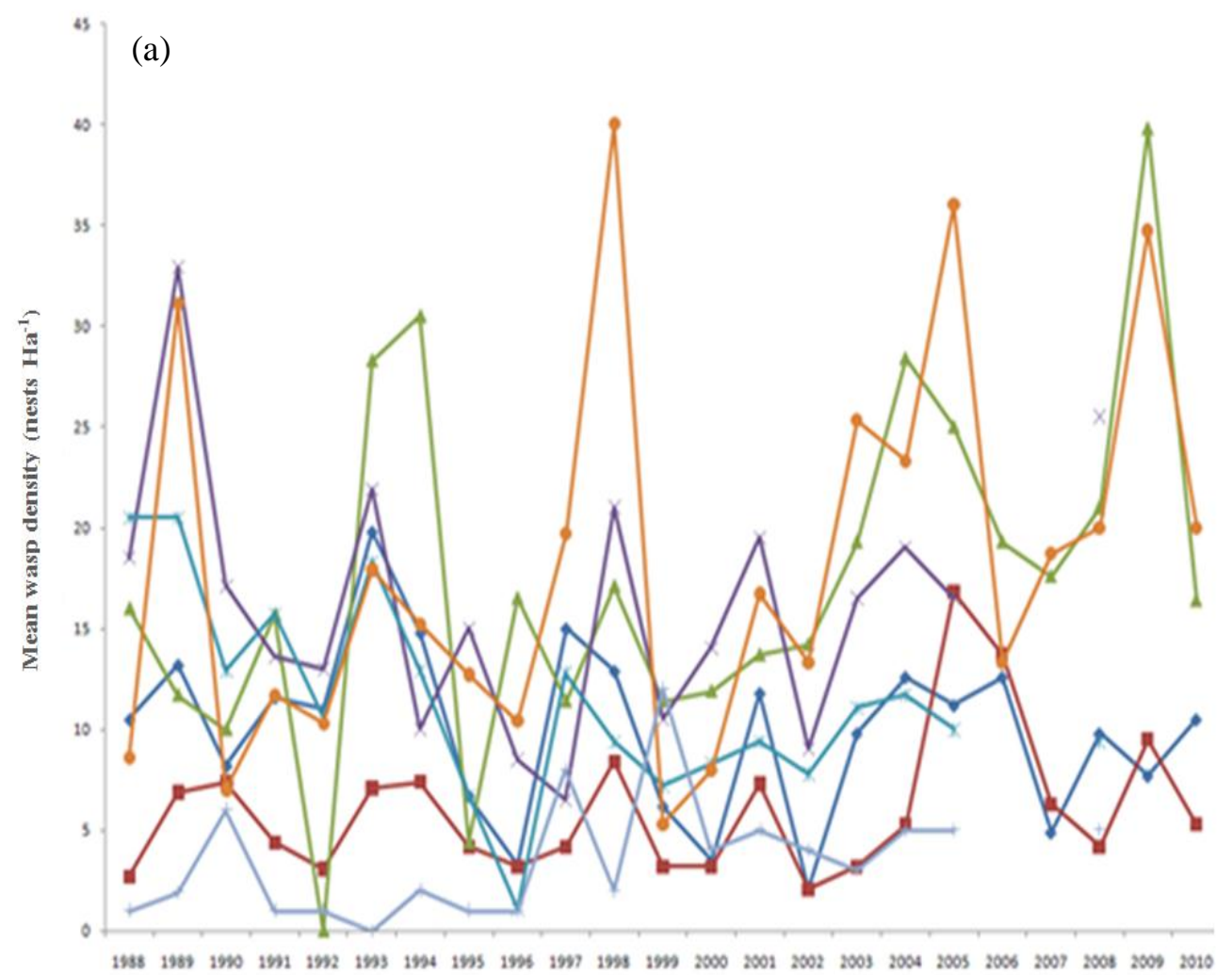

Year $\rightarrow$ Pelorus

$\rightarrow$-spooners

I-Mitisery

*Tiraumea

-Matakitaki

$\rightarrow$ Rotoiti

+Graham Valley

(b)

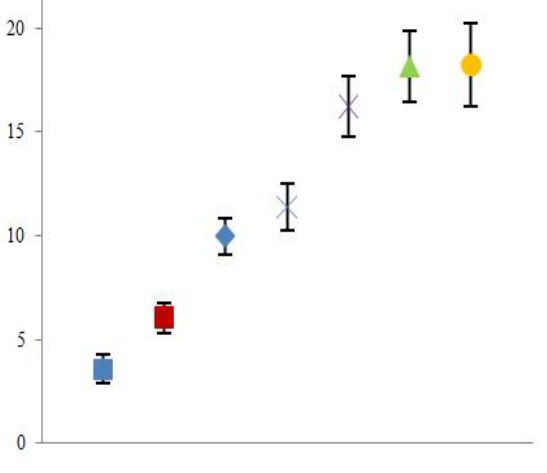

Site

Figure 2. 1 (a) Annual wasp density (nests $\mathrm{Ha}^{-1}$ ) at seven South Island beech forest sites between 1988 and 2010 ; (b)Mean annual wasp density (nests $\mathrm{Ha}^{-1}$ ) \pm 1 standard error between 1988 and 2010. 


\subsection{Results}

\subsubsection{Wasp density}

Considerable variation was observed in within-site wasp densities from year to year. However, average wasp density over the twenty year period delineates sites that are consistently infested with wasps at high densities (Tiraumea Saddle, Mt. Misery and Lake Rotoiti) and those where wasps are consistently less abundant (Graham Valley, Spooner's Range, Pelorus Bridge and Matakitaki) (Figure 2.1).

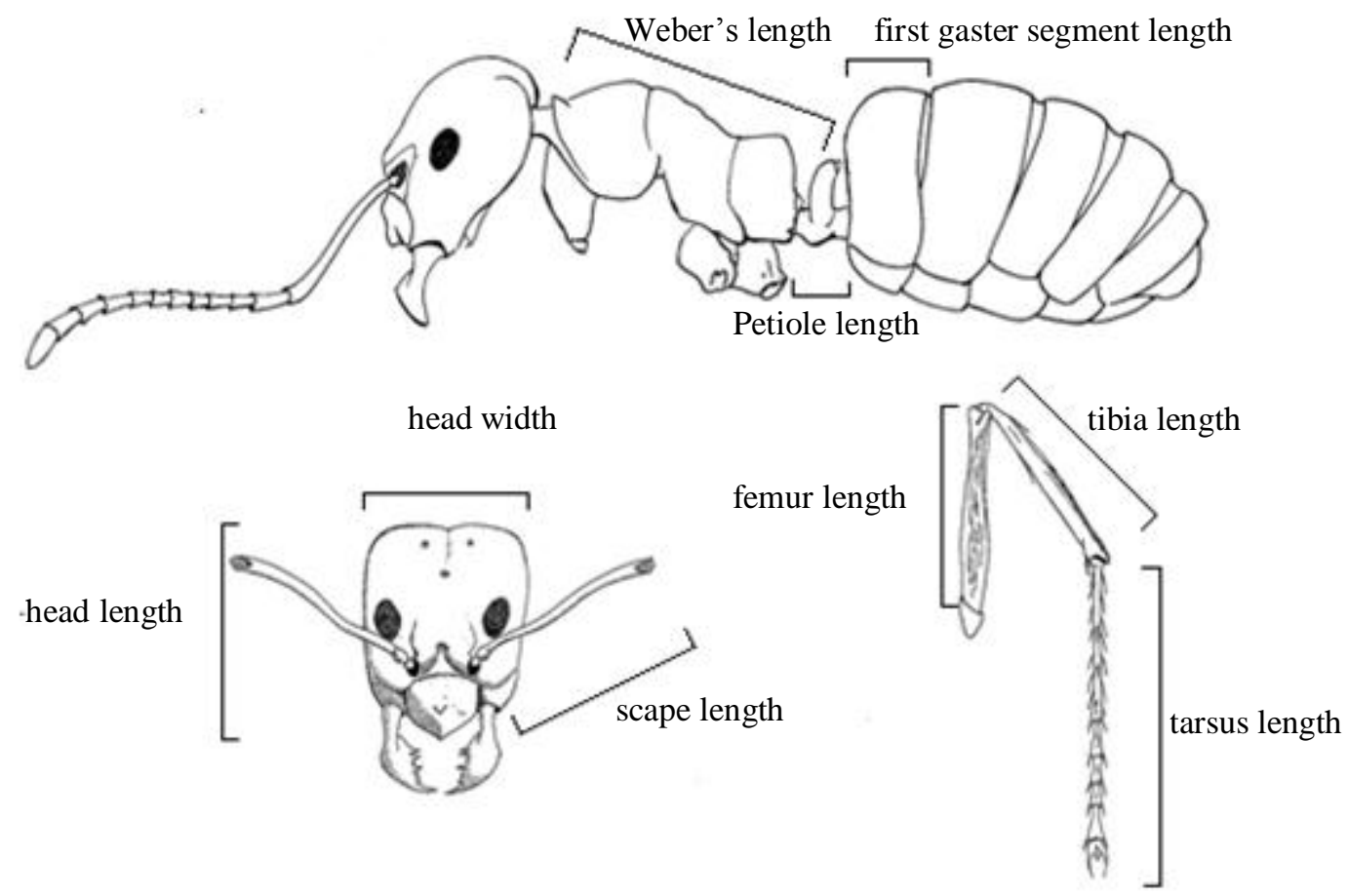

Figure 2.2 Nine character measurements taken from Prolasius advenus workers: head length, head width, scape length, Weber's length, petiole length, first gaster segment length, femur length, tibia length and tarsus length.

\subsubsection{Effects of increasing wasp density on worker size}

Prolasius advenus workers decrease in size with increasing wasp density. Workers are variable in size and differ significantly among sites. Worker total lengths range between $1.74 \mathrm{~mm}$ and $2.65 \mathrm{~mm}$, meaning some workers are up to 1.5 times the size of others. The results of the 
ANCOVA showed a significant difference in mean worker total length among sites $(\mathrm{F}=86.998$; d. f. $=6 ; \mathrm{P}<0.0001)$ and at different wasp densities $(\mathrm{F}=5.86 ;$ d. $\mathrm{f} .=1 ; \mathrm{P}=0.016)$ (Figure 2.3). Parameter estimates indicated a significant negative effect of wasp density on worker total length $(\beta=-0.001 ; \mathrm{SE}>0.001 ; \mathrm{P}=0.016)$. However, assumptions of homoscedasticity were violated (Levene's Test $\mathrm{P}<0.001$ ), even after attempts at transformation. For this reason data were rerun using PERMANOVA (Anderson et al., 2008), which does not make assumptions of normal distribution or homoscedasticity. The results of the permutational MANCOVA were in support of the ANCOVA indicating a significant difference in mean worker total length among sites $(\mathrm{P}=$ $0.0001)$ and at differing wasp density $(\mathrm{P}=0.0001)$. Because of the similarity in the output of the two tests and because unequal variances are to be expected in a dataset this size, I suggest that the parameter estimates of the parametric test may be viewed as robust, as may the results of the tests below.

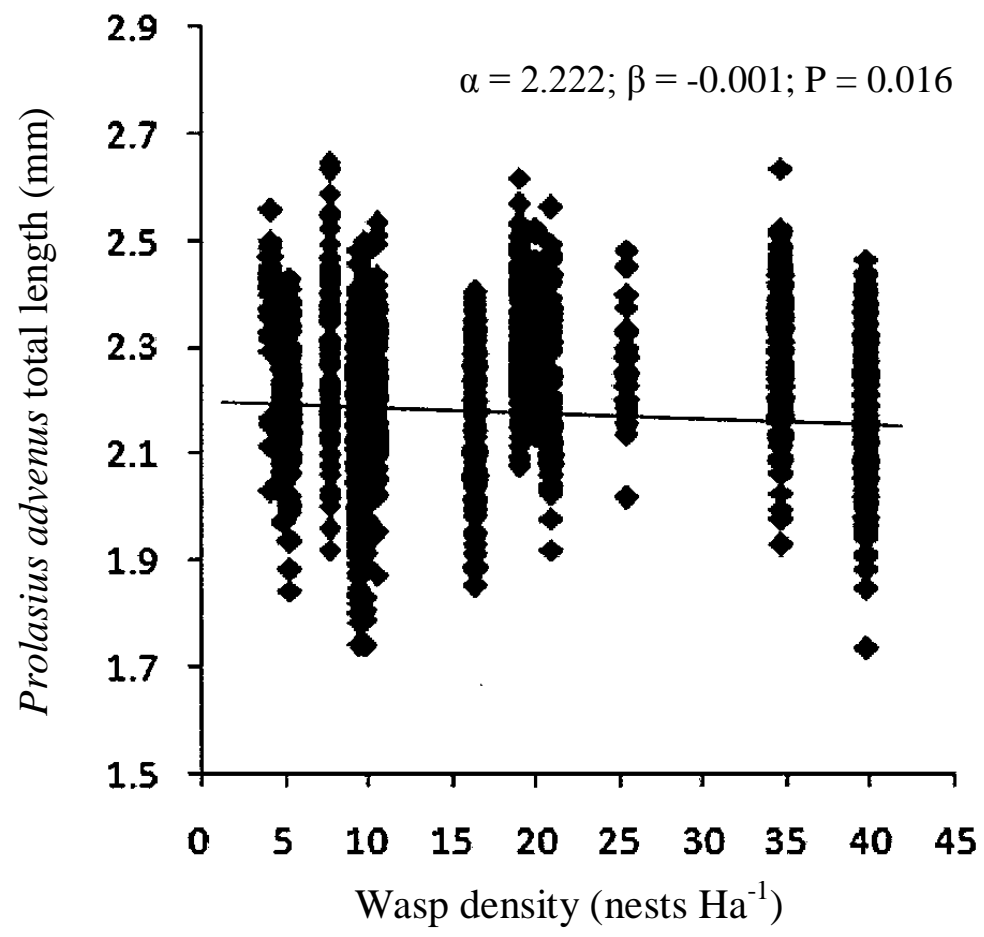

Figure 2. 3 The negative relationship between increasing wasp density (nests $\mathrm{Ha}^{-1}$ ) and mean worker size (total length mm) of Prolasius advenus at seven Nothofagus beech forest sites based on parameter estimates generated from ANCOVA analysis. 


\subsubsection{Effects of increasing wasp density on worker morphology}

Five of the nine characters measured: head length, scape length, Weber's length, femur length and tibia length, reduced in size with increasing wasp density. The results of MANCOVA and PERMANCOVA indicated a significant difference in the mean size of all characters among sites $(\mathrm{P}<0.001)$. A significant difference $(\mathrm{P}<0.05)$ was also found in the mean size of all characters except head width, petiole length, length of the first gaster segment and tarsal length at different wasp densities. Parameter estimates indicate a significant $(\mathrm{P}<0.001)$ negative relationship between character size and wasp density for all characters measured except head width, petiole length, the length of the first gaster segment and the tarsal length (Table 2.1).

Table 2.1 The effects of site and wasp density on the size of nine morphological characters measured in $P$. advenus workers. Parameter estimates generated by MANCOVA are also displayed showing the effect of increasing wasp density on the mean size of morphological characters of $P$. advenus workers after site effects have been standardised.

\begin{tabular}{|c|c|c|c|c|c|c|}
\hline & \multicolumn{2}{|c|}{ Site } & \multicolumn{2}{|c|}{ Wasp density } & \multicolumn{2}{|c|}{$\begin{array}{l}\text { Parameter estimates of } \\
\text { wasp density }\end{array}$} \\
\hline Character & $\mathrm{F}$ & $\mathrm{P}$ & $\mathrm{F}$ & $\mathrm{P}$ & Slope $(\beta)$ & $\begin{array}{l}\text { Standard } \\
\text { error }\end{array}$ \\
\hline Head length & 41.037 & $<0.001$ & 16.074 & $<0.001$ & -0.001 & $<0.001$ \\
\hline Head width & 45.593 & $<0.001$ & 1.895 & 0.169 & 0 & $<0.001$ \\
\hline Scape length & 66.882 & $<0.001$ & 8.561 & 0.004 & -0.001 & $<0.001$ \\
\hline Weber's length & 26.209 & $<0.001$ & 9.168 & 0.003 & -0.001 & $<0.001$ \\
\hline Petiole length & 105.802 & $<0.001$ & 1.81 & 0.179 & 0 & $<0.001$ \\
\hline $\begin{array}{l}\text { First gaster } \\
\text { segment length }\end{array}$ & 83.378 & $<0.001$ & 0.002 & 0.963 & $<-0.001$ & $<0.001$ \\
\hline Femur length & 56.011 & $<0.001$ & 4.366 & 0.037 & -0.001 & $<0.001$ \\
\hline Tibia length & 44.305 & $<0.001$ & 5.011 & 0.025 & -0.001 & $<0.001$ \\
\hline Tarsus length & 46.682 & $<0.001$ & 2.679 & 0.102 & -0.001 & $<0.001$ \\
\hline
\end{tabular}




\subsubsection{Scaling relationships in P. advenus and the effect of high wasp densities}

Of the twelve scaling relationships I examined in $P$. advenus only three were isometric (i.e. where the $95 \%$ CI of $\beta$ includes 1): (i) head width scales isometrically with total length; (ii) total leg length scales isometrically with Weber's length; and (iii) the petiole scales isometrically with the first gaster segment (table 2.2). Positive scaling relationships (i.e. the $95 \% \mathrm{CI}$ of $\beta>1$ ) were observed between: (i) head width and head length; (ii) the first gaster segment and Weber's length; and (iii) the petiole length and Weber's length. The remaining relationships tested: (i) scape length and total length; (ii) head length and Weber's Length; (iii) Weber's length and total length; and (iv) total leg length and total length were all found to be negatively allometric (i.e. the $95 \%$ CI of $\beta<1$ ) (Table 2.2).

To examine whether any of the scaling relationships in $P$. advenus workers were discontinuous all regressions were repeated using raw data in Segreg statistical software (Table 2.3). A single significant breakpoint was detected in the slope of the relationship between length of the first gaster segment and petiole length $(\mathrm{P}=0.019)$ (Figure 2.4). The segmented regression line explained only $1.8 \%$ more of the variance in the dataset than the $62 \%$ explained by an unbroken linear regression. The 10 other interactions tested showed no significant evidence $(P>0.05)$ of a breakpoint (Table 2.3).

\subsubsection{Comparison of P. advenus worker size prior to wasp invasion with post-wasp workers}

The results of one way ANOVA comparing museum specimens of $P$. advenus workers collected prior to wasp invasion with specimens collected from the same locations after wasp invasion where wasp densities were maintained or reduced found no significant difference in mean worker total length among collections $(\mathrm{F}=1.156$; d.f. $=2 ; \mathrm{P}=0.319)$. The effect size recorded for the 90 samples was 0.025 ; non-central parameter $=2.312$; and observed power $=0.248$. Worker total length ranged from 1.84mm collected in Upper Matai Valley in 1949 to $2.53 \mathrm{~mm}$ collected from Lake Rotoiti in 1983 (Figure 2.5). However, the results of the power analysis indicated that in order to detect a "medium" (Cohen's $f=0.25$ ) effect with a power of 0.95 a total sample size of 252 individuals would be necessary (or 84 samples from each of the 3 groups). If the effect being investigated were "small" (Cohen's $f=0.1$ ) a sample of 1548 (or 516 samples per group) would be needed to perform a test with a power of 0.95 . Thus, given the amount of 
variation the sample size available was insufficient to detect an effect of wasps on ant worker size.

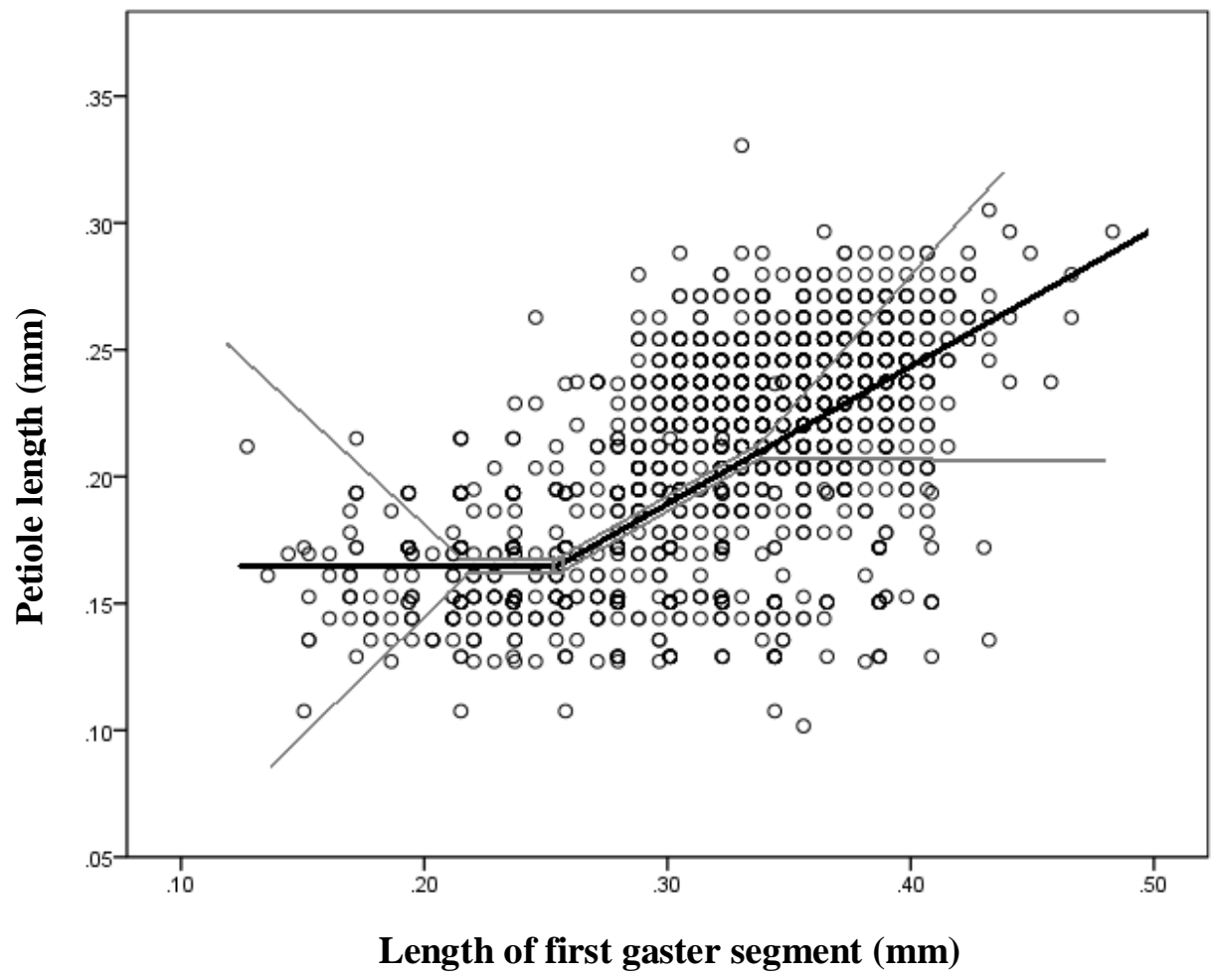

Figure 2. 4 Segmented regression of petiole length against first gaster segment length showing 95\% confidence belt and $95 \%$ confidence block of break-point. None of the other eleven relationships tested showed significant evidence of a break-point. 
Table 2.2 Results of reduced major axis (RMA) regression on morphological characters against size estimates. Where the $95 \%$ confidence intervals of the slope $\beta$ do not include 1 the scaling relationship may be deemed to be allometric. Slopes with values $>1$ represent positive allometry and those where the slope is $<1$ represent negative scaling relationships.

\begin{tabular}{|c|c|c|c|}
\hline Relationship & $\begin{array}{l}\text { Slope } \\
(\beta)\end{array}$ & $\mathbf{R}^{2}$ & $\begin{array}{l}\text { Nature of scaling } \\
\text { relationship }\end{array}$ \\
\hline head length vs. head width & $1.097(1.061,1.132)$ & 0.702 & + allometric \\
\hline total length vs. head width & $0.984(0.937,1.030)$ & 0.382 & isometric \\
\hline total length vs. scape length & $0.958(0.920,0.995)$ & 0.565 & - allometric \\
\hline Weber's length vs. head length & $0.722(0.684,0.760)$ & 0.238 & -allometric \\
\hline head length vs. scape length & $1.581(1.496,1.665)$ & 0.208 & + allometric \\
\hline $\begin{array}{l}\text { total length -Weber's length vs. } \\
\text { Weber's Length }\end{array}$ & $0.69(0.656,0.724)$ & 0.325 & -allometric \\
\hline total length vs. total leg length & $0.958(0.920,0.995)$ & 0.565 & -allometric \\
\hline $\begin{array}{l}\text { Weber's length vs. total leg } \\
\text { length }\end{array}$ & $1.027(0.975,1.079)$ & 0.297 & isometric \\
\hline $\begin{array}{l}\text { Weber's length vs. petiole } \\
\text { length }\end{array}$ & $3.529(3.332,3.376)$ & 0.05 & + allometric \\
\hline $\begin{array}{l}\text { first gaster segment length vs. } \\
\text { petiole length }\end{array}$ & $0.997(0.946,1.047)$ & 0.289 & isometric \\
\hline $\begin{array}{l}\text { Weber's length vs. first gaster } \\
\text { segment length }\end{array}$ & $3.541(3.338,3.743)$ & 0.095 & + allometric \\
\hline
\end{tabular}




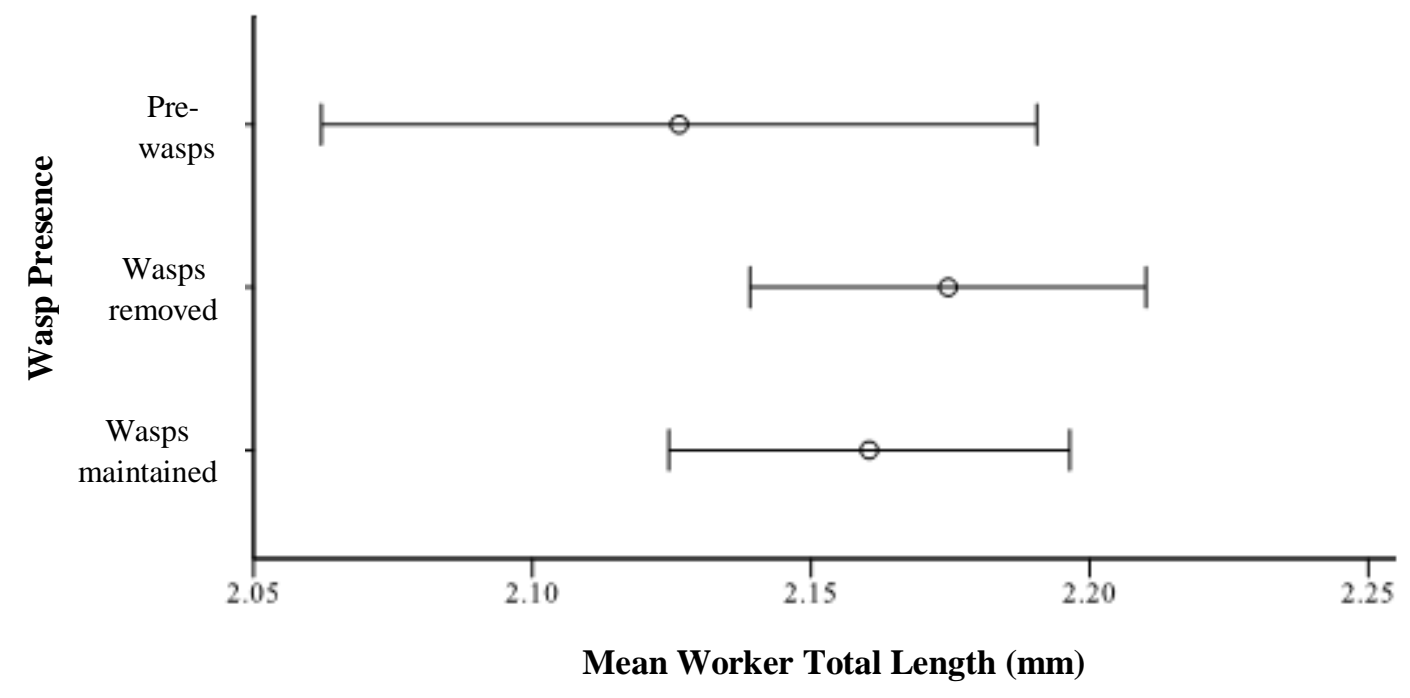

Figure 2.5 Comparison of mean \pm S.E. worker total length between dried museum specimens collected prior to wasp establishment with dried specimens from the same sites collected after wasps established. Post wasp infestation samples are from areas where wasp numbers have been reduced by poisoning (wasps removed) and at their natural population density (wasps maintained) $n=30$ for each group. 
Table 2.3 Results of the segmented regression analysis on $P$. advenus morphological characters. Where a single unbroken line best fits the scaling relationship it is marked 'Linear'. Where a segmented line better fits the data, the slope $(\beta)$ of the line before (As) and after $(\mathrm{Ag})$ the breakpoint are presented along with $\mathrm{F}$ and $\mathrm{P}$ values for both linear and where applicable segmented regression.

\begin{tabular}{|c|c|c|c|c|}
\hline Relationship & Slope (B) & $\begin{array}{c}\mathrm{F} \\
(\mathbf{1 , 1 0 6 6 )}\end{array}$ & $\overline{\mathbf{P}}$ & $\begin{array}{l}\text { Line of } \\
\text { best fit }\end{array}$ \\
\hline head length vs. head width & 0.810 & 2389.63 & 0.01 & Linear \\
\hline total length vs. head width & 0.181 & 627.50 & 0.01 & Linear \\
\hline total length vs. scape length & 0.304 & 1160.65 & 0.01 & Linear \\
\hline Weber's length vs. head length & 0.600 & 1299.50 & 0.01 & Linear \\
\hline head length vs. scape length & 0.654 & 307.20 & 0.01 & Linear \\
\hline total length -Weber's length vs. Weber's Length & 0.293 & 519.68 & 0.01 & Linear \\
\hline total length vs. total leg length & 0.811 & 1462.45 & 0.01 & Linear \\
\hline Weber's length vs. total leg length & 0.191 & 895.17 & 0.01 & Linear \\
\hline Weber's length vs. Petiole length & 0.167 & 51.58 & 0.01 & Linear \\
\hline first gaster segment length vs. petiole length & $\begin{array}{l}\mathrm{As}<0.001 \\
\mathrm{Ag}=0.055\end{array}$ & $\begin{array}{c}496.93 \\
14.61\end{array}$ & $\begin{array}{l}0.01 \\
0.02\end{array}$ & $\begin{array}{c}\text { Linear } \\
\text { Segmented }\end{array}$ \\
\hline Weber's length vs. first gaster segment length & $\begin{array}{l}\mathrm{As}=0.026 \\
\mathrm{Ag}=0.044\end{array}$ & $\begin{array}{c}124.75 \\
3.13\end{array}$ & $\begin{array}{l}0.01 \\
0.28\end{array}$ & $\begin{array}{c}\text { Linear } \\
\text { Segmented }\end{array}$ \\
\hline
\end{tabular}

Table 2.4 Scaling relationships of petiole, first gaster segment and scape with overall size in low $\left(<20\right.$ nests $\left.\mathrm{Ha}^{-1}\right)$ and high $\left(>20\right.$ nests $\mathrm{Ha}^{-1}$ ) wasp density sites. Weber's length is used as a proxy for total length in petiole and gaster comparisons.

\begin{tabular}{lcccc}
\hline Relationship & \multicolumn{2}{c}{$\begin{array}{c}\text { Low wasp density } \\
\left(<\mathbf{2 0} \text { nests Ha } \mathbf{H a}^{-1}\right)\end{array}$} & \multicolumn{2}{c}{$\begin{array}{c}\text { High wasp density } \\
\left(>\mathbf{2 0} \text { nests Ha } \mathbf{H a}^{-1}\right)\end{array}$} \\
& Slope $(\beta)$ & Std error & Slope $(\beta)$ & Std error \\
\hline $\begin{array}{l}\text { log Weber's length vs. log petiole } \\
\text { length }\end{array}$ & $3.54(3.18,3.89)$ & 0.17 & $2.054(1.82,2.29)$ & 0.12 \\
$\begin{array}{l}\text { log Weber's length vs. log first } \\
\text { gaster segment length }\end{array}$ & $3.83(3.44,4.20)$ & 0.19 & $1.832(1.65,2.02)$ & 0.09 \\
log total length vs. log scape length & $0.27(0.25,0.29)$ & 0.01 & $0.19(0.17,0.20)$ & 0.01 \\
\hline
\end{tabular}




\subsection{Discussion}

The results of this study indicate that there is a significant decrease in mean $P$. advenus worker size with increasing density of the invasive wasp $V$. vulgaris. My results are consistent with studies of other ant species, which have demonstrated that restriction of food resources results in production of smaller workers (Wheeler and Buck, 1992; Mirth and Riddiford, 2007; Sorvari and Hakkarainen, 2009), although I cannot totally discount the influence of other environmental factors that affect larval growth such as temperature or population density. The diet of $V$. vulgaris displays significant overlap with that of $P$. advenus (Duthie, 2011). Furthermore, the common wasp has been demonstrated to exert significant interference competition pressure on $P$. advenus (Duthie, 2011; Grangier and Lester, 2011). Given the wasp's documented consumption of honeydew (Moller and Tilley, 1989; Moller et al., 1991; Beggs et al., 1998) and invertebrate prey (Harris, 1991; Harris and Oliver, 1993) it arguably also exerts exploitive competition pressure on the small brown bush ant by reducing both the quality and quantity of these resources. I suggest that the observed reduction in worker size with increasing wasp density reflects a reduction in larval growth due to restricted resources mediated by competition with wasps.

In addition to a reduction in size, $P$. advenus displayed an alteration in its general morphology with increasing wasp density. A significant decrease was observed in the size of five out of the nine characters measured with increasing wasp density. The characters that did not decrease significantly with increasing wasp density were: head width, petiole length, length of the first gaster segment and tarsus length. That head and scape length decrease with increasing wasp density but head width does not, indicating the shape of the head alters with increasing wasp density. While head length and Weber's length both decrease, the length of two abdominal segments, the petiole and gaster, do not. This result indicates that these characters contribute a relatively larger proportion of the total length measure with increasing wasp density. Similarly, the tarsus contributes an increasing proportion of the total leg length. These differences in relative growth rates are consistent with Nijhout and Wheeler's (1996) hypothesis that when resources within a cocoon are limiting, growth of one imaginal structure comes at the cost of another. 
Examination of scaling relationships in P. advenus workers found evidence of positive allometric growth of the petiole and gaster, both of which increase disproportionately in size as the animals grow larger. The ecological significance of this result is uncertain. However, one may speculate that as the primary functions of a worker are defence and resource collection there may be a selective advantage to having a disproportionally larger abdomen associated with these tasks. The size of the gaster and petiole were conserved when other characters reduced in size with increasing wasp density, which may be indicative of its functional importance. In these beech forests, the main source of carbohydrate is honeydew (Moller and Tilley, 1989). Workers transport the liquid back to the nest in their crop and the gaster may swell to nearly twice its usual size (Smith, 1969). It is possible that larger workers with disproportionally larger abdomens may be better adapted to collect liquid resources. Furthermore, I found evidence of discontinuous allometry between the two abdominal segments. It is possible that as the gaster grows beyond a critical size a disproportionally larger petiole segment is needed to articulate it.

Alternatively, a larger gaster may provide a defensive advantage. $P$. advenus' primary means of defence is to spray acid (Grangier and Lester, 2011). The gland that produces this acid is situated in the gaster (Smith, 1969). It is possible then, that a large gaster has a larger poison gland and it would be interesting to examine the scaling relationships between the external and internal characters of the abdomen in a future study.

The combination of the negative scaling relationship between head length and Weber's length, the isometric relationship between head width and total length and the positive scaling relationship between head width and head length indicates that larger $P$. advenus workers have proportionally smaller but wider heads than smaller workers. If an increase in head width comes at the cost of head length, prioritising lateral rather than longitudinal growth may reflect a selective advantage to broader heads, perhaps by optimising space for mandibular musculature. Studies of scaling relationships in other ant species (Schöning et al., 2005) have illustrated that increased anterior head width was associated with increased mandibular gape and a more powerful bite. It is possible that the scaling relationships of the head observed in this study confer a competitive advantage in both prey acquisition and defence. Such a hypothesis needs experimental testing. 
A negative scaling relationship was found between the size of the scape and total length. Tschinkel et al. (2003) reported similar results in an analysis of scaling relationships in Solenopsis invicta and attributed the observed relationship to competition among imaginal structures during development as proposed by Nijhout and Wheeler (1996) and Emlen (2001). This hypothesis also seems applicable to P. advenus. As head width remains isometric to total length while head length reduces with increasing size, it seems likely that the cost of this investment is shared with the antennal scape, particularly given the increased demand for resources within the pupa by heavy investment in the gaster.

The scaling relationships examined were also found to vary among ant populations in high and low wasp density sites. Although the gaster and petiole scale positively in both high and low wasp density populations they were found to be disproportionally larger where wasps are sparse than where they are abundant. Assuming there is an isometric relationship between crop and gaster size it is possible that larger individuals, with disproportionally larger gasters would be more efficient carriers of liquid resources than their smaller counterparts. Where wasps are abundant it is expected that honeydew resources will be reduced (Moller and Tilley, 1989). It is possible that the benefit of having a large gaster does not outweigh the cost of producing it where wasps reduce the available honeydew resources. Scaling of the scape also varied between high and low wasp density populations displaying a stronger negative allometric relationship where wasps are at high density than where wasps were sparse. Again, this supports the hypothesis of competition among developing imaginal structures for limiting resources within the pupa as proposed by Nijhout and Wheeler (1996) and Emlen (2001).

Comparison of museum samples of $P$. advenus collected prior to wasp establishment with dried specimens collected recently from the same localities which are now experiencing high levels of wasp infestation and where there is an active poisoning programme in place found no significant difference between the three groups. This is contrary to what might be expected in light of the results presented above. However, given the high level of size variation observed in $P$. advenus it is likely that the comparatively small sample size dictated by using museum specimens was insufficient to address this hypothesis as supported by the results of the power analysis.

I acknowledge that my data in this study is correlational and as such may not necessarily reflect a causal relationship. While I cannot discount the influence of other environmental factors, such as 
temperature, that might affect both wasp density and ant worker size I argue that restriction of food resources by wasps provides the most likely explanation of my results. Further study is needed to confirm this and experimental manipulation of food availability under controlled laboratory conditions would be ideal. However, my attempts to rear P.advenus colonies in captivity have been unsuccessful despite experimentation with a variety of diets and artificial nest boxes as well as temperature and humidity conditions.

\subsubsection{Conclusions}

Invasive species exert considerable influence on recipient taxa. The effects of competition with exotic species are typically sub-lethal (Davis, 2003), but are usually reported in terms of displacement or reduction in abundance of native taxa. The results of this study show a sub-lethal density-dependent effect of an invasive wasp on worker size and morphology of a native ant. Where wasps are most abundant P.advenus workers tend to be smaller in size and display altered scaling relationships in their abdominal segments. Other studies have shown that worker size is positively correlated with foraging efficiency and survivorship (McGlynn, 1999), however, size related trade-offs also exist between discovery and dominance abilities in ants (Tanner, 2008). Whether the variation in size and morphology of $P$. advenus workers with increasing density of $V$. vulgaris observed in this study reflects the slow erosion of a native species' fitness or a plastic response to a novel invader is uncertain, however, my findings indicate that the effects of competition with exotic species on native organisms may be more subtle than previously reported and that their ecological significance warrants future study. 


\subsection{References}

Anderson, M.J., Gorley, R.N. and Clarke K.R. (2008) PERMANOVA+ for Primer: Guide to software and methods. PRIMER-E. Plymouth: 214pp

Atkinson, D. and Sibly, R.M. (1997) Why are organisms usually bigger in colder environments? Making sense of a life history puzzle. Trends in Ecology and Evolution 12(6): 235-239

Barlow, N.D., Beggs, J.R. and Barron, M.C. (2002) Dynamics of common wasps in New Zealand beech forests: a model of density dependence and weather. The Journal of Animal Ecology 71(4): 663-671

Begon, M., Harper, J.L. and Townsend, C.R. (1996) Ecology $3^{\text {rd }}$ Ed, Blackwell Science Ltd, Oxford U.K. 1068pp

Beggs, J.R., Toft, R.J., Malham, J.P., Rees, J.S., Tilley, J.A.V., Moller, H. and Alspach, P. (1998) The difficulty of reducing introduced wasp (Vespula vulgaris) populations for conservation gains. New Zealand Journal of Ecology 22(1): 55-63

Beggs, J. R. and Wilson, P. R. (1991) The kaka Nestor meridionalis, a New Zealand parrot endangered by introduced wasps and possums. BiologicalConservation 56: 23-38

Bohonak, A. J. and van der Linde, K. (2004) RMA: Software for Reduced Major Axis regression for Java

Boone, M.D. (2005) Juvenile frogs compensate for small metamorph size with terrestrial growth: Overcoming the effects of larval density and insecticide exposure. Journal of Herpetology 39(3): 416-423

Bourke, A. F. G. and Franks, N. R. (1995) Social evolution in ants. Princeton University Press, Princeton, New Jersey: 529pp

Breed, M.D. (2002) Allometry in the giant tropical ant Paraponera clavata. Insectes Sociaux 49: $125-128$

Burns, K.C., McHardy, R.P. and Pledger, S. (2009) The small-island effect: fact or artefact? Ecography 32(2): 269-276

Clarke, K.R. and Gorley, R.N. (2006) PRIMER v6: User Manual/Tutorial. PRIMER-E, Plymouth

Diniz-Filho, J. A. F., Von Zuben, C. J., Fowler, H. G., Schlindwein, M. N. And Bueno, O.C. (1994) Multivariate morphometrics and allometry in a polymorphic ant. Insectes Socieaux 41: 153-163

Davis, M.A. (2003) Biotic globalization: does competition from introduced species threaten biodiversity? Bioscience 53(5): 481-489

Don, W. (2007) Ants of New Zealand. Otago University Press, Dunedin, New Zealand: 239pp 
Duthie, C. (2011) Factors promoting coexistence between endemic ants and invasive wasps. Unpublished PhD thesis. Victoria University Wellington.

Duthie, C., Grangier, J. and Lester P.J. (2011) Foraging by ants facilitates foraging by competing invasive wasps, with density-dependent behavioural plasticity in competitive behaviour at food resources. In Preparation

Emlen, D.J. (2001) Costs and the diversification of animal structures. Science 291: 1534-1536

Emlen, D.J. and Allen, C.E. (2004) Genotype to Phenotype: physiological control of trait size and scaling in insects. Integrative and Comparative Biology 43: 617-674

Emlen, D.J. and Nijhout, H.F. (2000) The development and evolution of exaggerated morphologies in insects. Annual Review of Entomology 45: 661-708

Faul, F., Erdfelder, E., Lang, A.G. and Buchner, A. (2007). G*Power 3: A flexible statistical power analysis program for the social, behavioral, and biomedical sciences. Behavior Research Methods 39: 175-191

Grangier, J. and Lester, P.J. (2011) A novel interference behaviour: invasive wasps remove ants from resources and drop them from a height. Biology Letters 7(5): 664-667

Harris, R. (1991) Diet of the wasps Vespula vulgaris and V. germanica in honeydew beech forest of the South Island, New Zealand. New Zealand Journal of Zoology 18: 159-169

Harris, R.J. and Oliver, E.H. (1993) Prey diets and population densities of wasps Vespula vulgaris and Vespula germanica in a scrubland-pasture. New Zealand Journal of Ecology 15: 512

Huxley, J.F. (1931) Notes on differential growth. The American Naturalist 65(699): 289-315

Kessell, S.R. and Whittaker, R.H. (1976) Comparisons of three ordination techniques. Plant Ecology 32(1): 21-29

Knell, R. J. (2009) On the analysis of non-linear allometries. Ecological Entomology 34: 1-11

McColl, H.P. (1975) The invertebrate fauna of the litter surface of a Nothofagus truncata forest floor, and the effect of microclimate on activity. New Zealand Journal of Zoology 2(1): 15-34

McGlynn, T.P (1999) Non-native ants are smaller than related native ants. American Naturalist 154 (6): $690-699$

McGlynn, T.P and Owen, J.P. (2002) Food supplementation alters caste allocation in a natural population of Pheidole flavens, a dimorphic leaf-litter dwelling ant. Insectes Socieaux 14: 8-14

Mirth, C.K. and Riddiford, L.M. (2007) Size assessment and growth control: how adult size is determined in insects. Bioessays 29(4): 344-355

Moller, H. and Tilley, J.A.V. (1989) Beech honeydew: seasonal variation and use by wasps, honey bees, and other insects. New Zealand Journal of Zoology 16: 289-302 
Moller, H., Tilley, J.A.V., Thomas, B.W. and Gaze, P.D. (1991) Effect of introduced social wasps on standing crop of honeydew in New Zealand beech forests. New Zealand Journal of Zoology 18: 171-179

Morales, C.F., Hill, M.G. and Walker, A.K. (1988) Life history of the sooty beech scale (Ultracoelostoma assimile) (Maskell), (Hemiptera:Margarodidae) in New Zealand Nothofagus forests. New Zealand Entomologist 11: 24-38

Nijhout, H.F. and Wheeler, D.E. (1996) Growth models of complex allometries in holometabolous insects. The American Naturalist 148(1): 40-56

Ode, P.J. and Rissing, S. W. (2002) Resource abundance and sex allocation by queen and workers in the harvester ant, Messor pergandei. Behavioural Ecolology and Sociobiology 51: $548-556$

Oosterbaan, R.J. (1994) SegReg statistical software. http://www.waterlog. info/

Oster, G.E. and Wilson, E.O. (1978) Caste and ecology in the social insects. Princeton University Press, Princeton, N.J:352pp

Passera, L., Roncin, E., Kaufmann, B. and Keller,L. (1996) Increased soldier production in ant colonies exposed to intraspecific competition. Nature 379: 630-631

PASW 18.0.0 (2010) SPSS Inc., Chicago

Schoning, C., Kinuthia, W. and Franks, N.R. (2005) Evolution of allometries in the worker caste of Dorylus army ants. Oikos 110: 231-240

Smith, C.E. (1969). A morphological and behavioural study of the ants Amblyopone saundersi Forel and Prolasius advena Fr. Smith (Hymenoptera: Formicidae). Unpublished BSc(Hons) thesis, University of Otago, Dunedin

Smith, W.W. (1896) On the habits of New Zealand ants. Transactions and Proceedings of the New Zealand Institute 29: 468-479

Sorvari, J. and Hakkarainen, H. (2009) Forest clear-cutting causes small workers in the polydomous wood ant Formica aquilonia. Annales Zoologici Fennici 46: 431-438

Tanner, C. (2008) Resource characteristics and competition affect colony and individual foraging strategies of the wood ant Formica integroides. Ecological Entomology 33: 127-136

Thomas, C. D., Moller, H., Plunkett, G. M. and Harris, R. J. (1990) The prevalence of introduced Vespula vulgaris wasps in a New Zealand beech forest community. New Zealand Journal of Ecology 13: 63-72

Thomas, R.H. (1993) Ecology of body size in Drosophilla buzzatii untangling the effects of temperature and nutrition. Ecological Entomology 18(1): 84-90

Toft, R.J. and Beggs, J.R. (1995) Seasonality of crane flies (Diptera:Tipulidae) in South Island beech forest in relation to the abundance of Vespula wasps (Hymenoptera: Vespidae). New Zealand Entomologist 18: 37-43 
Tschinkel, W.R., Mikheyev, A.S., and Storz, S.R. (2003) Allometry of workers of the fire ant Solenopsis invicta. Journal of Insect Science 3(2): 1-11

Vitousek, P.M., D’Antonio, C.M., Loope, L.L. and Westbrooks R. (1996) Biological invasions as global environmental change. American Scientist 84: 468-478

Vogel, L.S. and Pechmann, H.K. (2010) Response of Fowler's Toad (Anaxyrus fowleri) to competition and hydroperiod in the presence of the invasive Coastal Plain Toad (Incilius nebulifer). Journal of Herpetology 44(3): 382-389

Wheeler, D.E. (1991) The developmental basis of worker caste polymorphism in ants. American Naturalist. 138: 1218-1238

Wheeler D.E. and Buck, N.A. (1992) Protein lipid and carbohydrate use during metamorphosis in the ant Solenopsis xyloni. Physiological Entomology 17(4): 397-403 
Chapter Three

Behavioural plasticity and size correlated task allocation in the New Zealand bush ant Prolasius advenus (Fr. Smith) in the presence of high densities of the invasive common wasp Vespula vulgaris (L.) 


\subsection{Abstract}

Competition and predation pressure exerted by invasive species may lead to exclusion or extinction of recipient taxa. However, native species may mitigate the impact of exotic competitors by modifying their behaviour and spatial or temporal niche use. The common wasp Vespula vulgaris is a highly abundant invasive species in New Zealand's Nothofagus beech forests. There it competes with the endemic bush ant Prolasius advenus for food resources. The wasp is an exclusively diurnal forager that has been estimated to reduce the standing crop of honeydew, the predominant carbohydrate resource in the forests, by more than $90 \%$.

Ants may allocate workers to specific tasks by size to maximise foraging or defensive efficiency. Prolasius advenus workers are variable in both size and morphology. Where wasps are most abundant $P$. advenus workers are smaller and display less pronounced allometric scaling relationships among certain body parts compared to workers where there are fewer wasps. In this study I tested the hypotheses that worker morphology and size would vary according to the task they performed and that this variation would be less pronounced in the presence of high densities of wasps. I also tested the hypothesis that where the exclusively diurnal wasps were most abundant, bush ants would minimise competitive interactions with wasps by foraging predominantly nocturnally.

My results indicate that rather than avoiding competition with wasps by foraging more at night, P. advenus forages as much or more by day in the presence of high densities of wasps. Size correlated task allocation was found only where wasps were most abundant. I speculate that the increase in $P$. advenus forager abundance is a response to diminished resource quality or availability which serves to increase the ants' competitive ability by numerical dominance. I also suggest that workers are allocated to task by size to maximise their resource gathering and defensive efficiency where wasps are present in high abundance. While this modified behaviour may negate the need to alter their niche, the increase in potential competitive interactions with wasps may impose significant costs at the colony level in terms of reduced energetic gain and increased worker mortality. 


\subsection{Introduction}

Invasive species frequently attain higher population densities in the invaded environment than they do in their native range (Carlton, 1990). The negative impact of exotic species on recipient communities is often density dependent and may lead to displacement or extinction of native taxa. While predation is the primary mechanism of extinction, recent findings suggest the effects of competition with invasive species are less severe. Davis (2003) suggests the non-lethal impact of competition with invasive species affords recipient taxa sufficient time to modify their niche use or behaviour promoting coexistence with the invader. For example McNatty et al., (2009) found invasive Anoplolepis gracilipes ants excluded Coenobita spp. crabs native to the Tokelau archipelago from carrion resources, forcing the crabs to alter their functional trophic level and adopt a more herbivorous diet. In addition to adjustment in spatial niche use, competition may drive temporal niche segregation. A study of two competing desert gerbil species found that Gerbillus allenbyi modified its period of foraging activity in the presence of G.pyramidium to forage predominantly between midnight and dawn. By contrast, where G.pyramidium was absent G.allenbyi foraged predominantly before midnight (Ziv et al., 1993).

Competitive interactions between similar heterospecific taxa may also result in environmental character displacement or character release (Brown and Wilson, 1956; Grant, 1972; Rice and Pfennig, 2010). Simberloff et al. (2000) demonstrated that the small Asian mongoose Herpestes javanicus is smaller and displays reduced sexual dimorphism in symaptry with two congeners compared with populations living in allopatry. The morphological divergence between these populations was estimated to have occurred in fewer than 100 years (100-200 generations). Directional selection may act on traits that lessen or mitigate the effects of resource competition (Rice and Pfennig, 2006). For example populations of two salamander species Plethodon hoffmani and P.cinereus living in sympatry displayed divergent jaw morphology resulting in prey segregation by size. Populations living in allopatry did not display such differentiation in diet or jaw morphology (Adams and Rohlf, 2000). Several recent studies indicate that morphological and behavioural selection can occur in an ecological timescale of tens of years rather than the millennia previously viewed as "evolutionary time" (reviewed in Stockwell et al., 2003; Kinnison et al., 2007). 
The Gause (1932) principle states that two species cannot coexist if they use the same limited resources in exactly the same manner. Competitive interactions between species for limiting food resources may result in one species reducing the abundance of another in an environment by directly reducing the availability of a resource, by interfering with its ability to obtain that resource or by depleting the energy gained from the resource by aggressive interaction (Schoener, 1974 a). Typically trade-offs exist between species' exploitive and interference abilities, however some species have been found to break the trade-off facilitating displacement of other species (Holway, 1999). One such species is the common wasp Vespula vulgaris (L.), which is invasive in the Nothofagus beech forests of New Zealand's upper South Island. The wasp has been reported to attain densities greater than 30 nests $\mathrm{Ha}^{-1}$, which are unparalleled in its native range (Thomas et al., 1990). The high abundance of this wasp has been attributed to the plentiful availability of honeydew, a sugary exudate excreted from the anal filaments of juvenile sooty beech scale insects (Ultracoelastoma assimile Maskell) that infest the Nothofagus fusca and N. solandri trees that dominate the forests (Morales et al., 1988). So substantial is the wasp's consumption of honeydew that it has been shown to reduce the quality and quantity of the resource to the detriment of native bird (Moller and Tilley, 1989; Moller et al., 1991; Beggs and Wilson, 1991) and insect species (Moller and Tilley, 1989). In addition, V. vulgaris is also a voracious predator of invertebrates (Harris, 1991; Harris and Oliver, 1993; Toft and Beggs, 1995) and aggressively interferes with the foraging of the endemic ant Prolasius advenus at protein resources (Grangier and Lester, 2011).

The diets of the invasive $V$. vulgaris and the dominant ant species in the beech forest $P$. advenus display significant overlap (Duthie, 2011). The ant is a generalist forager hunting invertebrate prey to satisfy its protein requirements and honeydew represents its primary (and potentially only) source of carbohydrate. The invasive wasp is thus both an exploitive and an interference competitor to the ant and yet both species appear to have persisted at high population densities since the wasp's arrival more than twenty years ago (Donovan, 1984; Clapperton et al., 1989; Sandlant and Moller, 1989; Barlow et al., 2002 and Chapter 5). It is possible for the effects of competition to be mitigated over time by niche partitioning or character displacement (Petren and Case, 1996). Indeed, morphological (Philips and Shine, 2004), behavioural (Reznick et al., 
1997) and physiological (Callaway et al., 2005) character displacement has been shown to occur over comparatively short periods of time particularly in recipient communities facing novel invaders (Simberloff et al., 2000; Whitney and Gabner, 2008).

Resource competition affects colony foraging strategy (Hölldobler, 1982). According to MacArthur and Pianka's (1966) optimal foraging theory, a reduction in food abundance (as may be caused by an invasive competitor) can reduce the value of a spatial habitat to a point where it is removed from an organism's feeding itinerary. Schoener (1974b) proposed that in addition to reducing the value of spatial habitat, competitors may also undermine the value of temporal habitats, such as time of day, resulting in an alteration of an organism's diel foraging habitat in a point in space inhabited by a competitor. Such temporal partitioning of resources is only viable as a form of niche partitioning if the resource is renewed between the two organisms' feeding times (MacArthur and Levins, 1967). Honeydew is excreted throughout the diel cycle, and peak productivity occurs at night (Kelly et al., 1992). Vespula vulgaris are only active diurnally (Thomas et al., 1990). The wasps' high level of honeydew consumption has been shown to reduce the quality of the resource by reducing the sugar concentration as well as affecting the quantity available by up to $92 \%$ (Moller and Tilley, 1989 and Beggs et al., 1998) and is arguably sufficiently severe to result in a temporal shift in the foraging habits of P. advenus.

Where resources are scarce it is important to maximize forager efficiency. Discrete worker polymorphism, resulting in morphologically distinct subcastes, is comparatively uncommon in ants, having been reported in only 15 to $20 \%$ of known genera (Hölldobler and Wilson, 1990). Morphological specialisation may come at the expense of behavioural flexibility (Mertl and Traniello, 2009). However, continuous allometric scaling relationships among body parts may promote increased efficiency in defence, foraging and resource use among workers of different size in a population; producing workers that are better suited, but not limited to particular tasks (Braendle et al., 2003). Prolasius advenus workers are highly variable in size and display positive allometric scaling of the abdomen (Chapter 2). A negative allometric relationship was found in the scaling of the head, however, head shape was also found to alter with size becoming proportionally wider relative to head length. Furthermore, the nature of these scaling relationships varies among populations in high and low wasp density areas (Chapter 2). 
The morphology of ants influences their ability to collect protein and carbohydrate resources. Protein, in the form of invertebrate prey and carrion, is secured and returned to the nest in the mandibles. Larger prey items are often broken up and retrieved by several individuals. Similar behaviour has been observed in $P$. advenus where multiple workers carry larger items back to the nest intact (Smith, 1969 and Duthie, 2011). Carbohydrate, in the form of honeydew, is consumed in liquid form and returned to the nest in the worker's crop. Larger P. advenus workers with disproportionally larger gasters may be more efficient at collecting honeydew. Larger workers in other species have been reported to ingest greater quantities of honeydew and at a faster rate than smaller workers (Medan and Josens, 2005) and to specialise in the collection and transport of the resource (Fowler, 1985). By contrast smaller workers may be better suited to collecting prey items as they retain proportionally larger heads and may be better able to move through leaf litter.

The invasive common wasp clearly competes with $P$. advenus for resources (Grangier and Lester, 2011; Duthie, 2011) and has been shown to reduce the quality and quantity of honeydew (Moller and Tilley, 1989 and Beggs et al., 1998). Here I tested the hypothesis that $P$. advenus workers reduce potential competitive interactions with wasps by means of a temporal niche shift and predicted a proportional increase in nocturnal foraging where wasps are at their most abundant compared with areas where wasps are less prevalent. I also tested the hypothesis that $P$. advenus worker size will vary according to task. Based on the findings of Chapter 2, I predicted that larger workers, with disproportionally larger gasters, will primarily be observed collecting liquid (honeydew) resources, intermediate sized workers will forage for protein resources in litter on the forest floor and that smaller workers will be engaged in brood care. In the previous chapter I found allometric scaling relationships of the petiole and gaster with Weber's length were less pronounced where wasp density was greatest. Based on this result I also predicted that size correlated foraging will be less pronounced where honeydew resources are reduced by high levels of competition with the invasive wasp $V$. vulgaris compared to areas where the wasps are at lower densities. 


\subsection{Methods}

\subsubsection{Day and night foraging behaviour}

Wasp abundance data was drawn from an annual survey of wasp density conducted by Landcare Research Nelson between 1988 and 2010 (Barlow et al., 2002; Beggs et al., 2008 and Toft and Rees unpublished) at four sites. These sites were Pelorus Bridge $\left(41^{\circ} 18^{\prime} \mathrm{S}, 173^{\circ} 34^{\prime} \mathrm{E}\right)$, Spooner's Range $\left(41^{\circ} 27^{\prime} \mathrm{S}, 172^{\circ} 55^{\prime} \mathrm{E}\right)$, Mt. Misery (41 $\left.{ }^{\circ} 54^{\prime} \mathrm{S}, 172^{\circ} 39^{\prime} \mathrm{E}\right)$ and Lake Rotoiti. The fourth site, Lake Rotoiti, offers an additional opportunity to assess the effect of wasps on $P$. advenus worker activity as it has been the subject of an ongoing wasp control program by the St. Arnaud office of The Department of Conservation since 2000. This effectively allows the site to be subdivided for the purpose of a direct comparison of ant foraging behaviour when wasp numbers have been reduced (hereafter "Rotoiti wasps removed" $41^{\circ} 48^{\prime} \mathrm{S}, 172^{\circ} 50^{\prime} \mathrm{E}$ ) and where wasp densities remain at the surveyed level (hereafter "Rotoiti wasps maintained" $41^{\circ} 49^{\prime}$ $\left.\mathrm{S}, 172^{\circ} 50^{\prime} \mathrm{E}\right)$. The historical data illustrates the annual fluctuations in wasp density and allows delineation of sites with consistently higher and consistently lower levels of wasp infestation (Figure 3.1).

Pitfall traps were set day and night in four sites of known wasp density to test the hypothesis that $P$. advenus foragers will be more active at night where the diurnal invasive competitor $V$. vulgaris is most abundant. Three randomly placed $10 \times 10 \mathrm{~m}$ quadrats were positioned at each site. Within each of these eight pitfall traps were haphazardly placed. The pitfall traps consisted of tapered $285 \mathrm{ml}$ plastic cups with a $75 \mathrm{~mm}$ diameter aperture, that were approximately one third filled with water with a small amount of surfactant added to break surface tension. The traps were set immediately before sunrise at each site and left in place until sunset the same day, when they were replaced with equivalent traps that were left in until the next sunrise. Traps were first set in early January 2009 at Spooner's Range, Pelorus Bridge, Mount Misery and Lake Rotoiti to coincide with peak ant forager abundance and repeated at the same locations in March and April of 2009 to coincide with peak wasp abundance.

In February 2009 poison baits containing Xstinguish ${ }^{\mathrm{TM}}$ bait (active ingredient fipronil at $0.1 \mathrm{~g} / \mathrm{kg}$ ) were placed in a $50 \times 200 \mathrm{~m}$ grid pattern over an 825 ha area of the Nelson Lakes National Park to 
poison wasps. Any uneaten bait was then removed after 48 hours. This single poisoning event reduces wasp numbers by approximately $70 \%$ for the rest of the season (Duthie, 2011). To examine the effects of wasp removal on the diurnal and nocturnal foraging habits of $P$. advenus pitfall traps were placed at Lake Rotoiti in both poison $\left(41^{\circ} 48^{\prime} \mathrm{S}, 172^{\circ} 50^{\prime} \mathrm{E}\right)$ and control $\left(41^{\circ}\right.$ $49^{\prime} \mathrm{S}, 172^{\circ} 50^{\prime} \mathrm{E}$ ) sites after poisoning had taken place in early February. All traps were returned to the lab, where the collected insects were sorted under a microscope. Prolasius advenus workers were separated and counted.

The relative abundance of diurnal and nocturnal foragers at four sites with differing wasp density was assessed using counts of $P$. advenus workers collected in pitfall traps set between dawn and dusk and dusk and dawn over a 24 hour period in three separate months at each site. The dataset contained many zero counts, which violated the assumption of normal distribution necessary for a parametric analysis such as ANOVA. The results of a Levene's Test of Equality of Error Variances performed using PASW 18.0.0 statistical software (SPSS.inc., 2010) indicated a significant $(\mathrm{F}=18.771$; df 27, 644; $\mathrm{P}<0.001)$ deviation from the null hypothesis of equal variance across groups, which violated the assumptions necessary for a non-parametric analysis such as Kruskal -Wallis. For this reason data were analysed in PRIMER v6 (Clarke and Gorley, 2006) using PERMANOVA+ (Anderson et al., 2008), which generates $P$ values by permutation without assumptions of normality or homoscedasticity. A resemblance matrix was first constructed based on Euclidian distance. Euclidian distance was chosen as a measure of resemblance over Bray-Curtis because of the latter's tendency to clump zero counts irrespective of weight in the analysis (Kessell and Whittaker, 1976). A permutational ANOVA analysis was then performed based on Type 1 Sum of Squares with unrestricted permutations of raw data with 9999 permutations. The number of workers caught at each wasp density (site) was the dependent variable. There were four factors: wasp density (a fixed factor with five levels); quadrat (nested in wasp density, random with three levels); Month (fixed with three levels) and time of day (nested in month, random with two levels). A main effects test was performed initially followed by a pair-wise test of the interaction term of wasp density $\times$ time of day. Because the number of possible permutations was often less than 100, pair-wise comparisons using random sampling 
from the asymptotic permutation distribution was employed to generate Monte Carlo $\mathrm{P}$ values (Anderson and Robinson, 2003).

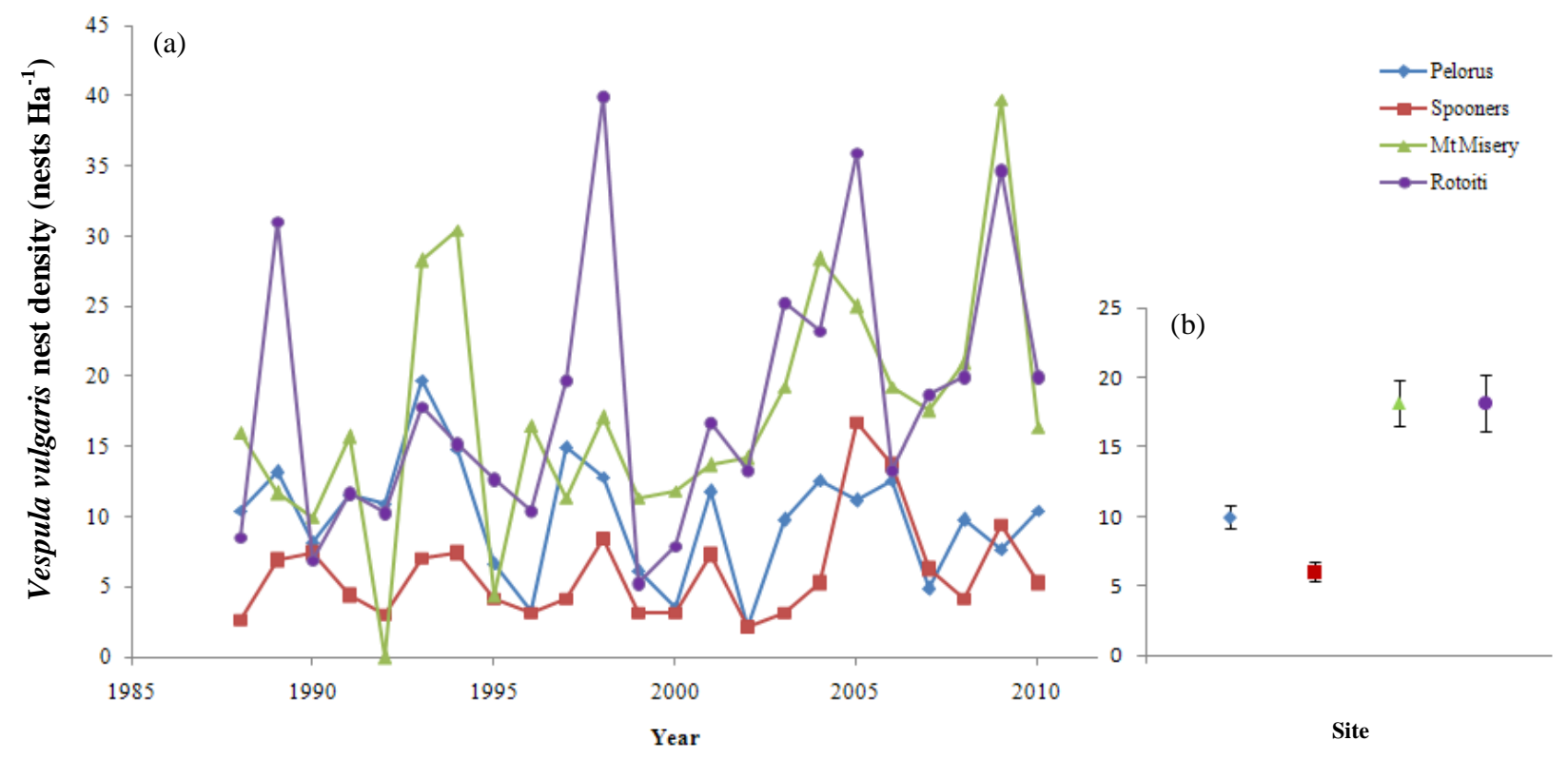

Figure 3.1 (a) Annual Vespula vulgaris nest density and (b) mean \pm S.E. nest density between 1988 and 2010 at four New Zealand South Island Nothofagus beech forest sites (Landcare Research, Nelson).

\subsubsection{Size correlated division of labour at high and low wasp density}

Prolasius advenus workers were collected whilst engaged in one of three tasks: honeydew foraging, litter foraging or brood care (hereafter nurses) at four sites of varying wasp density. These ants were measured to test the hypotheses that the morphology of workers will vary depending on task, that task allocation is size correlated and that task allocation by size will be more prevalent where wasp are less abundant.

Two high and two low wasp density areas were chosen based on the ongoing monitoring programme conducted by Landcare Research Nelson (Barlow et al., 2002; Beggs et al., 2008 and Toft and Rees, unpublished). Specimens were collected in February 2010 from Pelorus Bridge $\left(41^{\circ} 18^{\prime} \mathrm{S}, 173^{\circ} 34^{\prime} \mathrm{E}\right)$ and Spooner's Range $\left(41^{\circ} 27^{\prime} \mathrm{S}, 172^{\circ} 55^{\prime} \mathrm{E}\right)$ representing low wasp 
density sites and Lake Rotoiti wasps maintained ( $\left.41^{\circ} 49^{\prime} \mathrm{S}, 172^{\circ} 50^{\prime} \mathrm{E}\right)$ and Mt. Misery $\left(41^{\circ} 54^{\prime}\right.$ $\mathrm{S}, 172^{\circ} 39^{\prime} \mathrm{E}$ ) which have been a consistently high wasp density sites since records started (Figure 3.1).

Approximately thirty workers were haphazardly collected from each of three substrate types at each of the four sites: 1. vertical bark of Nothofagus spp. trees bearing honeydew excreted from Ultracoelastoma assimile Maskell scale insect anal filaments (hereafter honeydew foragers); 2. the horizontal substrate beneath beech leaf litter (hereafter litter foragers) and 3. below ground from within nests (hereafter nurses). To minimise potential collection of honeydew foragers trailing to or from the nest, specimens were not collected from litter within a 1 metre radius of a honeydew bearing tree. Care was also taken to collect only workers observed tending brood within the nest to reduce the likelihood of collecting returning nest foragers. To achieve this, stones or logs were carefully turned over to find brood chambers, which, in summer, tend to be near the soil surface. As soon as a chamber was located workers tending brood were collected by mouth aspirator. Any brood collected were returned to the chamber and the stone or log was replaced.

Size estimates of the 360 ants collected were made using a total length measurement derived from a combination of the following four measurements: (i) head length (measured dorsally from the anterior tip of the clypeus to the occiput); (ii)Weber's length (viewed laterally; the diagonal distance between the anterior margin of the pronotum to the posterior margin of the metapleural bulla); (iii) petiole length, (viewed ventrally, the distance from the anterior to the posterior margin of the petiole); and (iv) the first gaster segment (viewed laterally the distance from the anterior-most point of the dorsal surface of the first gaster segment to its posterior margin). All measurements were made using a using a Nikon SMZ1500 microscope. Weber's length was measured at $80 \times$ magnification in order to fit the thorax into the field of view in its entirety; all remaining characters were measured at $112.5 \times$ magnification.

To assess morphological variation among workers engaged in each of three tasks; brood care, litter foraging and honeydew foraging measure values of each body part were converted into proportions of total length for each individual. Data were then analysed using MANCOVA, with 
proportional values of head length, Weber's length, petiole length and length of the first gaster segment as dependent variables, task as the independent variable and wasp density as a covariate. Data were assessed for, and conformed to, assumptions of normality and homoscedasticity in PASW 18.0.0 statistical software (SPSS Inc., 2010).

To assess size correlated task specialization total length measures comprised of the sum of head length, Weber's length, petiole length and the length of the first gaster segment of workers collected whilst engaged in one of three tasks honeydew foraging, litter foraging or brood care were analysed for normality and homoscedasticity. The results of Levene's test of equality of variance showed the data did not conform $(\mathrm{P}<0.001)$ to the assumptions of equal variance necessary for parametric comparison of means. Square root or log transformation of the data did not remedy the problem. For this reason data were analysed in PRIMER v6 (Clarke and Gorley, 2006) using PERMANOVA+ (Anderson et al., 2008). The dependent variable was total length, and task and wasp density were fixed factors. 


\subsection{Results}

\subsubsection{Day and night foraging behaviour}

The abundance of $P$. advenus workers caught in pitfall traps was used to test the hypothesis that $P$. advenus workers in areas where wasps are abundant would avoid competition for food resources by foraging proportionally more at night compared to workers in areas where there are fewer wasps. The mean number of ants collected at all sites is presented in Figure 3.2. The mean number of diurnal foragers collected per trap between January and April ranged between $7.94( \pm$ 2.24) collected at Mount Misery and $0.15( \pm 0.06)$ at Pelorus Bridge. The mean number of workers collected at night ranged between $4.44( \pm 1.42)$ at Mt. Misery and $0.50( \pm 0.12)$ at Lake Rotoiti wasps maintained.

The relative day and night foraging patterns of $P$. advenus workers varied between high and low wasp density but remained consistent at each site throughout the sampling period. The PERMANOVA results indicated the relative abundance of diurnal and nocturnal $P$. advenus foragers varied significantly at high and low wasp density sites $(\mathrm{P}<0.001)$. No significant within site difference was found in the relative abundance of day and night foragers among months sampled $(\mathrm{P}=0.456)$, suggesting that a site where workers forage predominantly at night does not alter over time.

Prolasius advenus workers forage as much or more during the day in areas where wasps are abundant than in areas where there are fewer wasps. The results of a pairwise PERMANOVA indicated that a significantly greater $(\mathrm{P}=0.013)$ abundance of $P$. advenus foragers were active by day than by night at the Rotoiti wasps maintained site where wasp densities were 34.7 nests/ $\mathrm{Ha}^{-1}$. No significant difference was found in the number of nocturnal and diurnal foragers active at Mt. Misery $(\mathrm{P}=0.211)$ at a wasp density of $39.4 \mathrm{nest} / \mathrm{Ha}^{-1}$.

By contrast significantly more $P$. advenus foragers were collected at night at the two lower wasp density sites Pelorus Bridge $(\mathrm{P}=0.001)$ and Spooner's Range $(\mathrm{P}=0.010)$ where wasp densities were 7.7 and 9.5 nests $\mathrm{Ha}^{-1}$ respectively. 
Wasp removal resulted in an increase in nocturnal foraging by $P$. advenus workers relative to diurnal foraging. Prolasius advenus workers were found to forage significantly ( $<0.001)$ more by night at the Rotoiti wasps removed site where poisoning had taken place (Figure 3.2).

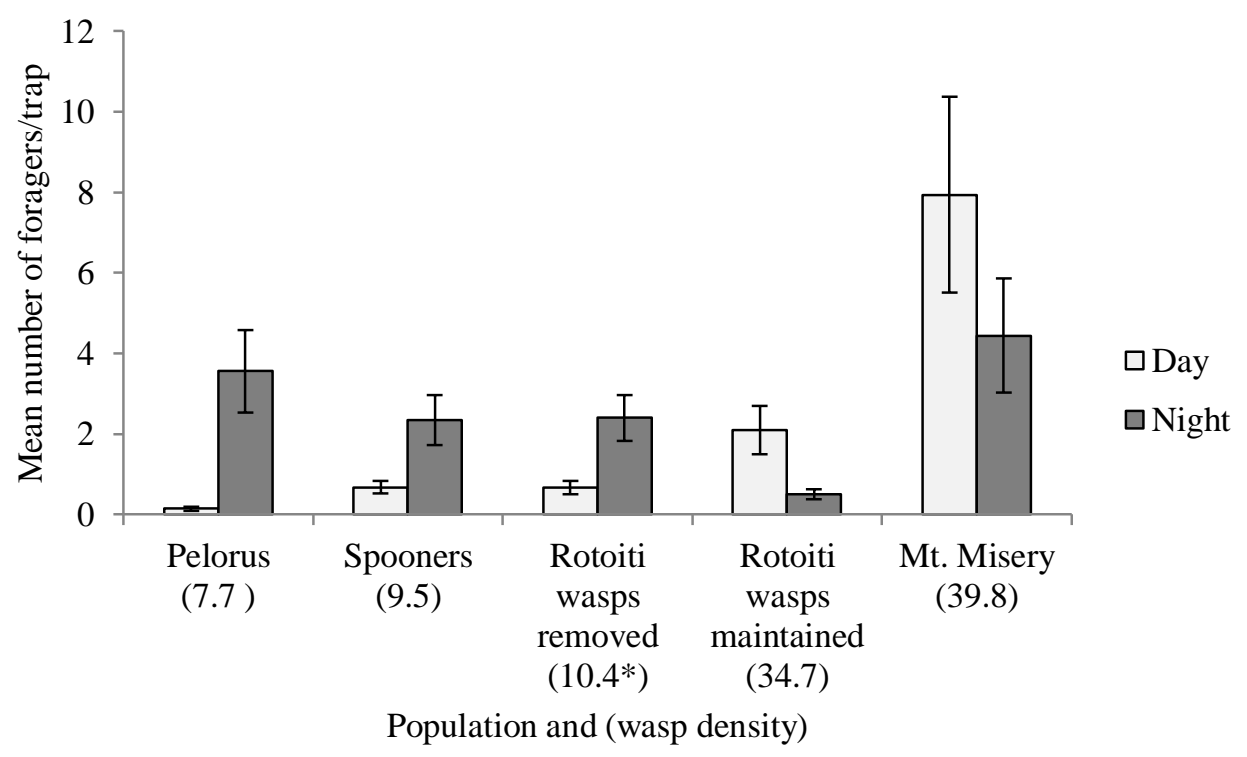

Figure 3.2 The combined mean \pm S.E number of Prolasius advenus workers per pitfall trap collected between January and April 2009 at four locations with varying Vespula vulgaris density. The figures in brackets are wasp density (nests $\mathrm{Ha}^{-1}$ ) based on the 2009 Landcare wasp survey except $(*)$, which is an estimate based on findings that poisoning reduces wasp density by $70 \%$ (Duthie, 2011).

Prolasius advenus forager abundance decreased over time. The number of foragers caught per trap varied significantly across months. Maximum forager abundance was observed at all sites in January and declined in March and April $(\mathrm{P}<0.001)$. However, the relative abundance of daytime and night time foragers at each site did not differ significantly between months $(\mathrm{P}=$ 0.203) suggesting that diurnal/nocturnal foraging patterns remain constant over time at each site. 


\subsubsection{Size correlated division of labour at high and low wasp density}

The relative proportions of worker body parts differ at high and low wasp density, but do not differ according to the task they are performing. No evidence was found of morphological variation among workers collected whilst engaged in different tasks at either high or low wasp density. No significant difference $(\mathrm{F}=2.848 ; \mathrm{df}=2 ; \mathrm{P}=0.059)$ was found in mean proportional head length; mean proportional Weber's length $(\mathrm{F}=1.983$; $\mathrm{df}=2 ; \mathrm{P}=0.139)$; mean proportional petiole length $(\mathrm{F}=0.962 ; \mathrm{df}=2 ; \mathrm{P}=0.383)$ or mean proportional length of the first gaster segment $(\mathrm{F}=0.105 ; \mathrm{df}=2 ; \mathrm{P}=0.901)$ of workers collected whilst foraging for honeydew, foraging in litter or tending brood at any of the four sites. However, the proportional headlength was significantly lower $(\mathrm{F}=8.206$;f $=1 ; \mathrm{P}=0.004 ; \beta=-0.281)$ and proportional Weber's length was significantly greater $(\mathrm{F}=18.693 ; \mathrm{df}=1 ; \mathrm{P}<0.001 ; \beta=0.455)$ in workers collected from areas at high wasp density (Figure 3.3). 

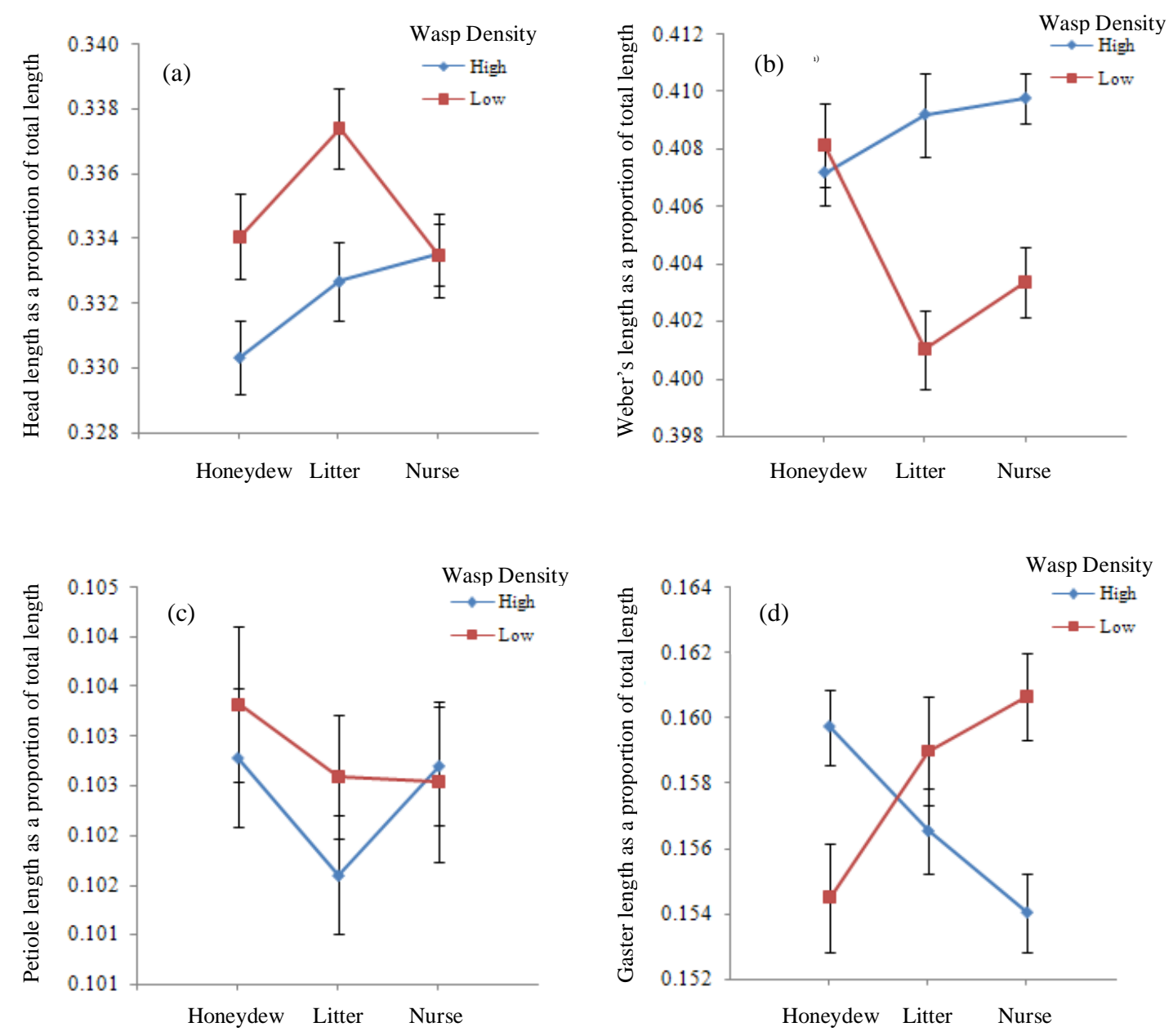

Figure 3.3 The mean \pm S.E proportion of total length contributed by each of four morphological characters: (a) head length, (b) Weber's length, (c) petiole length and (d) the length of the first gaster segment in $P$. advenus workers collected whilst engaged in one three tasks: foraging for honeydew (Honeydew), foraging in leaf litter (Litter) and tending brood (Nurse) at sites with either high or low densities of the invasive wasp Vespula vulgaris.

Where wasps are most abundant, $P$. advenus workers that forage for honeydew and those that tend brood are larger than litter foragers (Figure 3.4). Where there are fewer wasps there is no relationship between worker size and the task they perform. The results of a pairwise PERMANOVA comparing mean total length of workers collected whilst performing differing tasks at consistently high (Mt. Misery and Rotoiti) and consistently low (Pelorus Bridge and Spooner's Range) wasp density sites showed that in high wasp density areas honeydew foragers 
were significantly larger that litter foragers $(\mathrm{P}=0.025)$ but not significantly different from nurses $(P=0.481)$. Nurses were also found to be significantly larger than litter foragers $(P=0.046)$. By contrast no significant difference was found in worker total length between nurses and honeydew foragers $(\mathrm{P}=0.143)$; nurses and litter foragers $(\mathrm{P}=0.805)$ and honeydew and litter foragers $(\mathrm{P}=$ 0.158 ) at the low wasp density sites (Figure 3.4).

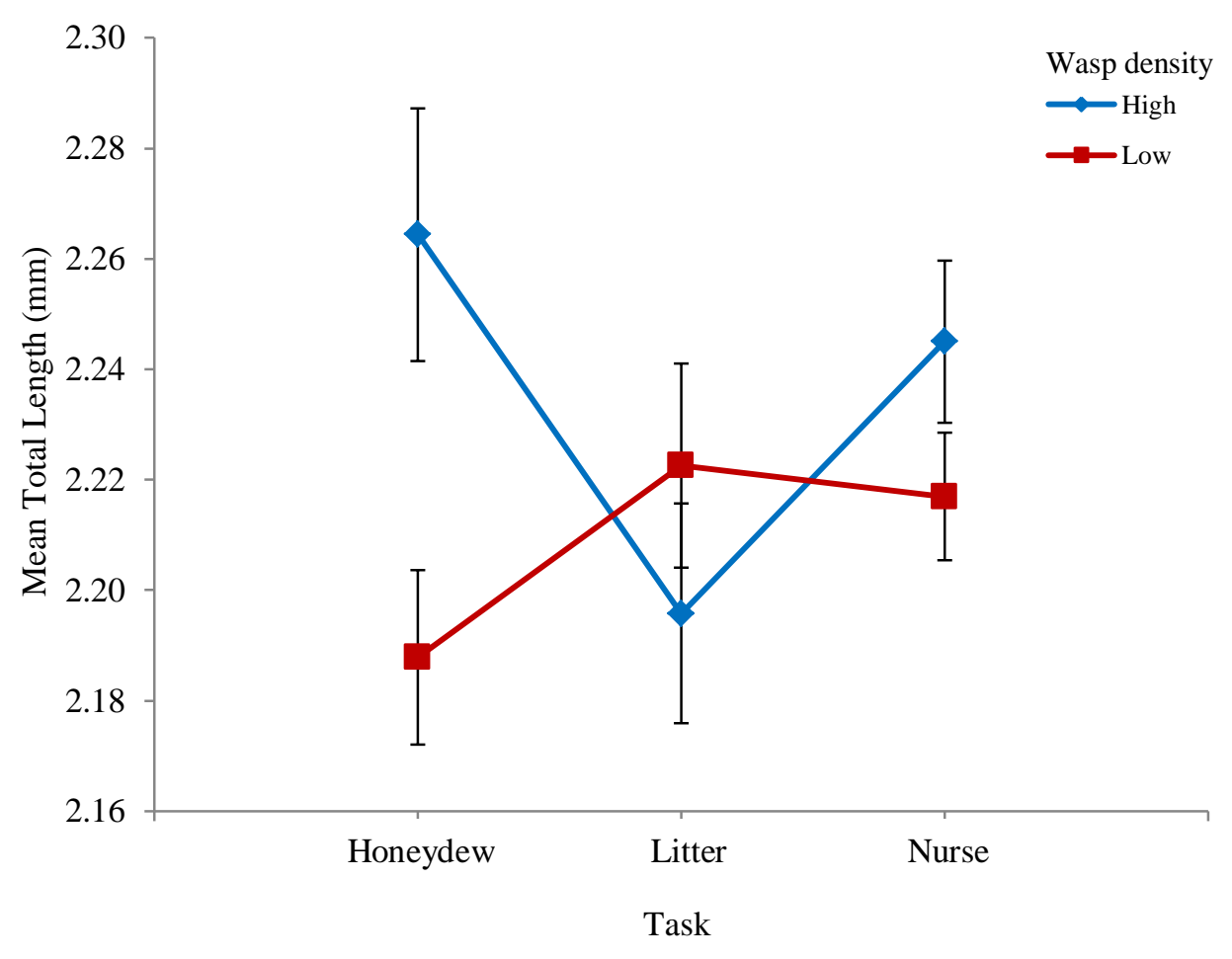

Figure 3.4 The relationship between the mean \pm SE total length of Prolasius advenus workers engaged in one of three tasks: honeydew foraging (Honeydew), litter foraging (Litter) and brood care (nurse) collected from high wasp density (Mount Misery (16.4 nests $\mathrm{Ha}^{-1}$ ) and Lake Rotoiti (20 nests $\left.\mathrm{Ha}^{-1}\right)$ ) and low (Spooner's Range (5.3 nests $\left.\mathrm{Ha}^{-1}\right)$ and Pelorus Bridge (10.5 nests/ $\left.\mathrm{Ha}^{-1}\right)$ ) wasp density sites. 


\subsection{Discussion}

\subsubsection{Day and night foraging behaviour}

The results of this study indicate that temporal foraging patterns in P. advenus vary between sites that are heavily infested with invasive wasps and those where wasps are less abundant. Workers forage as much or more during the day as they do by night in areas where wasp density is highest. By contrast, $P$. advenus workers forage predominantly at night where wasp densities are lower. Where wasp numbers were reduced by poisoning at Lake Rotoiti significantly more $P$. advenus workers foraged at night than during the day, which was consistent with observations at the two naturally lower wasp density sites. These results do not support my hypothesis that $P$. advenus alter their temporal niche to avoid competition with the common wasp, but rather indicate that diurnal forager abundance is increased in areas where $V$. vulgaris is most abundant.

Potential hypotheses to explain these results include: $P$. advenus increases forager recruitment in response to a reduction in resource quality or availability mediated by diurnal foraging by wasps, or, additional workers are deployed when wasps are present in high abundance to increase competitive ability.

Prolasius advenus increases forager recruitment in response to a reduction in resource quality or availability mediated by diurnal foraging by wasps (Figure 3.2). Previous work has demonstrated both significant dietary overlap between the invasive common wasp $V$. vulgaris and $P$. advenus (Duthie, 2011) and clear competition for food resources (Grangier and Lester, 2011). The wasp has been shown to demonstrably reduce both the quality and quantity of honeydew available (Moller and Tilley, 1989 and Beggs et al., 1998) and consume significant quantities and of invertebrate prey (Harris, 1991; Harris and Oliver, 1993; Toft and Beggs, 1995).

Grangier (unpublished) found that captive $P$. advenus colonies increased forager recruitment when resources were restricted. Laboratory colonies were placed on a restricted carbohydrate or protein diet to measure its effect on foraging activity. A significant increase in $P$. advenus forager abundance was observed in the carbohydrate restricted treatments. When carbohydrate supply was reinstated forager numbers returned to their resting rate within 48 to 72 hours. No 
significant increase in forager activity was observed when protein was withheld; possibly because limited brood were being reared in the laboratory colonies.

At Mt. Misery, the mean wasp density between 1988 and 2010 was $18.16( \pm 1.68)$ nests $\mathrm{Ha}^{-1}$. In 2009, when the ants for this study were collected, wasp nest density was 39.7 nests $\mathrm{Ha}^{-1}$, which is more than double the annual average for the site (Toft and Rees, unpublished). As V. vulgaris has been estimated to reduce the standing crop of honeydew by as much as 90\% (Beggs et al., 1998), my results at this site may be indicate a reduction in resource quality or availability to a point where it is necessary for increased numbers of $P$. advenus foragers to be deployed both diurnally and nocturnally. Predominantly diurnal foraging was also observed at Lake Rotoiti, where wasp density at the time of the ants' collection was 34.7 nests $\mathrm{Ha}^{-1}$, again almost double the average for the site of $18.23( \pm 2.02)$ nests $/ \mathrm{Ha}^{-1}$. This result too may reflect an increase in worker recruitment when resource availability is at its lowest. Where wasps were removed by poisoning at Lake Rotoiti $P$. advenus foraging was predominantly nocturnal, consistent with sites experiencing lower wasp infestation.

Prolasius advenus may deploy additional workers to maximize competitive ability. When $P$. advenus workers are present in greater numbers they behave more aggressively toward wasps and are better able to exclude them from food resources (Duthie, 2011). Numerical dominance has frequently been cited as a means of gaining competitive superiority (Human and Gordon, 1995; Holway, 1999; Blight et al., 2010). The increased proportion of diurnal foragers observed in areas of high wasp density may afford the ants a measure of "safety in numbers" that increases their competitive efficiency and promotes co-existence with the wasps.

Temporal separation of peak forager abundance and brood rearing may promote co-existence of $P$. advenus and $V$. vulgaris. No significant within-site difference was found in the relative proportion of diurnal and nocturnal foragers between months irrespective of wasp density, suggesting that $P$. advenus workers forage mainly by day or mainly at night at each site arguably in response to the level of competition with wasps. However, P. advenus forager abundance was found to decrease significantly from January to March at all sites. By contrast, wasp forager abundance increases over this period reaching its peak in late summer (March- 
April) when larvae have hatched and are being fed (Barlow et al., 2002). The clear peak observed in $P$. advenus forager abundance in January is conducive with feeding developing larvae for the nuptial flight of queens and males observed for the species in March and early April (Smith, 1896; McColl, 1975; Don, 2007; pers. obs.). Smith (1969) describes a developmental period in excess of one hundred days for $P$. advenus. Eggs take approximately forty days to hatch, suggesting larvae are present approximately two months prior to the observed nuptial flight. Thus the presence of larvae would coincide with peak $P$. advenus forager abundance in January. The observed decrease in $P$. advenus forager abundance would in turn coincide with a decrease in demand for food as reproductive individuals leave the nest.

\subsubsection{Worker morphology and task at high and low wasp density}

Worker morphology did not vary significantly according to task irrespective of wasp density. I found no significant variation in the relative size of the head, thorax or abdominal segments measured among workers performing each of three tasks: honeydew foraging, foraging in litter or tending brood. Given the significant difference observed in size of litter foragers this is surprising as the findings of Chapter 2 indicate a positive scaling relationship for the petiole and gaster with size. However, workers had proportionally smaller heads and larger thoraxes regardless of task at high wasp density relative to those at low wasp density sites. The relative proportion of the total length comprised by the petiole and first gaster segment did not vary with differing wasp densities. This is consistent with the findings of the Chapter 2 and appears to support Nijhout and Wheeler's (1996) hypothesis that during growth, developing imaginal structures compete for limiting resources within the cocoon, with the result that the increase in size of one morphological structure may come at the cost of another. One could also speculate that the relative contribution of the abdomen to total length is conserved because of its importance to a worker's primary functions which are arguably, food gathering and defence. Both the crop, which is used to collect and transport liquid carbohydrate resources and the poison glands, which Smith (1969) describes as large in P. advenus, are housed in the abdomen. 


\subsubsection{Worker size and task at high and low wasp density}

This study found evidence of size correlated task allocation among $P$. advenus workers in areas where wasps are most abundant. Litter foragers were significantly smaller than honeydew foragers and nurses at the two high wasp density sites, but no significant difference in size was observed in workers engaged in the three tasks at the low wasp density sites. The presence of large workers tending brood at high wasp density does not support my hypothesis that larger workers will primarily be involved in the collection of honeydew. Nevertheless, these results are suggestive of a relationship between worker size and task as described in studies of other ant species (Braendle et al., 2002; Tanner, 2008).

The ecological advantage, if any, of the observed size correlated division of labour in high wasp density areas is uncertain. A potential hypothesis to explain my results is that larger workers perform a combined defensive and carbohydrate gathering function while smaller workers work collaboratively to recover protein resources.

Where wasps are abundant, variation in $P$. advenus worker size distribution in terrestrial, arboreal and epigaeic habitats may reflect the demands of defence, interference and exploitive competitive interactions in each environment. In this system, beech trees represent stable territories with renewable resources, which may be defended from competitors. Carbohydrate is perennially necessary for workers to maintain foraging and defence. By contrast, protein resources are predominantly used by larvae and queens to promote colony growth (Hölldobler and Wilson, 1990). Furthermore, protein resources, such as prey items, are ephemeral; their efficient discovery and removal is arguably more important than defence. Indeed, it has been suggested a single nest could defend several trees without needing to defend the ground between them (Hölldobler and Lumsden, 1980).

Larger workers may perform a combined function in defence and resource acquisition. Numerous studies of other ant species have found that larger workers are better able to defend a resource than smaller workers (Braendle et al., 2003; Kay and Rissing, 2005; Tanner, 2008). Smaller foragers of the ant Formica perpilosa have been shown to be energetically more efficient at nectar collection than larger workers, but are more susceptible to attack and less able 
to defend resources resulting in a trade-off between foraging efficiency and safety (Kay and Rissing, 2005). Tanner (2008) demonstrated that Formica integroides colonies increased the number of large workers attending a resource in response to competitive pressure from Formica xerophila in arboreal but not terrestrial habitats. The results of the current study show that where wasps are most abundant nurses and honeydew foragers are larger than litter foragers. It is possible that larger workers collecting honeydew in high wasp density areas perform a dual function as both defenders of arboreal territories and collectors of carbohydrate resources, possibly at the expense of foraging efficiency. Large workers tending brood may also serve a defensive role in the colony.

Smaller workers may be better able to move through interstices, such a leaf litter (Kaspari and Weiser, 1999). This may confer an advantage in discovery and removal of protein resources. Furthermore, $P$. advenus workers have been observed working collaboratively to remove protein resources (Smith, 1969; Duthie, 2011). It is possible then, that the size related division of labour among $P$. advenus workers where competition from wasps is highest may increase both their interference and exploitive competitive ability.

Where wasp densities were lower no significant difference was observed in worker size among the three habitats. However, the trend was for honeydew foragers to be smaller than litter foragers or nurses (Figure 3.4.). Smaller workers in some species have been found to be more efficient at honeydew collection but less capable of defending the resource against competitors (Kay and Rissing, 2005). Tanner (2008) observed that where competitors were excluded from resource patches, smaller $F$. integroides workers actively collected honeydew while a small number larger workers stood guard between patches. It is possible P. advenus employ a similar strategy. The large error around the mean size of honeydew foragers collected at low wasp density sites may reflect a mixture of large and small workers that perform different functions.

\subsubsection{Conclusions}

Native organisms may mitigate the detrimental effects of invasive competitors by modifying their behaviour and altering their spatial or temporal niche use (Davis, 2003). In this chapter I tested the hypotheses that $P$. advenus would reduce competitive interactions with invasive wasps 
by altering their temporal niche and that they would optimise their foraging by allocating workers to task by size.

I found that rather than avoiding competitive interactions $P$. advenus seems to court them by increasing the number of workers foraging where wasps are most abundant. The purpose of this behaviour is uncertain, but I speculate that it may serve to maximise resource acquisition or to increase interference competitive ability, or both, in response to competition with a novel competitor. Further study is needed to confirm that removal of wasps is accompanied by a shift to nocturnal foraging at more than one site

While ants do not appear to minimise competitive interactions with wasps on a diel timescale, the level of interaction and resultant effects of competition, may be mitigated to some degree on a seasonal scale. Each species' period of brood rearing and concomitant peak forager abundance are offset by approximately 60 days, which may somewhat reduce competitive overlap. The implications this has for predation of $P$. advenus dispersing sexuals by wasps are discussed in Chapter 4.

There was evidence of size correlated task specialisation. Where wasps are abundant larger workers tend brood and collect honeydew while smaller workers forage on the forest floor. This size distribution appears consistent with a defensive function combined with resource acquisition in honeydew foragers. By contrast where wasp densities were lower there was no significant difference in worker size according to the task they performed. This may indicate $P$. advenus ants have modified both their foraging behaviour and worker size distributions in response to interference and exploitive competition with wasps. However, further work to measure the relative efficiency of workers of different sizes in both honeydew acquisition and defence against wasps is needed to confirm these hypotheses. 


\subsection{References}

Adams, D.C. and Rohlf, F.J. (2000) Ecological character displacement in Plethodon: biomechanical differences found from a geometric morphometric study. Proceedings of the National Academy of Sciences U.S.A 97(8): 4106-4111

Anderson, M.J. and Robinson, J. (2003) Generalised discriminant analysis based on distances. Australian \& New Zealand Journal of Statistics 45: 301-318

Anderson, M.J., Gorley, R.N. and Clarke K.R. (2008) PERMANOVA+ for Primer: Guide to software and methods. PRIMER-E. Plymouth: 214pp

Barlow, N.D., Beggs, J.R. and Barron, M.C. (2002) Dynamics of common wasps in New Zealand beech forests: a model of density dependence and weather. The Journal of Animal Ecology 71(4): 663-671

Beggs, J.R., Toft, R.J., Malham, J.P, Rees, J.S., Tilley, J.A.V., Moller, H. and Alspach, P. (1998) The difficulty of reducing introduced wasp (Vespula vulgaris) populations for conservation gains. New Zealand Journal of Ecology 22(1): 55-63

Beggs, J. R. and Wilson, P. R. (1991) The kaka Nestor meridionalis, a New Zealand parrot endangered by introduced wasps and possums. Biological Conservation 56: 23-38

Braendle, C., Hockley, N., Brevig, T., Shingleton, A. W. and Keller, L. (2003) Size-correlated division of labour and spatial distribution of workers in the driver ant, Dorylus molestus. Naturwissenschaften 90: 277-281

Brown, W.L. and Wilson, E.O. (1956) Character displacement. Systematic Zoology 5: 49-64

Carlton, J.T., Thompson, J.K., Schemel, L.E. and Nichols, F.H. (1990) Remarkable invasion of San Francisco Bay (California, USA) by Asian clam Potamocorbula amurensis. I. Introduction and dispersal. Marine Ecology Progress Series 66: 81-94

Clapperton, B.K., Moller, H. and Sandlant, G.R. (1989) Distribution of social wasps (Hymenoptera:Vespidae) in New Zealand in 1987. New Zealand Journal of Zoology 16: 315-323

Clarke, K.R. and Gorley, R.N. (2006) PRIMER v6: User Manual/Tutorial. PRIMER-E, Plymouth

Clemencet, J., Rome, Q., Federici, P. and Doums, C. (2008) Aggressions and size related fecundity of queenless workers in the ant Cataglyphis cursor. Naturwissenschaften 95: 133-139

Davis, M.A. (2003) Biotic globalization: does competition from introduced species threaten biodiversity? Bioscience 53(5): 481-489 
Don, W. (2007) Ants of New Zealand. Otago University Press, Dunedin, New Zealand: 239pp

Donovan, B.J. (1984) Occurrence of the common wasp, Vespula vulgaris (L.) (Hymenoptera: Vespidae) in New Zealand. New Zealand Journal of Zoology 11: 417-427

Duthie, C. (2011) Factors promoting coexistence between endemic ants and invasive wasps. Unpublished PhD thesis. Victoria University Wellington.

Gause, G.F. (1932) Experimental studies on the struggle for existence I. Mixed population of two species of Yeast. Journal of Experimental Biology 9: 389-402

Grangier, J. and Lester, P.J. (2011) A novel interference behaviour: invasive wasps remove ants from resources and drop them from a height. Biology Letters 7(5): 664-667

Grant, P.R. (1972) Convergent and divergent character displacement. Biological Journal of the Linnean Society 4: 39-68

Harris, R. (1991) Diet of the wasps Vespula vulgaris and V. germanica in honeydew beech forest of the South Island, New Zealand. New Zealand Journal of Zoology 18: 159-169

Harris, R.J. and Oliver, E.H. (1993) Prey diets and population densities of wasps Vespula vulgaris and Vespula germanica in a scrubland-pasture. New Zealand Journal of Ecology 15: 512

Hölldobler, B. And Lumsden, C.J. (1980)Territorial strategies in ants. Science 210(4471): 732739

Hölldobler, B. (1982) Interference strategy of Iridomyrmex pruinosum (Hymenoptera:Formicidae) during foraging. Oecologia 52(2): 208-213

Hölldobler, B. and Wilson, E.O. (1990) The Ants. Harvard University Press, Cambridge, MA: $732 \mathrm{pp}$

Holway, D. A. (1999) Competitive mechanisms underlying the displacement of native ants by the invasive Argentine ant. Ecology 80: 238-251

Human, K. G. and Gordon, D. M. (1999) Behavioural interactions of the invasive Argentine ant with native ant species. Insectes Sociaux 46: 159-163

Kaspari, M. and Weiser, M.D. (1999) The size-grain hypothesis and interspecific scaling in ants. Functional Ecology 13 (4): 530-538

Kay, A. and Rissing, S.W. (2005) Division of foraging labour in ants can mediate demands for food and safety. Behavioral Ecology and Sociobiology 58: 165-174 
Kelly, D., Sterling, D.J., Hunt, G.R., Newell, C.L. and Jarvis, C.E. (1992) Honeydew standing crop and

production over 24 hours in Nothofagus solandri forest in Canterbury. New Zealand Journal of Ecology 16(2): 69-75

Kessell, S.R. and Whittaker, R.H. (1976) Comparisons of three ordination techniques. Plant Ecology 32(1): 21-29

Kinnison, M.T. and Hairston jr., N.G. (2007) Eco-evolutionary conservation biology: contemporary evolution and the dynamics of persistence. Functional Ecology 21: 444-454

MacArthur, R.H. and Pianka, E. R. (1966) On optimal use of a patchy environment. American Naturalist 100: 603-609

MacArthur, R.H. and Levins R. (1967) The limiting similarity, convergence, and divergence of coexisting species The American Naturalist 101(921): 377-385

McColl, H.P. (1975) The invertebrate fauna of the litter surface of a Nothofagus truncata forest floor, and the effect of microclimate on activity. New Zealand Journal of Ecology 2: 15-34

McNatty, A., Abbott, K.L. and Lester, P.J. (2009) Invasive ants compete with and modify the trophic ecology of hermit crabs on tropical islands. Oecologia 160: 187-194

Mertl, A.L. and Traniello, J.F.A. (2009). Behavioral evolution in the major worker subcaste of twig-nesting Pheidole (Hymenoptera: Formicidae): does morphological specialization influence task plasticity? Behavioral Ecology and Sociobiology 63: 1411-1426

Moller, H. and Tilley, J.A.V. (1989) Beech honeydew: seasonal variation and use by wasps, honey bees, and other insects. New Zealand Journal of Zoology 16: 289-302

Moller, H., Tilley, J.A.V., Thomas, B.W. and Gaze, P.D. (1991) Effect of introduced social wasps on standing crop of honeydew in New Zealand beech forests. New Zealand Journal of Zoology 18: 171-179

Morales, C.F., Hill, M.G. and Walker, A.K. (1988) Life history of the sooty beech scale (Ultracoelostoma assimile) (Maskell), (Hemiptera:Margarodidae) in New Zealand Nothofagus forests. New Zealand Entomologist 11: 24-38

Nijhout, H.F. and Wheeler, D.E. (1996) Growth models of complex allometries in holometabolous insects. The American Naturalist 148(1): 40-56

PASW 18.0.0 (2010) SPSS Inc., Chicago.

Petren, K. and Case, T.J. (1996) An experimental demonstration of exploitation competition in an ongoing invasion. Ecology 77(1): 118-132 
Philips, B.L. and Shine, R. (2006) An invasive species induces rapid adaptive change in a native predator: cane toads and black snakes in Australia. Proceedings of the Royal Society B 273: $1545-1550$

Reznick, D.N. and Ghalambor, C.K. (2001) The population ecology of contemporary adaptations: what empirical studies reveal about the conditions that promote adaptive evolution. Genetica 112-113: 183-198

Rice, A.M. and Pfennig, D.W. (2006) Character displacement: in situ evolution of novel phenotypes or sorting of pre-existing variation? Journal of Evolutionary Biology 20(2): 448-459

Rice, A.M. and Pfennig, D.W. (2010) Does character displacement initiate speciation? Evidence of reduced gene flow between populations experiencing divergent selection. Journal of Evolutionary Biology 23: 854-865

Sandlant, G.R. and Moller, H. (1989) Abundance of common and German wasps (Hymenoptera:Vespidae) in honeydew beech forests of New Zealand in 1987. New Zealand Journal of Zoology 16: 333-343

Schoener, T.W. (a) (1974) Resource partitioning in ecological communities. Science 185 (4145): 27-39

Schoener, T.W. (b) (1974) The compression hypothesis and temporal resource partitioning. Proceedings of the National Academy of Sciences U.S.A. 71(10): 4169-4172

Simberloff, D., Dayan, T., Jones, C. A. and Ogura, O. (2000) Character displacement and release in the small Indian mongoose, Herpestes javanicus. Ecology 81(8): 2086-2099

Smith, C.E. (1969) A morphological and behavioural study of the ants Amblyopone saundersi Forel and Prolasius advena Fr. Smith (Hymenoptera: Formicidae). Unpublished BSc(Hons) thesis, University of Otago, Dunedin

Smith, W.W. (1896) On the habits of New Zealand ants. Transactions and Proceedings of the New Zealand Institute 29: 468-479

Stockwell, C.A., Hendry, A.P. and Kinnison, M.T. (2003) Contemporary evolution meets conservation biology. TRENDS in Ecology and Evolution 18(2): 94-101

Tanner, C. (2008) Resource characteristics and competition affect colony and individual foraging strategies of the wood ant Formica integroides. Ecological Entomology 33: 127-136

Thomas, C. D., Moller, H., Plunkett, G. M. and Harris, R. J. (1990) The prevalence of introduced Vespula vulgaris wasps in a New Zealand beech forest community. New Zealand Journal of Ecology 13: 63-72 
Toft, R.J. and Beggs, J.R. (1995) Seasonality of crane flies (Diptera:Tipulidae) in South Island beech forest in relation to the abundance of Vespula wasps (Hymenoptera: Vespidae). New Zealand Entomologist 18: 37-43

Whitney, K.D. and Gabler, C.A. (2008) Rapid evolution in introduced species, 'invasive traits' and recipient communities: challenges for predicting invasive potential. Diversity and Distributions 14: 569-580

Ziv, Y., Abramsky, Z., Kotler, B.P. and Subach, A. (1993) Interference competition and temporal and habitat partitioning in two gerbil species. Oikos 66(2): 237-246 
Chapter Four

Evidence of a genetic bottleneck in populations of the endemic New Zealand bush ant Prolasius advenus (Fr. Smith) subject to intense predation by the invasive wasp Vespula vulgaris (L.) 


\subsection{Abstract}

Intense predation by invasive species can reduce the effective population size of native species causing a genetic bottleneck, which results in a loss of allelic diversity and reduced heterozygosity. Reduced populations are more susceptible to loss of alleles through genetic drift. However, gene flow among populations can counteract the effects of both drift and intensive predation. In ants, dispersal is typically undertaken by a winged reproductive female caste (alate queens) and males. In the Nothofagus beech forests of northern South Island of New Zealand the most abundant ant species is the small brown bush ant Prolasius advenus. These forests are heavily infested with the predatory invasive common wasp Vespula vulgaris. The bush ant's nuptial flight coincides with the wasp's peak abundance and alate queens can comprise more than $25 \%$ of the wasp's diet.

Six polymorphic microsatellite markers were developed specifically for $P$. advenus for this study and were used to examine allelic diversity and test for evidence of a genetic bottleneck in $P$. advenus populations collected from seven sites with varying levels of wasp infestation. In addition I examined whether the ants at the seven sites formed a single panmictic population, varied genetically across a spatial continuum or formed two or more discrete populations. Significant heterozygote deficit was observed in all populations. Whether this deficit reflects population substructure, a function of the ants' mating system or indicates that predation by even the smallest populations of wasps results in significant loss of genetic diversity is uncertain. However, populations of ants at high wasp densities showed significant evidence of a genetic bottleneck, which I suggest is the result of intense predation on dispersing queens by Vespula wasps. The seven sites examined were broadly divided into two distinct populations with some evidence of either limited admixture or that they were derived from a common ancestral population. The observed loss of genetic variation has numerous potentially detrimental effects including reduced resistance to pathogens and decreased adaptive potential. As such, the results of the current study appear to illustrate a short term effect of high levels of predation by an invasive species with long term implications for the recipient species. 


\subsection{Introduction}

The influence of invasive species on native taxa is often negative. Predation by exotic species is frequently cited as a major contributing factor to the extinction, displacement or population thinning of native species (MacDonald and Harrington, 2003; Patankar et al., 2006). Exotic predators generally have a greater impact on native prey communities than their local equivalents (Salo et al., 2007). By contrast competitive interactions are typically sub-lethal (Davis, 2003 and Sagoff, 2005), and may promote character displacement (Rice and Pfennig, 2010) or niche shifts (McNatty et al., 2009). The magnitude of an invader's impact on a recipient species is often density-dependent (McNatty et al., 2009; Pawson et al., 2010; Alto, 2011) and its historical impact on effective population size may be reflected by the levels of population genetic diversity.

Many studies have focused on the population genetics of invasive species, both in their introduced and native ranges (Shoemaker et al., 2006; Sunamura et al., 2011; Bronnenhuber et $a l ., 2011$ ), but research is lacking in information about the potential types of genetic change native taxa may undergo as a result of invasion. These changes may include altered population genetic subdivision, a decline in the level of genetic variation and selective genetic changes. Population bottleneck resulting from a decline in effective population size will manifest itself as a reduction in heterozygosity and allelic diversity in the affected population (Nei et al., 1975). Such bottlenecks have been demonstrated in the brown anole lizard (Anolis sagrei), which displayed significantly reduced levels of genetic diversity in populations on islands invaded by predatory rats in comparison to populations on un-invaded islands (Gasc et al., 2010). Reduced populations are more susceptible to the effects of stochastic processes such as genetic drift. In the absence of counteracting evolutionary forces genetic drift may result in divergence of allele frequencies among populations.

Of key importance in counteracting the effects of drift on small populations is dispersal. Gene flow can maintain a high effective population size and prevent differentiation among populations (Allendorf and Luikart, 2007). The distribution of genetic variation among populations may be broadly categorised in one, or a combination, of three ways: (i) distinct populations; where gene flow is limited and populations diverge. (ii) continuous change, where gene flow between populations decreases with increasing geographical distance and a pattern of continuous change 
and isolation by distance occurs; (iii) undifferentiated, where gene flow is equal among all populations, genetic structure is homogeneous and the population is panmictic (Laikre et al., 2005).

In ants, dispersal is undertaken by a reproductive female caste and males. These are generally winged individuals that leave their natal nest en masse in response to a unifying environmental cue. Significantly more resources are invested in reproductive females than in males (Boomsma and Isaaks, 1985) with the result that fewer new queens are produced relative to the number of males, and sex ratios are accordingly usually male biased (Noordijk et al., 2008). Male aggregation is the more common mating strategy in the higher Formicidae (Hölldobler and Wilson, 1990). In this mode of reproduction, alate queens and males are simultaneously released from their natal nests and undergo a nuptial flight during which they mate either in flight or on the ground. Mated queens either re-join their natal colony or form new colonies independently. In polygynous colonies it is common for queens to disperse only short distances and to rejoin their natal nest after mating (Bourke and Franks, 1995; Pamilo et al., 1997; Ross, 2001).

Winged queens represent a high value prey item to many predators. To aid in colony foundation the alate queen's thorax is modified to store metabolic reserves, which are typically hystolysised to provide proteins for oogenesis along with the wing muscles when the wings are lost after the nuptial flight (Peeters and Ito, 2001). Storage proteins are also accumulated in the fat bodies housed in the gaster (Martinez and Wheeler, 1994). In addition, alate queens carry large quantities of carbohydrate in the form of glycogen and free sugars, which are used to fuel the nuptial flight, as well as lipids, which are depleted during initial colony formation (Keller and Passera, 1989 and Passera and Keller, 1990). Indeed it has been reported that the mass of alate queens in some species increases fourfold between eclosion and leaving the natal nest (Boomsma and Isaaks, 1985). As adults do not grow after eclosion, this increase in mass is likely due to stockpiling resources for the nuptial flight.

In the Nothofagus beech forests of New Zealand's upper South Island, the invasive common wasp Vespula vulgaris (L.) has consistently been recorded at population densities that greatly exceed those attained in its native range since it became established in the late 1980's (Thomas et 
al., 1990; Barlow et al., 2002). The wasp is a voracious predator of numerous invertebrate orders (Harris, 1991; Harris and Oliver, 1993; Toft and Beggs, 1995; Toft and Rees, 1998), which it feeds to its developing young (Harris, 1991). A survey of wasp prey consumption in New Zealand Nothofagus beech forests found that one third of the prey items caught belonged to the order Hymenoptera and of those $83 \%$ were ants, predominantly alate queens (Harris, 1991; Harris pers. com.). The wasps are at peak abundance in March and April (Beggs et al., 1998), which coincides with the nuptial flight of the most abundant ant species in the forest Prolasius advenus (Fr.Smith) (McColl, 1975; Don, 2007; pers. obs.). It is thus probable that $P$. advenus queens comprise approximately $25 \%$ of the wasps' protein diet at this time. This degree of predation pressure potentially represents a substantial reduction in the effective population size of $P$. advenus.

Despite its abundance throughout New Zealand there have been few published studies of $P$. advenus and nothing is known of its population genetic structure and the influence of wasps on its population genetics. In this study I have used microsatellite DNA markers to examine the within population structure of the species in seven wasp infested beech forest sites in New Zealand's northern South Island. I tested the hypothesis that high densities of $V$. vulgaris are associated with a genetic bottleneck in $P$. advenus populations, such as would be expected if an invasive predator were to reduce the effective population size of a recipient species to a point that diminished allelic diversity and reduced heterozygosity. I also aimed to determine whether among population structure in $P$. advenus is distinct, panmictic or displays continuous change in my study area in the northern South Island. 


\subsection{Methods}

\subsubsection{Study species and study sites}

The small brown bush ant $P$. advenus is the most abundant ant species in the honeydew beech forests of the Nelson Lakes area in New Zealand's northern South Island (McColl, 1975; Don 2007; Grangier and Lester, 2011 and Chapter 5). The species is polygynous (Smith, 1969) and large numbers of unmated winged queens and males make their nuptial flight between late February and April each year (Smith, 1896; Don, 2007; pers. obs.). Since the late 1980s these forests have become infested with the invasive common wasp V. vulgaris (L.), which attain some of the highest population densities on record (Thomas et al., 1990). The wasp is a voracious predator of terrestrial invertebrates, particularly in late summer when they tend their brood (Harris, 1991).

An annual survey of wasp nest density was conducted along transects through Nothofagus beech forest by Landcare Research Nelson between 1988 and 2008 at seven sites: Pelorus Bridge (41 ${ }^{\circ}$ $\left.18^{\prime} \mathrm{S}, 173^{\circ} 34^{\prime} \mathrm{E}\right)$, Graham Valley ( $\left.41^{\circ} 09^{\prime} \mathrm{S}, 173^{\circ} 31^{\prime} \mathrm{E}\right)$, Spooner's Range $\left(41^{\circ} 27^{\prime} \mathrm{S}, 172^{\circ} 55^{\prime}\right.$ E), Lake Rotoiti ( $\left.41^{\circ} 49^{\prime} \mathrm{S}, 172^{\circ} 50^{\prime} \mathrm{E}\right)$, Mt. Misery ( $\left.41^{\circ} 54^{\prime} \mathrm{S}, 172^{\circ} 39^{\prime} \mathrm{E}\right)$, Tiraumea Saddle $\left(41^{\circ}\right.$ $54^{\prime} \mathrm{S}, 172^{\circ} 37^{\prime} \mathrm{E}$ ) and Matakitaki ( $\left.42^{\circ} 58^{\prime} \mathrm{S}, 172^{\circ} 20^{\prime} \mathrm{E}\right)$. For detailed survey methods see: Beggs et al., (1998) and Barlow et al., (2002). A reduced survey was conducted in 2009 and 2010 at four sites Pelorus Bridge, Spooner's Range; Mt. Misery and Lake Rotoiti. The results of these surveys (Beggs et al., 1998; Barlow et al., 2002; Toft and Rees unpublished) provide a historical record of wasp population density since $V$. vulgaris became established in the region and allows areas of consistently high and low wasp density to be delineated (Figure 4.1).

\subsubsection{Specimen collection, DNA extraction and amplification}

Specimens of $P$. advenus were collected haphazardly by mouth aspirator from six to seven nests opened along the Landcare transect line at each of the seven sites surveyed for wasp densities, except Graham Valley where only four nests were found. Between 37 and 52 specimens were collected from each site (Mean $\pm \mathrm{S} . \mathrm{E}=48.3 \pm 4.8)$. Once collected, specimens were killed by freezing and stored in $95 \% \mathrm{EtOH}$ at $-10^{\circ} \mathrm{C}$. 
Microsatellite markers were used to examine within and among population genetic structure among $P$. advenus workers and test for evidence of genetic bottleneck at seven sites with varying density of invasive predatory wasps. A modified Chelex protocol (Sepp et al., 1994) was used to extract genomic DNA. Each $P$. advenus worker was placed in a $1.7 \mathrm{ml}$ centrifuge tube with 100 $\mu \mathrm{L} 10 \%$ (weight/volume) Chelex resin/Tris solution and ground with a sterile plastic pestle. Samples were then vortexed briefly and centrifuged at 13,000rpm for 30 seconds before being heated for 15 minutes at $95^{\circ} \mathrm{C}$. Samples were then cooled on ice for 5 minutes and spun at $13,000 \mathrm{rpm}$ at $4^{\circ} \mathrm{C}$ for 15 minutes to concentrate the Chelex beads and remnants of ant tissue at the bottom of the tube. The resulting supernatant was then drawn off by pipette to a fresh tube and stored at $4^{\circ} \mathrm{C}$.

Microsatellite loci were developed for P. advenus by ATG Genetics Inc. (University of British Columbia, Canada). Six loci were used in this study: $\operatorname{Pad} 2$, $\operatorname{Pad} 4$, Pad 5, Pad 9, Pad 10, and Pad 15 (table 4.1). Samples were amplified using the polymerase chain reaction (PCR) in $15 \mu 1$ volumes comprising: $1 \mu \mathrm{l}$ of $20 \mathrm{ng} / \mu \mathrm{l}$ template DNA; $1.5 \mu \mathrm{l}$ 10×Reaction Buffer (Bioline); 0.6 $\mu 1 \mathrm{~mL}^{-1}$ bovine serum albumin (BSA); $0.6 \mu \mathrm{l} 0.2 \mathrm{mM}$ dNTPs; $0.6 \mu 1$ 1.5 - 2.5mM MgCl; $9.23 \mu \mathrm{l}$ ddH2O; $0.6 \mu$ of 10mM fluorescent dye-labelled M13 Primer (Schuelke, 2000); $0.6 \mu 1$ 10mM Reverse primer; $0.15 \mu \mathrm{l}$ 10mM Forward primer and $0.12 \mu \mathrm{l} \mathrm{Taq}$ DNA Polymerase (Bioline). The fluorescent dyes used were VIC (Pad 2, Pad 9 and Pad 10) and FAM (Pad4, Pad5 and Pad15).Thermal cycling was conducted on an Eppendorf 2700 (Applied Biosystems) thermal cycler with modifications for M13 labelled primers (Schuelke, 2000): an initial denaturing period of three minutes at $95^{\circ} \mathrm{C}$ followed by 27 cycles of $95^{\circ} \mathrm{C}$ for 40 seconds, $57^{\circ} \mathrm{C}$ for 40 seconds, $72^{\circ}$ $\mathrm{C}$ for 40 seconds, then a further 8 cycles of $95^{\circ} \mathrm{C}$ for 40 seconds, $53^{\circ} \mathrm{C}$ for 40 seconds, $72^{\circ} \mathrm{C}$ for 40 seconds and a final extension of $72^{\circ} \mathrm{C}$ for 10 minutes. The resulting PCR products were then analysed on an ABI 3730 Genetic Analyzer and scored using Genemapper v3.7 (Applied Biosystems). The data were then checked for scoring errors due to stutter, large allele dropout and the presence of null alleles using Micro-Checker v. 2.2.3 software (Van Oosterhout et al., 2003). 


\subsubsection{Within population variation and the effects of wasps}

Each population was tested for deviation from Hardy Weinberg equilibrium, based on global heterozygote deficit, in addition I tested for linkage disequilibrium and calculated the inbreeding coefficient $F_{\text {IS }}$ using Genepop v 4.0.10 (Raymond and Rousset, 1995). Measures of genetic diversity, observed $\left(\mathrm{H}_{o}\right)$ and expected $\left(\mathrm{H}_{E}\right)$ heterozygosity and allele frequencies were calculated using GenAlEx v 6.3 (Peakall and Smouse, 2006). Assignment of individuals to the nests they were collected from was used to estimate within nest relatedness using the Assignment function in GenAlEx v 6.3 (Peakall and Smouse, 2006). Allelic richness was calculated using HP-RARE (Kalinowski, 2005). Loss of genetic variation due to a reduction in effective population size was tested for using BOTTLENECK v 1.2.02 (Cornuet and Luikart, 1996). A two-phase model of mutation (TPM), which best fits microsatellite data (Di Rienzo et al., 1994), was used. Variance for the model was set at 10 and the proportion of single step mutations was set at $70 \%$. Estimation was based on 1000 iterations per population.

Correlations between the mean annual wasp density per site between 1988 and 2010 (nests $\mathrm{Ha}^{-1}$ ), mean allele number, effective allele number, allelic richness and average heterozygosity were tested using non-parametric Spearman's Rank correlation coefficient and two tailed significance tests performed using PASW 18.0.0 statistical software (SPSS Inc., 2010).

\subsubsection{Among population structure}

Spatial population structure was evaluated with Wright's F-statistics using GenAlEx (Peakall and Smouse, 2006) and AMOVA was used to examine the amount of genetic variation partitioned within and among populations. Genetic isolation by distance was examined using a Mantel test of genetic distance and population genetic clustering was examined using principal components analysis using GenAlEx v 6.3 (Peakall and Smouse, 2006). The presence of multiple breeding groups was tested using STRUCTURE v 2.3.3 (Pritchard et al., 2000), which attempts to cluster individuals together to minimise Hardy-Weinberg disequilibrium between loci within groups. The number of populations was determined from posterior probabilities of $\mathrm{K}$ estimates. Ten runs were performed for each value of K between one and seven. A burn-in of 10,000 
simulations was followed by 1,000,000 further simulations. In the case of migration rates between populations not being equal the log likelihood estimates generated for each value of $\mathrm{K}$ were then used to calculate a best estimate of $\mathrm{K}$ using the $\Delta \mathrm{K}$ method (Evanno et al., 2005).

To estimate levels of population differentiation Jost's D (Jost, 2008) was calculated using the programme SMOGD v1.2.5 (Crawford, 2010). Jost's D was chosen as an estimate of differentiation over $F_{\mathrm{ST}}$ or PhiPt because they are artificially down-biased by polymorphic markers such as microsatellites (Allendorf and Luikart, 2007). Calculation of $F_{\mathrm{ST}}$ and PhiPt are based on heterozygosity as a measure, which may be subject to atypical variation in groups with haplo-diploid mating systems such as ants.

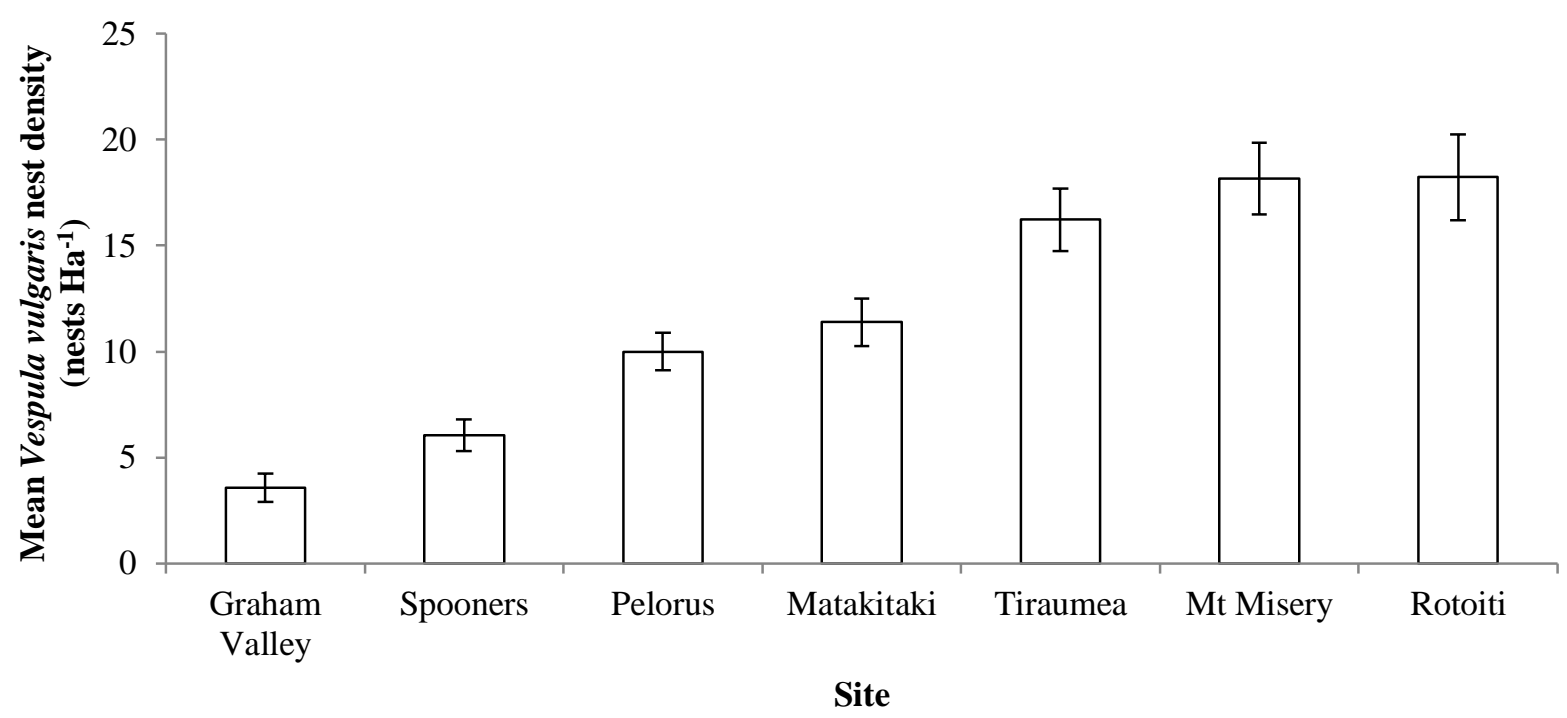

Figure 4. 1 The mean \pm S.E common wasp (Vespula vulgaris) nest density (nests $\mathrm{Ha}^{-1}$ ) between 1988 and 2010 at seven New Zealand South Island Nothofagus beech forest sites. 


\subsection{Results}

\subsubsection{General genetic variation}

The six di-nucleotide repeat microsatellite markers were all found to be polymorphic. There were between 13 (Pad9) and 32 (Pad5) alleles per locus. All six markers had allele size ranges between 24 (Pad2) and 126 (Pad15) base pairs. All loci except Pad4 displayed significant heterozygote deficit. This was reflected by predominantly positive $F_{\text {IS }}$ values, which ranged between -0.084 (Pad4) and 0.727 (Pad5). The observed heterozygosity of two markers in particular Pad5 and Pad15 was markedly lower than expected based on the number of alleles (Table 4.1). Allele frequency distributions for all loci in all populations are presented in Appendix 1.

The results of the Micro-Checker analysis found no evidence of large allele dropout. Scoring error due to strand slippage during DNA synthesis (stuttering) was indicated by a combination of heterozygote deficit and the presence of alleles differing in size by one repeat unit. However, when the chromatograms were re-checked the allele peaks appeared to be scored appropriately and, as the pattern of error was not consistent at any locus and did not coincide with any of the observed private alleles, it was decided to retain the scoring of the alleles. Based on the observed heterozygote deficit it was also indicated that the presence of null alleles was possible at the Pad5, Pad9, Pad10 and Pad15 loci. However, heterozygote deficit is often found in multi-queen ant species such as P. advenus (Chapuisat et al., 1997; Pamilio et al., 1997; Chapuisat and Keller, 1999; Ross, 2001).

\subsubsection{Within population variation and the effects of wasps}

Within site analyses were indicative of limited dispersal and potential within population structure at all sites. None of the seven populations tested was found to be in Hardy-Weinberg equilibrium; all displayed significant $(\mathrm{P}<0.001)$ heterozygote deficit. Estimates of inbreeding by $F_{\text {IS }}$ were accordingly all positive and ranged between 0.188 at Pelorus Bridge and 0.343 at Spooner's Range indicating some level of inbreeding in all populations (Table 4.2). An exact test for linkage disequilibrium between all locus pairs within all populations found significant $(\mathrm{P}<0.050)$ 
linkage among loci at all sites except $\operatorname{Pad5}$ and $\operatorname{Pad} 9(\mathrm{P}=0.130)$. The number of linked locus pairs per population ranged between two (Pelorus Bridge) and twelve (Lake Rotoiti) of a possible fifteen pairs, perhaps indicating limited gene flow or local population substructure.

The results of the assignment test indicated that within nest relatedness was low with population means ranging from $69 \%$ of workers excluded from the nests from which they were collected at Rotoiti and 34\% excluded at Pelorus Bridge. The mean proportion across populations of workers that were not assigned to the nest they were collected from was $43 \%$ suggesting multiple matrilines and patrilines per nest or exchange of workers among nests (Figure 4.2).

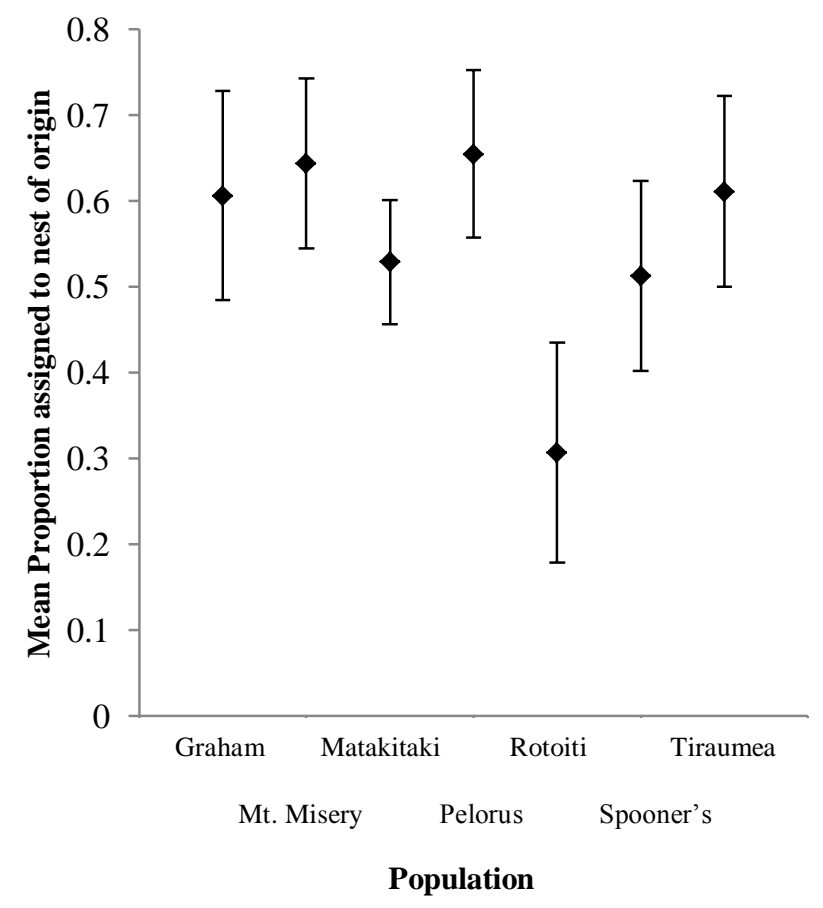

Figure 4.2 The mean \pm S.E. proportion of workers assigned to the nest they were collected from based on relatedness at each of seven New Zealand South Island Nothofagus beech forest sites. 
Table 4.1 Primer sequences, repeat motif, annealing temperature (TM), sample size, number of alleles, observed and expected heterozygosity and inbreeding coefficient $\left(F_{\text {IS }}\right)$ for six microsatellite markers developed for the New Zealand endemic bush ant Prolasius advenus.

\begin{tabular}{|c|c|c|c|c|c|c|c|c|c|}
\hline Locus & Primer sequence $\left(5^{\prime}-3^{\prime}\right)$ & $\begin{array}{c}\text { Repeat } \\
\text { Motif }\end{array}$ & $\mathrm{TM}$ & $\begin{array}{c}\text { Size } \\
\text { Range }\end{array}$ & $\begin{array}{c}\text { Sample } \\
\text { size }\end{array}$ & $\begin{array}{c}\text { Number of } \\
\text { alleles } \\
\text { observed }\end{array}$ & $\begin{array}{c}\text { Observed } \\
\text { Heterozygosity } \\
\left(\mathrm{H}_{o}\right)+/-\mathrm{SE} \\
\end{array}$ & $\begin{array}{c}\text { Expected } \\
\text { heterozygosity } \\
\left(\mathrm{H}_{E}\right)+/-\mathrm{SE}\end{array}$ & $F_{\text {IS }}$ \\
\hline & Forward & & & $123-$ & & & $0.671+/-0.018$ & & \\
\hline Pad2 & $\begin{array}{c}\text { CCAGTTTTCACAGACGAGAG } \\
\text { Reverse } \\
\text { TGGATTATAAAATTCTCTGGCG }\end{array}$ & $\mathrm{TC}$ & 57 & 147 & 314 & 13 & & $0.748+/-0.018$ & 0.103 \\
\hline Pad4 & $\begin{array}{c}\text { Forward } \\
\text { AACGGTGAGACAAGGAAAGA } \\
\text { Reverse TCCCACCCTCTCACTCTG }\end{array}$ & $\mathrm{AG}$ & 57 & $\begin{array}{l}114- \\
172\end{array}$ & 314 & 20 & $0.855+/-0.025$ & $0.789+/-0.018$ & $\overline{-}$ \\
\hline Pad5 & $\begin{array}{c}\text { Forward } \\
\text { GTGACATTCTCGTAAATGCC } \\
\text { Reverse }\end{array}$ & CT & 57 & $\begin{array}{l}168- \\
258\end{array}$ & 314 & 32 & $0.206+/-0.022$ & $0.756+/-0.033$ & 0.727 \\
\hline Pad9 & $\begin{array}{c}\text { TTCTCGCGTGTCTAGAGAAC } \\
\text { Forward } \\
\text { CACATTCTCCCCCCCTCTC } \\
\text { Reverse } \\
\text { TCCTTCGCGAGAGCTAAGAA }\end{array}$ & CT & 57 & $\begin{array}{l}144- \\
194\end{array}$ & 314 & 13 & $0.564+/-0.043$ & $0.793+/-0.023$ & 0.290 \\
\hline Pad10 & $\begin{array}{c}\text { Forward } \\
\text { TCTCTAGAACATCCTTAATCC } \\
\text { Reverse }\end{array}$ & GA & 57 & $\begin{array}{l}172- \\
246\end{array}$ & 314 & 29 & $0.733+/-0.057$ & $0.863+/-0.010$ & 0.151 \\
\hline Pad15 & $\begin{array}{c}\text { TGCAGCCTTTGATTAGGTCC } \\
\text { Forward } \\
\text { AATGGAATGGCTAGAGCGAC } \\
\text { Reverse } \\
\text { CTGCCTTTGACCCTTTAGCT }\end{array}$ & GA & 57 & $\begin{array}{l}152- \\
278\end{array}$ & 314 & 15 & $0.393+/-0.058$ & $0.663+/-0.039$ & 0.407 \\
\hline
\end{tabular}


Prolasius advenus populations in areas where wasps are highly abundant show evidence of genetic bottleneck that is consistent with a significant reduction in effective population size. The results of the one-tail Wilcoxon rank test for heterozygote deficiency found significant evidence of genetic bottleneck in the $P$. advenus populations at the high wasp density sites of Mount Misery $(\mathrm{P}=0.039)$ and Rotoiti $(\mathrm{P}=0.039)$. The Tiraumea $P$. advenus population also showed evidence of bottleneck at the $10 \%$ level $(\mathrm{P}=0.055)$. Of the lower wasp density P. advenus populations, only Graham Valley showed significant $(\mathrm{P}=0.023)$ evidence of genetic bottleneck. No significant indication of genetic bottleneck was evident in the Matakitaki $(\mathrm{P}=0.219)$; Pelorus $(\mathrm{P}=0.500)$; Spooner's Range $(\mathrm{P}=0.719)$ populations (Table 4.2).

The results of a Spearman's rank correlation analysis indicated no significant correlation between wasp density and the mean number of alleles per population $(\rho=-0.054 ; P=0.908)$ (Figure $4.3 \mathrm{a}$ ); wasp density and heterozygosity across all loci $(\rho=0.00 ; \mathrm{P}=1.00)$ (Figure $4.3 \mathrm{~b}$ ); wasp density and effective number of alleles across all loci $(\rho=0.00 ; P=1.00)$ or wasp density and allelic richness $(\rho=0.055 ; \mathrm{P}=0.908)$.
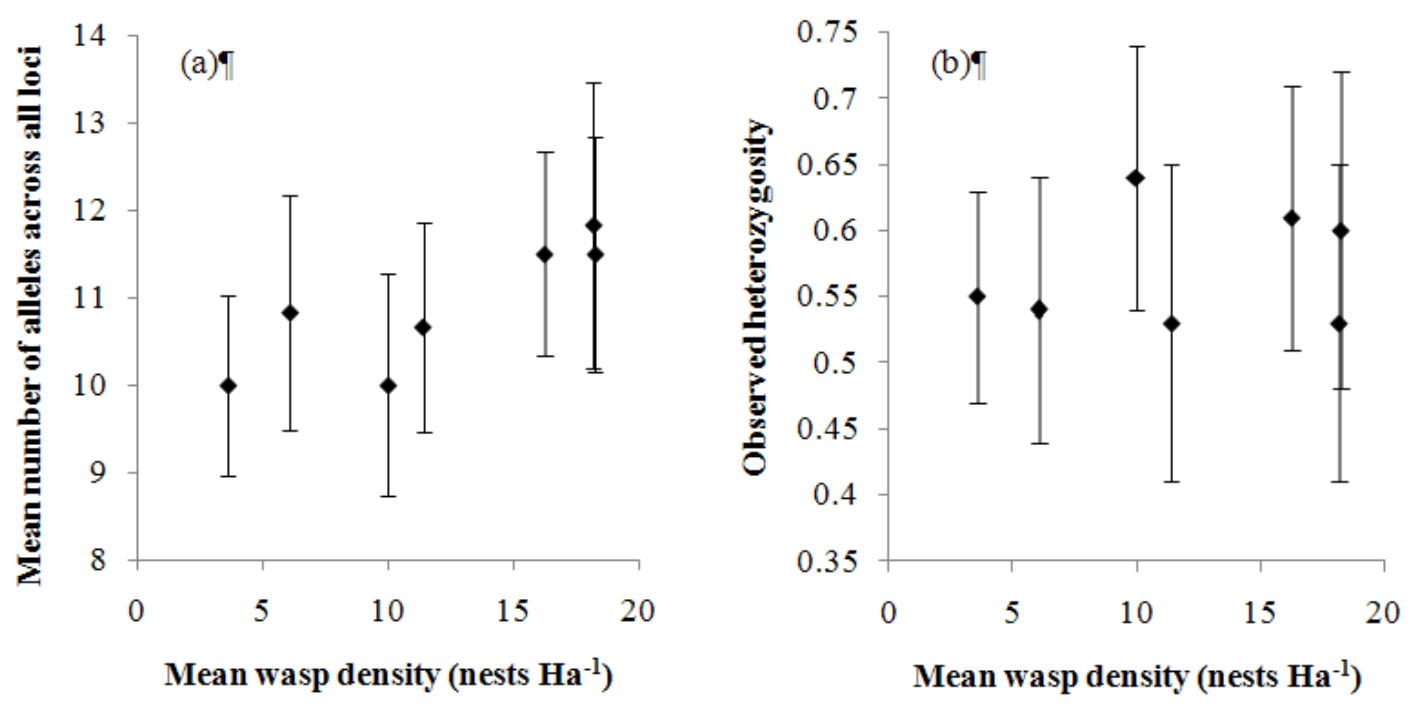

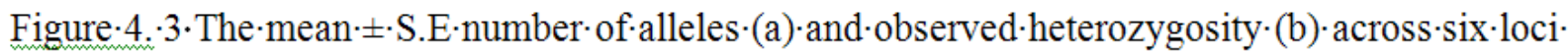
for-Prolasius·advenus $\cdot$ workers $\cdot$ sampled from $\cdot$ seven populations $\cdot$ in $\cdot$ areas $\cdot$ with $\cdot$ varying $\cdot$ wasp · density. $\rightarrow$ 
Table 4.2 Allelic diversity, heterozygosity, inbreeding coefficient $\left(F_{\mathrm{IS}}\right)$ and Wilcoxon probability (one-tail) of genetic bottleneck in seven New Zealand South Island populations of the small brown bush ant Prolasius advenus.

\begin{tabular}{|c|c|c|c|c|c|c|c|c|c|}
\hline Population & $\begin{array}{c}\text { Mean wasp } \\
\text { density (nests } \\
\text { Ha-1) }\end{array}$ & Sample size & $\begin{array}{c}\text { Number of } \\
\text { alleles } \pm \text { S.E. }\end{array}$ & $\begin{array}{c}\text { Number of } \\
\text { private alleles }\end{array}$ & $\begin{array}{c}\text { Mean } \\
\text { allelic } \\
\text { richness }\end{array}$ & $\begin{array}{c}\text { Observed } \\
\text { Heterozygosity } \\
\left(H_{O}\right)\end{array}$ & $\begin{array}{c}\text { Expected } \\
\text { heterozygosity } \\
\left(\mathbf{H}_{E}\right)\end{array}$ & $F_{\text {IS }}$ & $\begin{array}{c}\text { Probability } \\
\text { of genetic } \\
\text { bottleneck } \\
(P=)\end{array}$ \\
\hline Graham & 3.57 & 37 & $10.00+/-1.03$ & 3 & 3.66 & $0.55+/-0.08$ & $0.75+/-0.03$ & 0.275 & 0.023 \\
\hline Matakitaki & 11.38 & 44 & $10.67+/-1.20$ & 5 & 3.66 & $0.53+/-0.12$ & $0.73+/-0.06$ & 0.280 & 0.219 \\
\hline Mt. Misery & 18.16 & 47 & $11.83+/-1.64$ & 8 & 3.84 & $0.53+/-0.12$ & $0.77+/-0.03$ & 0.318 & 0.039 \\
\hline Pelorus & 9.97 & 44 & $10.00+/-1.27$ & 3 & 3.84 & $0.64+/-0.10$ & $0.78+/-0.03$ & 0.188 & 0.500 \\
\hline $\begin{array}{l}\text { Spooner's } \\
\text { Range }\end{array}$ & 6.05 & 47 & $10.83+/-1.35$ & 5 & 4.03 & $0.54+/-0.10$ & $0.81+/-0.03$ & 0.343 & 0.719 \\
\hline Rotoiti & 18.23 & 43 & $11.50+/-1.34$ & 4 & 3.89 & $0.60+/-0.12$ & $0.78+/-0.04$ & 0.240 & 0.039 \\
\hline Tiraumea & 16.24 & 52 & $11.50+/-1.17$ & 7 & 3.86 & $0.61+/-0.10$ & $0.78+/-0.04$ & 0.218 & 0.055 \\
\hline
\end{tabular}




\subsubsection{Among population structure}

I examined whether among population structure in $P$. advenus from the seven sample sites was distinct, continuous or panmictic. My results indicated that $P$. advenus at the seven sites examined are derived from two distinct populations. The results of AMOVA indicated that among population variation accounted for $10 \%$ of the allelic diversity in the dataset $(\varphi \mathrm{PT}=$ 0.099; df 6, 307; P < 0.001). The mean \pm S.E number of alleles across all loci for all populations was $20.33( \pm 0.93)$. Little variation was found in the mean number of alleles over all loci per population, which ranged between $10.00( \pm 1.03)$ at Graham Valley and Pelorus and $11.50( \pm$ 1.34) at Lake Rotoiti and (11.50 \pm 1.17$)$ Tiraumea Saddle. However, the number of private alleles per population across all loci varied markedly and ranged between 3 at Graham Valley and Pelorus Bridge and 8 at Mt. Misery indicating either limited connectivity among populations or the rarity of some alleles. The effective number of alleles ranged between 4.32 at Graham Valley and 6.00 at Spooner's Range supporting the argument for lack of connectivity. Allelic richness across loci varied between 3.66 and 4.03 per population (Table 4.2). Population genetic analyses indicated that the $P$. advenus colonies sampled were derived from two lineages. Each lineage was more commonly represented in either the North Eastern or South Western populations (Figure 4.4 a). The STRUCTURE analysis produced a highest log likelihood for seven genetic clusters $(\ln P(D)=-7231)$. However, analysis using the $\Delta \mathrm{K}$ method indicated that two distinct clusters were most likely (Figure $4.4 \mathrm{~b}$ ). The first and second components of the principal components analysis of population distribution explained $67.63 \%$ of the variance in the dataset and showed population clustering that closely matched the populations' geographic distribution and degree of assignment to each of the North East and South West populations (Figure $4.4 \mathrm{c}$ ). The third principal component explained a further $14.15 \%$ of the variance in the dataset and increased the cumulative total to $81.77 \%$ (Figure $4.4 \mathrm{~d}$ ). Plotting the third component against the first revealed the greater degree of differentiation among the North Eastern Populations and particularly highlighted the separation of the Pelorus Bridge population from the other members of the North Eastern populations. 
(a)

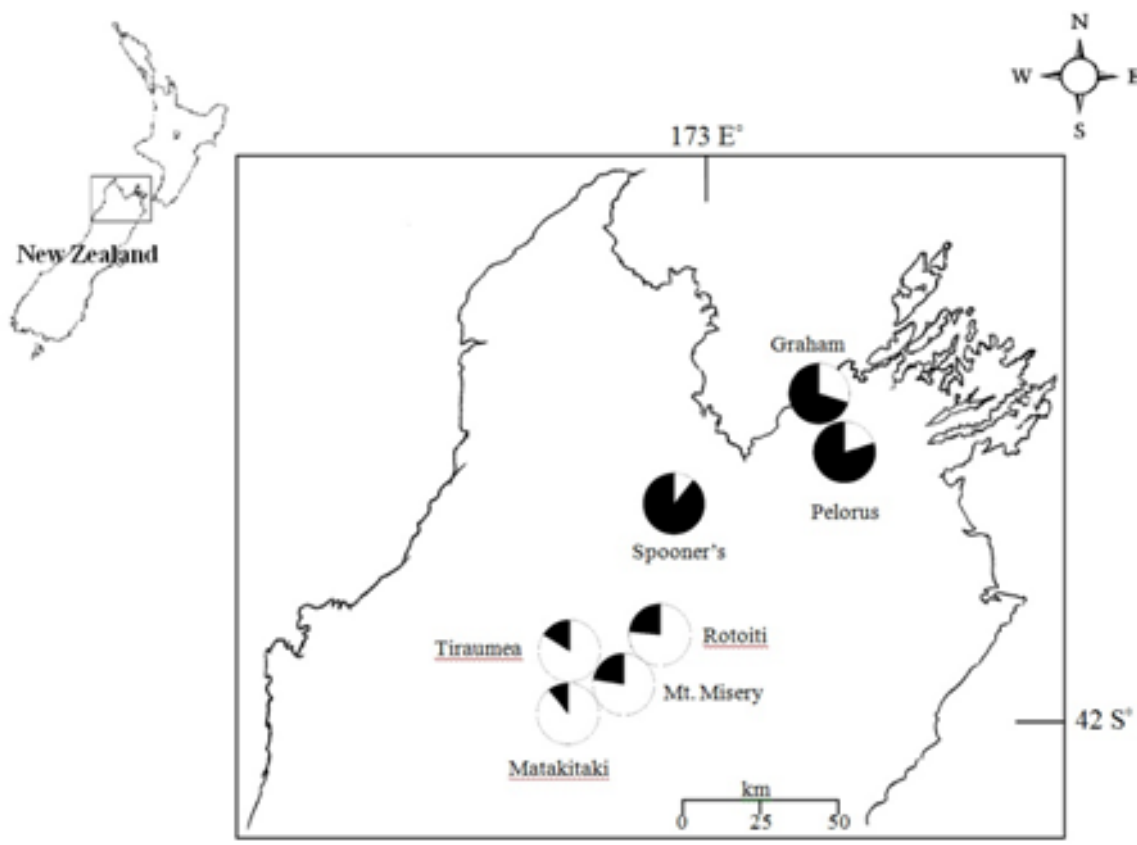

(b)

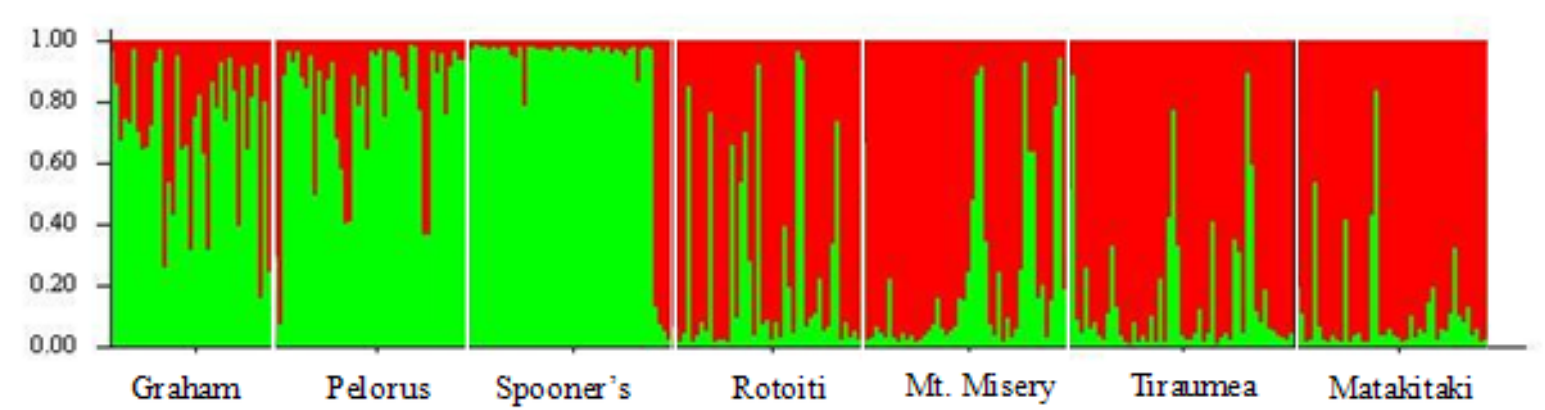

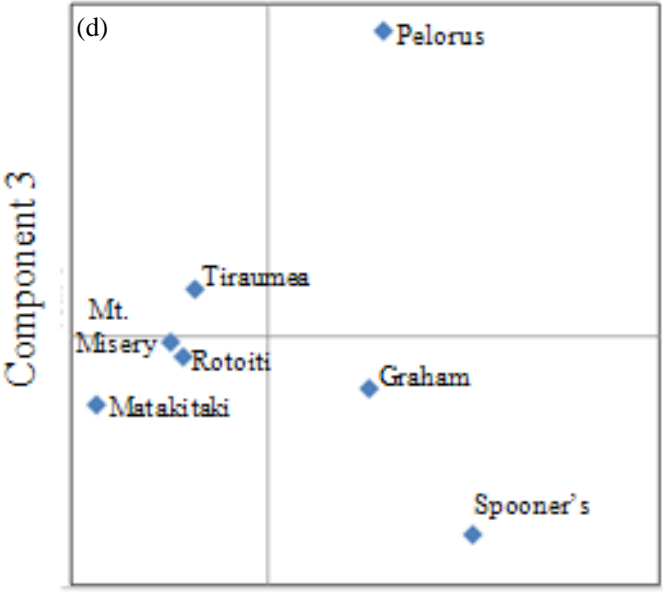

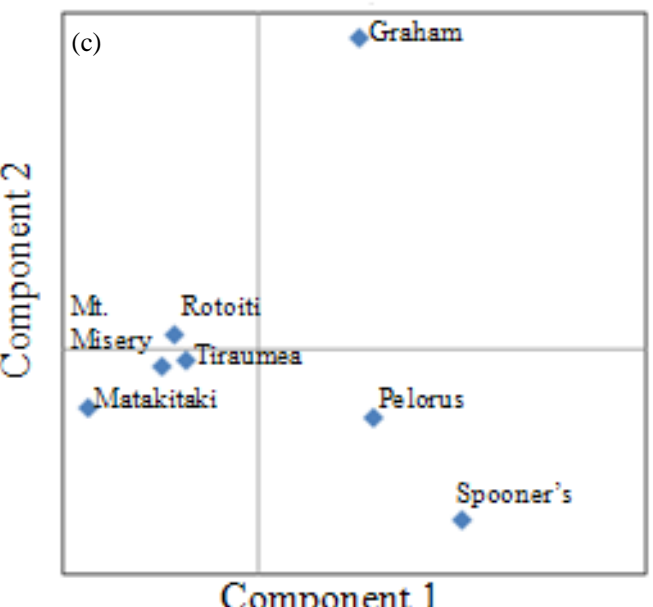

Component 1

Figure 4.4 Population genetic structure of Prolasius advenus at seven New Zealand Nothofagus beech forest sites. (a) Seven New Zealand South Island study sites showing relative proportions of each $P$. advenus lineage derived by $\triangle \mathrm{K}$ method. Population genetic structure showing two distinct populations and (b) STRUCTURE analysis plot $(\mathrm{K}=2)$ populations showing two clusters across seven sub-populations.Principal components analysis plots showing clustering based on genetic similarity of Prolasius advenus populations from seven Nothofagus beech forest sites when the first principal component is plotted against (c) the second component and (d) the third principal component. 
This result was supported by the results of the analysis of Jost's D, which indicated the North Eastern populations (Graham River, Pelorus and Spooner's Range) were more differentiated from other populations than were the South Western populations. Jost's measure of differentiation among populations across all loci ranged between D = 0.041 (Mt. Misery and Tiraumea) and D = 0.375 (Spooner's Range and Matakitaki) (Table 4.3)

Table 4.3 Pairwise harmonic mean of Jost's D across all loci among pairs of Prolasius advenus populations. Values closer to zero indicate less differentiation among populations and those closer to 1 indicate greater differentiation.

\begin{tabular}{cccccccc}
\hline & Graham & Matakitaki & Mt.Misery & Pelorus & Spooner's & Rotoiti & Tiraumea \\
\hline Graham & -- & 0.226 & 0.179 & 0.213 & 0.351 & 0.191 & 0.210 \\
Matakitaki & -- & -- & 0.044 & 0.219 & 0.375 & 0.063 & 0.096 \\
Mt. Misery & -- & -- & -- & 0.162 & 0.348 & 0.054 & 0.041 \\
Pelorus & -- & -- & -- & -- & 0.171 & 0.196 & 0.179 \\
Spooner's & -- & -- & -- & -- & -- & 0.355 & 0.357 \\
Rotoiti & -- & -- & -- & -- & -- & -- & 0.075 \\
Tiraumea & -- & -- & -- & -- & - & - \\
\hline
\end{tabular}

The results of a Mantel test indicated no significant genetic isolation by distance $\left(\mathrm{r}^{2}=0.089 ; \mathrm{P}=\right.$ 0.079) presumably reflecting the incomplete divergence of the two groups and higher levels of divergence observed in the North eastern populations in comparison with the South Western populations (Figure 4.5). 


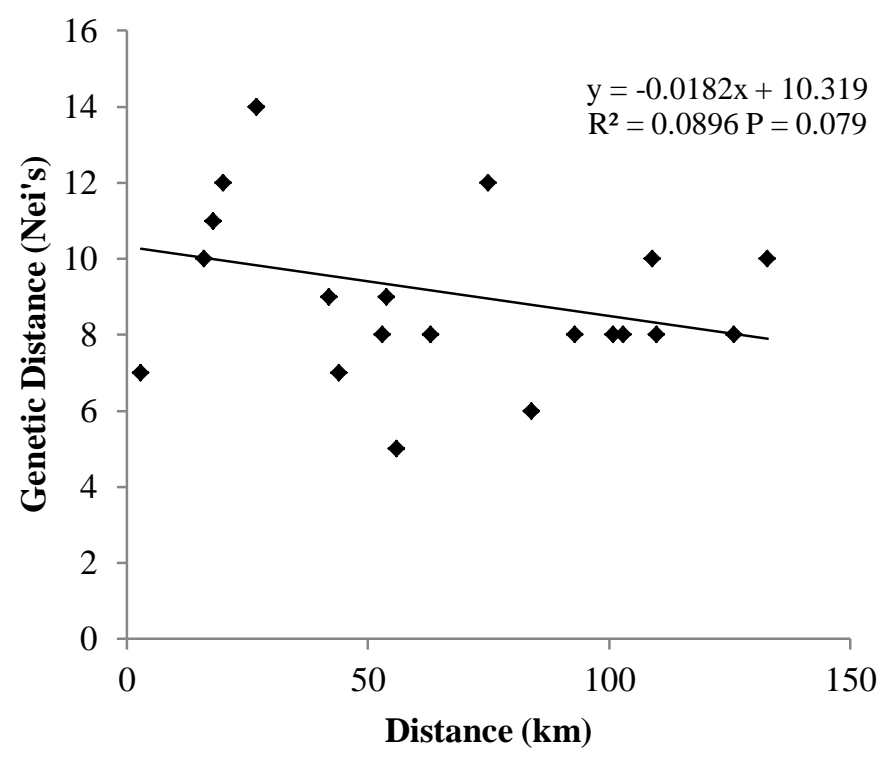

Figure 4.5 Genetic isolation by distance of seven Prolasius advenus populations. A Mantel test of genetic isolation by distance indicated no significant $(\mathrm{P}=0.079)$ relationship between genetic and geographic distance among seven $P$. advenus populations in Nothofagus beech forest in New Zealand's northern South Island. 


\subsection{Discussion}

In this study I examined the genetic structure of the small brown bush ant $P$. advenus within and among seven New Zealand South Island beech forest populations experiencing differing levels of invasive wasp infestation. I also tested the hypothesis that increasing wasp density would be associated with a genetic bottleneck. The results from analysing six microsatellite loci suggested limited dispersal and population substructure at all sites, which is consistent with observations made of other polygynous ant species. I found evidence of genetic bottleneck in the populations where predatory wasps were most abundant. Analysis of the among population structure indicated that the seven populations sampled were broadly derived from two distinct groups distributed in the North East and South West of the study area.

\subsubsection{Within Population variation and the effects of wasps}

A significant heterozygote deficit was observed in all seven of the P. advenus populations examined and it was particularly high at the Pad5 and Pad15 loci. The possibility that the observed heterozygote deficit is an artefact of null alleles cannot be entirely discounted; however a combination of limited dispersal, population substructure and non-random mating likely offers a more plausible explanation of these results.

Prolasius advenus colonies are polygynous (Smith, 1969 and Don, 2007) with as many as 81 dealate queens observed in a single nest (pers. obs.). Several studies have reported heterozygote deficiency similar to those observed here in other polygynous ant species (Chapuisat et al., 1997; Pamilio et al., 1997; Chapuisat and Keller, 1999; Ross, 2001), which were attributed to population substructure resulting from limited dispersal. A high cost of dispersal resulting from predation of sexuals, competition or resource patchiness is thought to be a key factor driving polygyny in ants (Bourke and Franks, 1995) and it is common for alate queens produced by polygynous colonies to disperse only over short distances or to forgo dispersal altogether (Bourke and Franks, 1995; Pamilo et al., 1997; Peeters and Ito, 2001; Ruppell et al., 2001; Gyllenstrand and Seppa, 2003; Mäki-Petäys et al., 2005). Reducing dispersal distance reduces the risk of predation and increases the probability of successful colony foundation (Amor et al., 2011). Furthermore, newly mated queens are more likely to be accepted into an existing nest if 
they are related to existing colony members (Ross, 2001) and inbreeding has been reported in several species (Trontti et al.,2005; Schrempf et al.,2006). In combination, reduced dispersal and localized mating will reduce heterozygote frequency and result in genetic structuring among populations (Chapuisat et al., 2004). As alate queens have been demonstrated to form up to $25 \%$ of the V. vulgaris diet (Harris, 1991) and P. advenus is the most abundant ant species in Nothofagus beech forest (McColl, 1975 and Chapter 5) it is likely that all seven of the populations examined in this study experience some level of predation of dispersing sexuals dependent on the density of invasive wasps. In addition, the wasps display significant dietary overlap with $P$. advenus (Duthie, 2011) and have been shown to compete with them directly for food resources (Grangier and Lester, 2011), which may further promote reduced colony dispersion (Levins and Traniello, 1987 and Chapter 5). Viewed in combination with the observed linkage disequilibrium and comparatively high inbreeding coefficients, it is likely that the heterozygote deficit is in some part the product of limited dispersal and subsequent population substructure in $P$. advenus mediated by a combination of predation and competitive pressure exerted by $V$. vulgaris.

Intra-nest relatedness was variable among populations. The assignment of only $31 \%$ of individuals to the nest they were collected from at Lake Rotoiti is consistent with poorly defined nest boundaries (Chapuisat and Keller, 1997). Relaxed nest boundaries may be indicative of exchange of workers among nests. This is a facultative trait in some ant species that occupy multiple nests which may have arisen in response to high dispersal costs imposed by predation (Bourke and Franks, 1995; Debout et al., 2007). The trait, known as polydomy, is typified by aggregations of comparatively small nests at high density (Debout et al., 2007). Given the extremely high nest density, comparatively small nest size and lower inter-nest distances of $P$. advenus observed at Lake Rotoiti (Mean $\pm \mathrm{SE}=2400 \pm 180$ nests $\mathrm{Ha}^{-1}$ (Chapter 5)) in combination with the low assignment to nests observed in this chapter it is possible that $P$. advenus is polydomous in this area.

The low proportion of individuals assigned to the nests they were collected from suggests that within nest relatedness is low. While this is common among polygynous species (Rees et al., 2010) it appears at odds to the inbreeding and heterozygote deficit observed in this study. This 
result may reflect that sampling from each nest was insufficient to capture all of the diversity they contain particularly where the number of queens per nest is as high as 80. Alternatively, it is possible that alate queens assortively mate with closely related males in polygynous colonies to maximise their genetic contribution to the next generation. Such behaviour has been reported in the ant Plagiolepis pygmaea (Thurin and Aron, 2009). The species is polygynous and accepts only alate queens from the natal nest, which preferentially mate with closely related males. However, it is difficult to make any meaningful inferences without detailed knowledge of the $P$. advenus mating system, which has been difficult to obtain as the species does not appear to reproduce in captivity and attempts to open nests and mark individuals with the intention of measuring their movements among nests have consistently resulted in nests being abandoned (pers. obs.).

The results of this study indicate that $P$. advenus populations in localities where predatory wasps are highly abundant have experienced a reduction in effective population size that has resulted in a genetic bottleneck. The Rotoiti, Mt. Misery and Tiraumea populations, which have consistently had the highest infestation of wasps per hectare since their establishment (Beggs et al., 1998; Barlow et al., 2002; Figure 4.1), displayed significant evidence of a genetic bottleneck. Other causes of effective population decline, such as pathogens, climatic extremes or severe restriction of resources cannot be discounted as contributing to this result. However, I suggest that as peak abundance of wasps coincides with the nuptial flight of $P$. advenus (Toft and Rees, 1998; Don, 2007 ) and that winged ants comprise more than $25 \%$ of the wasps' diet (Harris, 1991) predation by wasps is the most probable cause of the reduction in effective population size. This is consistent with the findings of Gasc et al., (2010), who showed that predation by invasive rats resulted in a genetic bottleneck in a recipient native reptile population. The lack of correlation between decreased heterozygosity and allelic diversity and increasing wasp density observed in this study was surprising given these results. However, as a deficit in heterozygotes was observed in all populations in this study it is possible that population substructure mediated by limited dispersal may be masking the effect of the bottleneck. 


\subsubsection{Among population structure}

The seven $P$. advenus populations sampled appear to be derived from two genetically distinct groups. No single individual could be fully assigned to a single lineage suggesting either historical population admixture or divergence from a common ancestral population. The current distribution may be broadly divided into North Eastern and South Western populations. The North Eastern populations, which experience consistently lower levels of wasp infestation, display higher levels of differentiation than the South Western populations. This is the opposite of what would be expected if predation by wasps were reducing gene flow. It is possible that the observed pattern of differentiation in these areas is the product of habitat fragmentation. For example, the most highly differentiated population exists in Spooner's Range, a 7.2 $\mathrm{Ha}^{-1}$ forest remnant surrounded by recently introduced pine plantation. Similarly, the Pelorus Bridge site was designated a reserve in 1912 after the majority of the surrounding forest had been felled (DOC information sheet) and the Graham Valley site too is a beech remnant surrounded by pine forestry since the 1950s. Exotic plantation pine forest is unsuitable for colonisation by $P$. advenus and is potentially a barrier to dispersal. Such habitat modification has been observed as a barrier in other ant species. A study of the polygynous wood ant Formica aquilonia, reported a high level of subpopulation differentiation over comparatively short distances after habitat fragmentation (Mäki-Petäys et al., 2005). The authors suggested that habitat fragmentation in combination with social factors such as short distance dispersal and non acceptance of new queens from other nests, typical of polygynous species (Bourke and Franks, 1995, Meunier et al., 2011), resulted in sub-population differentiation.

The Graham Valley population also displayed significant evidence of a genetic bottleneck. As it is a site that consistently displays the lowest wasp density of those surveyed, this clearly cannot be attributed to predation by wasps. The P.advenus nest density of the other North Eastern populations (Pelorus and Spooner's) exceeded 560 nests per hectare (Chapter 5). Although a full survey was not conducted for Graham Valley, only four P. advenus nests were located along a 10 $\times 1000 \mathrm{~m}$ transect in 2008 (pers. obs.). Assuming this distribution is typical for the site that equates to 40 nests per hectare, which may reflect population isolation by habitat fragmentation. 
Although I cannot discount the influence of other environmental factors, such as pathogens or climatic change, which might result in a genetic bottleneck in P.advenus populations, I argue that predation by high densities of invasive wasps provides the most likely explanation for my results. An ongoing study would be needed to confirm this in order to examine whether genetic diversity continues to decline where wasps are most abundant. Furthermore, there may be synergistic effects of a reduction in effective population size by predation and a restriction of gene flow by habitat fragmentation that could only be detected by longer term study.

\subsubsection{Conclusions}

The $P$. advenus populations in this study displayed a significant heterozygote deficit. Such a deficit is common in polygynous ant species and may reflect life history traits such as limited dispersal, assortive mating or population substructure. I also presented evidence of low intra-nest relatedness in some P.advenus populations, suggesting relaxed nest boundaries. Clearly further study is needed to unravel the complexities of this species' breeding system and social structure before any conclusive inferences can be made about the influence of environmental factors on their population genetics. Nonetheless, my results also indicated that $P$. advenus populations in areas where predatory wasps are most abundant have undergone a significant reduction in effective population size. Such genetic bottlenecks may be caused by a broad range or combination of factors including predation, pathogens or habitat fragmentation. It seems likely that predation of dispersing queen ants by high population densities of wasps has contributed significantly to the reduced levels of genetic diversity observed in the south-western P.advenus populations in this study. Evidence of a genetic bottleneck was also found in one P. advenus population in the northeast where there were few wasps. This population inhabits an isolated forest fragment surrounded by exotic forestry, which likely presented a barrier to dispersal that contributed to the observed loss of genetic variation.

This study indicates that a combination of predation by exotic species and anthropogenic barriers to gene flow may reduce a native species' effective population size in a timeframe as short as twenty years. - particularly in isolated populations, or those where dispersal is limited. Reduction in genetic diversity has potentially serious fitness implications in ants and may reduce worker 
Chapter Four - Genetic Variation

efficiency, disease resistance, queen longevity and adaptive potential. These effects may not be immediately apparent as large effective population sizes serve as a buffer. 


\subsection{References}

Allendorf, F.W. and Luikart, G. (2007) Conservation and the genetics of populations. WileyBlackwell Publishing: 642pp

Amor, F., Ortega, P., Jowers, M.J., Cerdá, X., Billen, J., Lenoir, A. and Boulay, R.R. (2011) The evolution of worker-queen polymorphism in Cataglyphis ants: interplay between individual-and colony-level selections. Behavioural Ecology and Sociobiology 65: 1473-1482

Alto, B.W. (2011) Interspecific Larval Competition between Invasive Aedes japonicas and Native Aedes triseriatus (Diptera: Culicidae) and Adult Longevity. Journal of Medical Entomology 48(2): 232-242

Barlow, N.D., Beggs, J.R. and Barron, M.C. (2002) Dynamics of common wasps in New Zealand beech forests: a model of density dependence and weather. The Journal of Animal Ecology 71(4): 663-671

Beggs, J.R., Toft, R.J., Malham, J.P., Rees, J.S., Tilley, J.A.V., Moller, H. and Alspach, P. (1998) The difficulty of reducing introduced wasp (Vespula vulgaris) populations for conservation gains. New Zealand Journal of Ecology 22(1): 55-63

Boomsma, J.J. and Isaaks, J.A. (1985) Energy investment and respiration in queens and males of Lasius niger (Hymenoptera: Formicidae). Behavioural Ecology and Sociobiology 18: 19-27

Bourke, A. F. G. and Franks, N. R. (1995) Social evolution in ants. Princeton University Press, Princeton, New Jersey: 529pp

Bronnenhuber, J.E., Dufour, B.A., Higgs, D.M. and Heath, D.D. (2011) Dispersal strategies, secondary range expansion and invasion genetics of the non-indigenous round goby, Neogobius melanostomus, in Great Lakes tributaries. Molecular Ecology 20: 1845-1859

Chapuisat, M., Goudet, J. and Keller, L. (1997) Microsatellites reveal high population viscosity and limited dispersal in the ant Formica paralugubris. Evolution 51(2): 475-482

Chapuisat, M. and Keller, L. (1999) Extended family structure in the ant Formica paralugubris: the role of the breeding system. Behavioural Biology and Sociobiology 46(6): 405-412

Chapuisat, M., Bocherens, S. and Rosset, H. (2004) Variable queen number in ant colonies: no impact on queen turnover, inbreeding, and population genetic differentiation in the ant Formica selysi. Evolution 58(5): 1064-1072

Cornuet, J.M. and Luikart, G. (1996) Description and power analysis of two tests for detecting recent population bottlenecks from allele frequency data.Genetics 144: 2001-2014

Crawford, N.G. (2010) SMOGD: software for the measurement of genetic diversity. Molecular Ecology Resources 10: 556-557 
Davis, M.A. (2003) Biotic globalization: does competition from introduced species threaten biodiversity? Bioscience 53(5): 481-489

Di Rienzo, A., Peterson A.C., Garza, J.C., Valdes, A.M., Slatkin, M. and Friemer, N.B. (1994) mutational processes of simple-sequence repeat loci in human-populations. Proceedings of the National Academy of Sciences of the United States of America 91(8): 3166-3170

Don, W. (2007) Ants of New Zealand. Otago University Press, Dunedin, New Zealand: 239pp

Duthie, C. (2011) Factors promoting coexistence between endemic ants and invasive wasps. Unpublished PhD thesis. Victoria University Wellington.

Evanno, G., Regnaut S. and Goudet, J. (2005) Detecting the number of clusters of individuals using the software STRUCTURE: a simulation study. Molecular Ecology 14: 2611-2620

Gasc, A., Duryea, M.C., Cox, R.M., Kern, A. And Calsbeek, R. (2010) Invasive predators deplete genetic diversity of island lizards. PloS One 5(8): 1-4

Grangier, J. and Lester, P.J. (2011) A novel interference behaviour: invasive wasps remove ants from resources and drop them from a height. Biology Letters 7(5): 664-667

Gyllenstrand, N. and Seppa, P. (2003) Conservation genetics of the wood ant, Formica lugubris, in a fragmented landscape. Molecular Ecology 12: 2931-2940

Harris, R. (1991) Diet of the wasps Vespula vulgaris and V. germanica in honeydew beech forest of the South Island, New Zealand. New Zealand Journal of Zoology 18: 159-169

Harris, R. J. and Oliver, E. H. (1993) Prey diets and population densities of the wasps Vespula vulgaris and V. germanica in scrubland-pasture. New Zealand Journal of Ecology 17(1): 5-12

Hölldobler, B. and Wilson, E.O. (1990) The Ants. Harvard University Press, Cambridge, MA:732pp

Jost, L. (2008) Gst and its relatives do not measure differentiation. Molecular Ecology 17: 40154026

Kalinowski, S. T. (2005) HP-RARE: a computer program for performing rarefaction on measures of allelic diversity. Molecular Ecology Notes 5: 187-189

Keller, L. and Passera, L. (1989) Size and fat content of gynes in relation to the mode of colony founding in ants. Oecologia 80: 236-240

Laikre, L., Palm, S. and Ryman, N. (2005) Genetic population structure of fishes: implications for coastal zone management Ambio 34(2): 111-119

Levins, S. and Traniello, J. E. A. (1981). Territoriality, nest dispersion, and community structure in ants. Psyche 88: 265-319 
MacDonald, D.W. and Harrington, L.A. (2003) The American mink: the triumph and tragedy of adaptaion out of context. New Zealand Journal of Zoology 30: 421-441

Mäki-Päys, H., Zakharov, A., Viljakainen, L., Corander, J. and Pamilo, P. (2005) Genetic changes associated to declining populations of Formica species in fragmented forest landscape. Molecular Ecology 14: 733-742

Martinez, T. and Wheeler, D.E. (1994) Storage proteins in adult ants (Camponotus festinatus): Roles in colony founding by queens and in larval rearing by workers. Journal of Insect Physiology 40(8): 723-729

McColl, H.P. (1975) The invertebrate fauna of the litter surface of a Nothofagus truncata forest floor, and the effect of microclimate on activity. New Zealand Journal of Ecology 2: 15-34 McNatty A, Abbott, K.L. and Lester, P.J. (2009) Invasive ants compete with and modify the trophic ecology of hermit crabs on tropical islands. Oecologia 160: 187-194

Meunier, J., Reber, A. and Chapuisat, M. (2011) Queen acceptance in a socially polymorphic ant. Animal Behavior 81: 163-168

Nei, M., Maruyama, T. and Chakraborty, R. (1975) The bottleneck effect and genetic variability in populations. Evolution 29(1): 1-10

Noordijk, J., Morrsinkhof, R., Boer, P., Schaffers, A.P., Heijerman, T.H. and Sýkora, K.V. (2008). How ants find each other; temporal and spatial patterns in nuptial flights. Insectes Sociaux 56: 266-273

Pamilo, P., Gertsch, P., Thoren, P. and Seppa, P. (1997) Molecular population genetics of social insects. Annual Review of Ecological Systematics 28: 1-25

Passera, L. and Keller, L. (1990) Loss of mating flight and shift in the pattern of carbohydrate storage in sexuals of ants (Hymenoptera: Formicidae). Journal of Comparative Physiology B 160: 207-211

Patankar, R., von Hippel, F.A. and Bell, M.A. (2006) Extinction of a weakly armoured threespine stickleback (Gasterosteus aculeatus) population in Prator Lake, Alaska. Ecology of Freshwater Fish 15: 482-487

PASW 18.0.0 (2010) SPSS Inc., Chicago.

Pawson, S.M., McCarthy, J.K., Ledgard, N.J. and Didham, R.K. (2010) Density dependent impacts of exotic conifer invasion on grassland invertebrate assemblages. Journal of Applied Ecology 47: 1053-1062

Peakall, R. and Smouse, P. E. (2006) GenAlEx 6: Genetic analysis in Excel. Population genetic software for teaching and research. Molecular Ecology Notes 6: 288-295.

Peeters, C. and Ito, F. (2001) Colony dispersal and evolution of the queen morphology in social Hymenoptera. Annual Review of Entomology 46: 601-630 
Pritchard, J. K., Stephens, M. and Donnelly, P. (2000) Inference of population structure using multilocus genotype data. Genetics 155: 945-959

Raymond, M. and Rousset, F. ( 1995) GENEPOP (version 1.2): population genetics software for exact tests and ecumenicism. Journal of Heredity 86: 248-249

Rees, S.D., Orledge, G.M., Bruford, M.W. and Bourke, A.F.G. (2010) Genetic structure of the black bog ant (Formica picea Nylander) in the United Kingdom. Conservation Genetics 11: 823834

Rice, A.M. and Pfennig, D.W. (2010) Does character displacement initiate speciation? Evidence of reduced gene flow between populations experiencing divergent selection. Journal of Evolutionary Biology 23: 854-865

Ross, K.G. (2001) Molecular ecology of social behaviour: analyses of breeding systems and genetic structure. Molecular Ecology 10: 265-284

Rüppell, O., Heinze, J. and Hölldobler, B. (2001) Complex determination of queen body size in the queen size dimorphic ant Leptothorax ruatulus (Formicidae: Hymenoptera). Heredity 87: 33 40

Sagoff, M. (2005) Do non-native species threaten the natural environment? Journal of Agricultural and Environmental Ethics 18: 215-236

Salo, P., Korpimäki, E., Banks, P.B., Nordström, M. and Dickman, C.R. (2007) Alien predators are more dangerous than native predators to prey populations. Proceedings of the Royal Society B: Biological Sciences 274: 1237-1243

Schuelke, M. (2000) An economic method for the fluorescent labeling of PCR fragments. Nature 18: 233-234

Schrempf, A., Aron, S. and Heinze, J. (2006) Sex determination and inbreeding depression in an ant with regular sib-mating. Heredity $97:$ 75-80

Sepp, R., Szabó, I., Uda, H. and Sakamoto,H. (1994) Rapid techniques for DNA extraction from routinely processed archival tissue for use in PCR. Journal of Clinical Pathology 47: 318-323.

Shoemaker, D.D., Deheer, C.J., Krieger, M.J.B. and Ross, K.G (2006) Population genetics of the invasive fire ant Solenopsis invicta (Hymenoptera: Formicidae) in the United States. Annals of the Entomological Society of America 99(6): 1213-1233

Smith, C.E. (1969) A morphological and behavioural study of the ants Amblyopone saundersi Forel and Prolasius advena Fr. Smith (Hymenoptera: Formicidae). Unpublished BSc(Hons) thesis, University of Otago, Dunedin

Smith, W.W. (1896) On the habits of New Zealand ants. Transactions and Proceedings of the New Zealand Institute 29: 468-479 
Sunamura, E., Hoshizaki , S., Sakamoto, H., Fujii, T., Nishisue, K., Suzuki, S., Terayama, M., Ishikawa, Y., and Tatsuki, S. (2011) Workers select mates for queens: a possible mechanism of gene flow restriction between supercolonies of the invasive Argentine ant. Naturwissenschaften 98: $361-368$

Thomas, C.D., Moller, H., Plunkett, G.M. and Harris, R.J. (1990) The prevalence of introduced Vespula vulgaris wasps in a New Zealand beech forest community. New Zealand Journal of Ecology.13: 63-72

Thurin, N. and Aron, S. (2009) Sib-mating in the ant Plagiolepis pygmaea; adaptive inbreeding? Journal of Evolutionary Biology 22: 2481-2487

Toft, R.J. and Beggs, J.R. (1995) Seasonality of crane flies (Diptera: Tipulidae) in South Island beech forest in relation to the abundance of Vespula wasps (Hymenoptera: Vespidae). New Zealand Entomologist 18: 37-43.

Toft, R.J. and Rees, J. (1998) Reducing predation of orb-web spiders by controlling common wasps (Vespula vulgaris) in a New Zealand beech forest. Ecological Entomology 23: 90-95

Trontti K., Aron, S. and Sundstöm, L. (2005) Inbreeding and kinship in the ant Plagiolepis pygmaea. Molecular Ecology14: 2007-2015

Van Oosterhout, C., Hutchinson, W.F., Wills, D.P.M. and Shipley, P. (2004) Micro-Checker: software for identifying and correcting genotyping errors in microsatellite data. Molecular Ecology Notes 4(3): 55-538 
Chapter Five

Nest size, spatial distribution and density of

the New Zealand endemic ant Prolasius

advenus (Fr. Smith) in the presence of

varying densities of the invasive wasp

Vespula vulgaris (L.) 


\subsection{Abstract}

Invasive species may exert a density dependent influence on the population density, abundance and spatial distribution of recipient taxa by means of competition and predation. Predation and competition can have opposing effects on spatial distribution; competitive interactions can result in overdispersed distribution, whereas in some prey species individuals aggregate to reduce the probability of predation. Environmental factors, such as resource availability and habitat heterogeneity further influence distribution and may either exacerbate or reduce the detrimental effects of competition.

In the Nothofagus beech forests of New Zealand's northern South Island, insect honeydew is a keystone resource. The invasive common wasp Vespula vulgaris is highly abundant in these forests and has been estimated to reduce the standing crop of honeydew by more than $90 \%$ and is also a voracious predator of many insect orders. There the wasp is a significant competitor to the endemic bush ant Prolasius advenus for both honeydew and prey resources. To test the hypotheses that $P$. advenus nests would be smaller, less densely distributed and spatially structured in the presence of high densities of wasps I measured the density, size and spatial distribution of $P$. advenus nests at sites of high and low wasp nest density. I also calculated an index of plant diversity and estimated the abundance of honeydew to examine their effects on $P$. advenus nest distribution.

Prolasius advenus nest density was greatest where there were most wasps. However, nests tended to be smaller and varied less in size in the presence of high densities of wasps. As nest size in ants is often strongly correlated with nest age I suggest this result reflects a reduction in the longevity of nests where wasps are most abundant. Ant nests were overdispersed where wasp and $P$. advenus nests were at high density. This overdispersed distribution may serve to reduce intra- and inter-specific competition. Prolasius advenus nest density was also found to be significantly lower where plant diversity was greatest and honeydew was least abundant indicating that in addition to competitive interactions habitat variation and resource availability interact to affect $P$. advenus density and distribution. 


\subsection{Introduction}

Invasive species shape patterns of native species distribution and abundance by means of competition and predation (Human and Gordon, 1999; Rowles and O'Dowd, 2007). The degree of influence an invasive organism has on distribution of recipient taxa may be dependent on the density of both the invasive and native species (McNatty et al., 2009 and Mercada et al., 2011). For example, abundance of the European eel Anguilla anguilla was significantly reduced with increasing density of the invasive catfish Silurus glanis. The catfish both preys on the eel and competes with it for food and space and it is a combination of these factors that contributes to the eels' decline (Bevacqua et al., 2011). However, where S. glanis was less abundant the population density of $A$. anguilla increased to a point where intraspecific competition for space restricted the species' abundance. The effect of competition and predation on spatial distribution may be reflected in opposing ways: competition can result in a regular distribution where individuals are distributed as far from one another as space will allow (Davies, 1978; Levins and Traniello, 1981; Johnson et al., 1987) whereas prey animals often aggregate to minimise the individual's risk of predation (Hamilton, 1971; Scharf et al., 2011; Tosh, 2011).

The spatial distribution of individuals in a given area may be broadly classified as aggregated, random or overdispersed using nearest neighbour measurements (Clark and Evans, 1954). Based on the assumption of random distribution within a given area, the ratio of the observed and expected distance between nearest neighbours can be used to classify distribution by producing a scoring scale between 0 and 2.149. A score of zero indicates complete aggregation; a score of 1 is indicative of random distribution and scores greater than 1 represent overdispersal. The maximum score of 2.149 indicates perfectly regular spacing, or overdispersion, where each individual (or nest) is as far from the next as is possible within a known area (Davies, 1978). The spatial distribution of ant nests may be affected by intra- and inter-specific competition (Traniello and Levins, 1986), predation (Bourke and Franks, 1995 and Debout et al., 2007), site quality (Cushman, 1988) and resource distribution (Pfeiffer and Linsenmair, 1998).

Levins and Traniello (1981) describe a conceptual framework for two or more competing ant species, which predicts the spatial distribution of nests based on the relative strength of intra- and inter-species interactions. Where there is an overlap in two species' resource use and foraging radii, the effect of intra- and interspecific competitive interactions on spatial distribution will be 
equally strong. This will hypothetically result in a distribution where the species identity of a nest's nearest neighbour is random, but the distribution of all nests in the array is overdispersed. By contrast, where two species' foraging radii overlap, but their resource use does not, intraspecific interactions will be stronger than interspecific interactions. This process will result in overdispersion of the whole array; however, it is more likely that nearest neighbours will be heterospecific than conspecific. Overdispersal of nests can reduce forager overlap and minimise direct competitive interactions among neighbours, particularly at high density (Davies, 1978).

The foraging radius of an ant nest is strongly correlated with its size, as demonstrated by an experimental study of the green head ant Rhytidoponera metallica which was found to significantly increase its foraging radius with increasing colony size (Thomas and Framenau, 2005). Nest size typically increases with nest age (Hölldobler and Wilson, 1990). For example, studies of Pogonomyrmex barbatus found that colonies increase in size with time until, at five years, they reach a stable size of approximately 10,000 individuals and begin production of alate queens (Gordon, 1992; Gordon and Wagner, 1997). Smaller nests are less likely to overlap their foraging range with their nearest neighbour than larger nests. A study of the spatial distribution of $P$. barbatus nests found that a one year old colony is most likely to establish in an area where its nearest neighbours are no more than two to three years old, because younger colonies are smaller and therefore have a smaller foraging radius, which reduces the probability of conflict because of forager overlap (Gordon and Kulig, 1996). Ant populations should be comprised of nests of varying sizes reflecting the life history of the colonies from initial formation to maturity and senescence.

Predation can affect the distribution of species. A high cost of dispersal resulting from predation of sexual individuals during their nuptial flight has been suggested to result in aggregation in ants at two scales: firstly, the accumulation of multiple queens per nest known as polygyny and secondly the aggregation of interconnected nests known as polydomy. Polydomous colonies are defined as those where workers and brood occupy two or more nests and where there is regular exchange of workers (Debout et al., 2007). Typically, polydomous colonies display reduced nest size and an aggregated nest distribution with shorter inter-nest distances than is found among monodomous nests (Debout et al., 2007). Both strategies are believed to increase the probability 
of successful colony foundation and reduce the risk of predation of sexuals where dispersal costs are high (Keller, 1995; Bourke and Franks; 1995; Debout et al., 2007).

Resource distribution also affects spatial distribution of colonies (Levins and Traniello, 1987). Central place foraging theory describes the costs incurred by animals that do not consume what they gather where it is acquired, but instead venture from and carry resources back to a central point where it is either eaten or fed to dependent young (Orians and Pearson, 1979; Schoener, 1979). Ants are generally regarded as central place foragers and incur both increasing risk and energetic cost with increasing distance between their nest and resources (Hölldobler and Lumsden, 1980). However, the use of space to maximise foraging efficiency is dependent on the stability and distribution of the resources themselves (Hölldobler and Lumsden, 1980). Protein resources, collected in the form of prey or carrion are ephemeral, therefore, it is not possible to position a nest in such a way as to maximise their exploitation as they require prompt recruitment rather than defence (Hölldobler and Lumsden, 1980). By contrast, resources such as vegetation infested with honeydew producing scale insects represent a stable resource that may be defended (Hölldobler and Lumsden, 1980). For example, Lasius fulginosus has been described recruiting en masse to ephemeral protein resources, but forming permanent trails to stable carbohydrates (honeydew). Foragers were found to be more likely to use honeydew patches that were close to the nest, except when supply was restricted when they tended to increase their foraging radius. (Quinet et al., 1997).

Honeydew is a keystone carbohydrate resource in the Nothofagus beech forests of New Zealand's northern South Island (Morales, 1988 and Grant and Beggs, 1989, Beggs and Wardle, 2005). Indeed, it has been suggested that there are no comparable alternative carbohydrate sources in southern beech forest (Moller et al., 1991). Southern Beech honeydew is the waste product of larval instars of the sooty beech scale insect Ultracoelostoma assimile (Maskell), which infest the trunks and branches of the Nothofagus beech species Nothofagus fusca, N.truncata, N. solandri var solandri and N.solandri var. cliffortioides, (but seldom N.menziesii) that dominate the forests (Beggs, 2001). Honeydew production is not homogeneous within each infested tree; the greatest infestation of scale occurs on the underside of branches in the canopy (Wardaugh et al., 2006). This makes it difficult to quantify, however, the biomass of sooty beech mould (Capnodium, Tricopeltheca and Capnocybe spp), which grows where honeydew falls, has 
been demonstrated to be an accurate proxy to estimate honeydew productivity (Wardaugh et al., 2006).

The New Zealand endemic small brown bush ant Prolasius advenus (Fr. Smith) is a generalist forager that feeds on honeydew and hunts macro-invertebrate prey (Duthie, 2011 and Chapter 3). It is the most abundant ant species in Nothofagus forest (McColl, 1975) and nests in the soil under stones and within or beneath rotten logs (Don, 2007). Its nests are generally between 300 and $600 \mathrm{~mm}$ in diameter, vertically stratified with multiple galleries and rarely extend deeper than $180 \mathrm{~mm}$ (pers. obs.). Despite its abundance, P. advenus features little in the literature and there have been no published studies to date of the spatial distribution of its nests. The only available description of nest size is based on a single nest collected by Smith (1969), which contained approximately 500 workers and twelve queens.

The Nothofagus beech forests inhabited by P. advenus have become heavily infested with the invasive common wasp Vespula vulgaris (L.). The common wasp constructs its nests from rotten wood, which it pulps to build paper-like structures that are either suspended from branches or secreted in pre-existing holes in the ground (Andrewes, 1969). A study of $V$. vulgaris nest sites conducted in 23 New Zealand South Island Nothofagus beech forest sites found that the majority (95.9\%) of nests were situated in the ground (Donovan et al., 1992). The floor of the beech forest provides an ideal habitat for wasps to nest as beech roots create a hollow lattice, which is often overgrown with moss or covered with fallen branches and leaf litter. In addition many sites are populated by the crown fern Blechnum discolour, the rhizomes of which create cavities ideal for wasps to construct their nests in (pers. obs.).

The common wasp in this region has consistently attained some of the highest population densities on record for the species since its establishment in the late 1980s (Barlow et al., 2002). Its abundance has been attributed to the high availability of honeydew (Barlow et al., 2002) and it has been estimated that $V$. vulgaris reduces the standing crop of honeydew by approximately $90 \%$ in the five months when the wasp is most active (Beggs et al., 1998). The wasp's consumption of the resource makes it a significant competitor for native bird (Moller and Tilley, 1989; Moller et al., 1991; Beggs and Wilson, 1991) and insect (Moller and Tilley, 1989) species. The wasp is also a predator of many invertebrate orders (Harris, 1991; Harris and Oliver, 1993; 
Toft and Beggs, 1995) and as such competes with insectivorous birds (Moller and Tilley, 1989) and predatory invertebrates (Thomas et al., 1990).

The common wasp displays considerable dietary overlap with P. advenus (Duthie, 2011), and exerts significant interference competitive pressure for protein resources (Grangier and Lester, 2011). The wasps' level of consumption of carbohydrate (Moller and Tilley, 1989; Moller et al., 1991; Beggs and Wilson, 1991) and protein (Harris, 1991; Harris and Oliver, 1993; Toft and Beggs, 1995) resources clearly make it an exploitive competitor also. In addition, $V$. vulgaris is a significant predator of $P$. advenus queens, which may comprise more than $25 \%$ of its diet when rearing brood (Harris, 1991), potentially imposing a high cost of dispersal for the ants where it is at high abundance.

Invasive species may alter the distribution and abundance of native species by means of competition and predation. The invasive wasp V. vulgaris is both a significant competitor for carbohydrate and protein resources to the endemic ant $P$. advenus as well as a predator of its dispersing queens. Here I tested two hypotheses. Firstly, that $P$. advenus nest densities are lower and that nests within a population are smaller and vary less in size where wasps are most abundant compared to areas where there are fewer wasps. Secondly, I tested the hypothesis that the spatial distribution of $P$. advenus nests is non-random where wasps are abundant and random where there are fewer wasps. Because factors such as resource availability and habitat heterogeneity can also shape distribution I used sooty mould biomass as a proxy to estimate honeydew availability and measured habitat diversity to examine the effects of resource availability and habitat variation on nest density, distribution and size in P. advenus. 


\subsection{Methods}

\subsubsection{Study sites}

Study sites for the current study were chosen based on the availability of historical wasp density data for Nothofagus forests in New Zealand's northern South Island that was collected annually between 1988 and 2010 by Landcare Research Nelson (for detailed methods see: Beggs et al., 1998; Barlow et al., 2002). The data collected provide a historical record of wasp densities and delineate sites of consistently higher and consistently lower levels of wasp infestation (see Beggs et al., 1998 and Barlow et al., 2002). Of these sites surveyed for wasp density four were chosen based on a combination of accessibility and continuity of data comprising two consistently low wasp density sites: Pelorus Bridge ( $\left.41^{\circ} 18^{\prime} \mathrm{S}, 173^{\circ} 34^{\prime} \mathrm{E}\right)$ and Spooner's Range $\left(41^{\circ} 27^{\prime} \mathrm{S}, 172^{\circ}\right.$ $\left.55^{\prime} \mathrm{E}\right)$, and two consistently high wasp density sites: Mt. Misery ( $\left.41^{\circ} 54^{\prime} \mathrm{S}, 172^{\circ} 39^{\prime} \mathrm{E}\right)$ and Lake

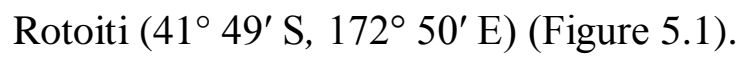

Lake Rotoiti offers an additional opportunity to assess the effect of wasps on $P$. advenus nest density, distribution and size as it has been the subject of an ongoing wasp control program by the St. Arnaud office of The Department of Conservation since 2000. The poisoning programme typically reduces wasp numbers by approximately 70\% (Duthie, 2011). This effectively allows the site to be subdivided for the purpose of a direct comparison of nest density, size and distribution when wasp numbers have been reduced (hereafter Rotoiti wasps removed $41^{\circ} 48^{\prime} \mathrm{S}$, $172^{\circ} 50^{\prime} \mathrm{E}$ ) and where wasp densities remain at the surveyed level (hereafter Rotoiti wasps maintained $\left.41^{\circ} 49^{\prime} \mathrm{S}, 172^{\circ} 50^{\prime} \mathrm{E}\right)$.

\subsubsection{Nest density}

To measure $P$. advenus nest density, ten $10 \times 10$ metre quadrats were haphazardly placed at each of the five study sites. The quadrats were separated by not less than 30 metres to accommodate as much heterogeneity in the habitat as possible. The corners of each quadrat were marked and it was subdivided into ten $1 \mathrm{~m} \times 10 \mathrm{~m}$ lanes. Each lane was then searched for ant and wasp nests in $1 \mathrm{~m} \times 1 \mathrm{~m}$ square increments. Ant nests were counted only when they contained either queens or brood and the presence was recorded on a $10 \times 10$ grid. Wasp nests were not opened, but were identified based on worker traffic and observation of the nest opening. Previous excavations of $P$. advenus nests indicated they could reach a diameter of approximately $600 \mathrm{~mm}$ and may contain 
more than one brood chamber at the soil surface (pers. obs.). In an attempt to avoid over estimating nest densities, where two chambers containing brood and or queens were found in a single square they were counted as one nest. Heterospecific nests encountered in a single square were counted individually. The total number of squares occupied by $P$. advenus nests and the total number of squares occupied by all species was then calculated for each quadrat. The dataset was assessed for normality and homoscedasticity. The results of a Levene's Test of Equality of Error Variances indicated a significant $(\mathrm{P}<0.001)$ deviation from the null hypothesis of equal variance across groups. For this reason data were analysed using a non-parametric KruskalWallis test with nest density (nests $100 \mathrm{~m}^{2}$ ) as the dependent variable and site as the grouping variable. Pairwise comparisons of median nest densities were made using a post-hoc Dunn's multiple comparison test using GraphPad InStat v. 3.10 statistical software (GraphPad Software inc., 2009).

\subsubsection{Nest distribution and distance to nearest neighbour}

To assess the spatial distribution of $P$. advenus nests the index "R" (Clark and Evans, 1954) was calculated based on the distance to each nest's nearest conspecific neighbour. Spatial distribution of all nests in the array was recalculated based on the distance to each nest's nearest neighbour irrespective of species. Because nests were recorded as present or absent from each square as opposed to the precise relative position of each nest in each square, nearest neighbour estimates were calculated from the centre of an occupied square to the centre of its nearest occupied neighbouring square. The result of this measurement is that the minimum recorded distance between conspecific nests is one metre. Where two species occupied a single square it was assumed that the inter-nest distance was $0.5 \mathrm{~m}$. To assess whether the observed nest distribution deviated from the assumption of randomness the statistic C (Clarke and Evans, 1954) was calculated as:

$$
C=\frac{\tilde{r} E-\tilde{r} A}{\sigma \tilde{r} E}
$$

Where $\tilde{r} \mathrm{E}$ is the mean expected distance to the nearest neighbour within each quadrat, $\tilde{r} \mathrm{~A}$ is the mean observed distance to the nearest neighbour within each quadrat and $\sigma \tilde{r}_{\mathrm{E}}$ is the standard error of $\tilde{r}_{\mathrm{E}}$ calculated: 
Chapter Five - Spatial Distribution

$$
\frac{0.26136}{\sqrt{N} \rho}
$$

Where, $\mathrm{N}$ is the number of measurements taken in the observed sample and $\rho$ is the observed density expressed as the number of nests per unit area. Assumptions of normality and homosecedasticity were tested and confirmed and a one way ANOVA was used to test for differences in mean inter-nest distances and deviation from random distribution among sites. A post hoc Tukey test was also performed to assess pairwise differences in mean inter-nest distances and if there was a deviation from random distribution among sites using PASW 18.0.0 statistical software (SPSS Inc., 2010).

\subsubsection{Connectedness of nests}

To estimate foraging distance from the nest and to ascertain whether workers move between nests, ten nests were randomly chosen at each of the Rotoiti wasps removed, Rotoiti wasps maintained and Mt. Misery sites. The chosen nests were separated by a distance of at least twenty metres. Their location was then marked with flagging tape as was the location of their nearest neighbours. Each nest was then quickly opened, workers were extracted using a mouth aspirator and the nest was reclosed. The collected workers were transferred into a one litre plastic container with Fluon coated sides to prevent them from escaping. Fifty workers were then counted out of the container by mouth aspirator and the remaining workers were returned to the nest area. The sampled workers were then put back into the one litre box and marked with FAS fluorescent acrylic body paint, which had been thinned with water and was applied by flecking using a firm bristled toothbrush. The paint and application method had previously been tested on captive workers in the lab and was found to adhere well to the ants for a period greater than 48 hrs without apparently impairing their movement or behaviour. The painted workers were allowed to dry for five minutes and were returned to the nest.

After 24 hours the nests and their nearest neighbours were re-examined. All the nests from which workers had been collected were found to be abandoned, as were many of their nearest neighbours that had been opened. Of the nearest neighbours that were not abandoned few than ten workers were present and no brood or queens were evident. The leaf litter surrounding the marked nests was checked using a portable U.V torch. Despite repeated searching no marked 
workers were found. The outcome was the same at all three sites and the experiment was abandoned.

\subsubsection{Nest size}

To examine whether nest size varied among sites ten nests were randomly selected and collected in toto from each site. Each nest was removed with all soil and /or rotten wood and placed in one or more two litre plastic boxes with mesh covered lids. All galleries were followed and excavated and care was taken to ensure all nest occupants were collected until only a small number of workers remained.

The excavated nests were returned to the lab where as much substrate was removed from the box as possible. Care was taken not to remove any ants, dead or alive with the substrate. Three glass nesting tubes were placed in each box. Each tube was approximately one third filled with water then a cotton wool plug was inserted to prevent leakage and raise humidity within the tube. The tubes were then wrapped in tin foil to block light and a small aperture was left at one end to allow the ants to enter. However, the ants would not leave the remaining substrate in favour of the nesting tubes and after approximately three weeks of incrementally removing substrate the ants were removed by sieving. The ants were then placed in a clear plastic container with fluon coated sides that had been placed on a gridded surface, and were photographed. Larger nests were photographed in several instalments. The contents of all middens were separated from any detritus by floating in a warm salt water solution and were also photographed.

Because $P$. advenus workers were not evenly distributed across the gridded area it was not possible to make estimates of total nest size based on a subsample of gridded squares. Nor was it possible to use the particle counting software such as ImageJ 1.43 to count ants, partly because of the workers tendency to aggregate in groups of five or six particularly around queens, but mostly because the gridded surface the ants were photographed on impaired the program's ability to differentiate ants from the background and caused it to count large areas as a single individual. For these reasons ants were counted manually square by square.

A Levene's test of equality of error variances indicated the assumption of homoscedasticity was violated $(\mathrm{P}<0.001)$, despite attempts to transform the data. For this reason a non parametric Kruskal-Wallis analysis was conducted to assess variation in the median nest size among sites. A 
post-hoc Dunn's multiple comparison test was used to examine pairwise differences in the median nest size between sites. In addition, the coefficient of variation was calculated to assess variability in nest size among sites.

\subsubsection{Resource availability}

Because high abundance of $V$. vulgaris nests may be linked to the availability of honeydew (Barlow et al., 2002) and because honeydew is the dominant (and arguably only) source of carbohydrate available in southern beech forest (Moller et al., 1991), a honeydew index was calculated to assess the resource's availability to $P$. advenus at each site. To calculate this index, ten $10 \mathrm{~m} \times 10 \mathrm{~m}$ quadrats were haphazardly placed at each of the five study sites. As sooty beech mould (Capnodium, Tricopeltheca and Capnocybe spp.) biomass is a reliable predictor of honeydew production (Wardaugh et al., 2006), fungal biomass was measured using methods described by Wardaugh et al.(2006). This method was modified as follows: eight cylindrical core samples $\left(2 \mathrm{~cm}\right.$ diameter to a depth of $2 \mathrm{~cm}$ ) were taken at $45^{\circ}$ intervals approximately half way between the trunk and outer edge of the canopy of one infested beech tree per quadrat. The samples were returned to the lab and oven dried for 48 hours at $60^{\circ} \mathrm{C}$. Any non fungal material was then removed and each sample was weighed on a Mettler balance accurate to $10^{-4} \mathrm{gm}$. The mean honeydew production per tree was then estimated based on the weight per unit volume $\left(\mathrm{gm} / \mathrm{cm}^{3}\right)$ of sooty mould biomass. To estimate the total honeydew production per quadrat the percentage of sooty mould ground cover was estimated calculated based on the number of occupied $1 \mathrm{~m}^{2}$ squares covered in each $10 \mathrm{~m} \times 10 \mathrm{~m}$ quadrat. An index of inferred honeydew abundance was then calculated by multiplying the mean production per tree $\left(\mathrm{gm} / \mathrm{cm}^{3}\right)$ and the mean percentage of sooty mould ground cover per $100 \mathrm{~m}^{2}$.

\subsubsection{Habitat diversity}

To assess whether ants nest density, size and distribution is affected by plant community composition, ten $10 \times 10 \mathrm{~m}$ quadrats were haphazardly placed at each site and all canopy, understory and ground cover plants were identified to species. The percentage of open canopy was quantified using a densitometer. Four measures of canopy gaps were taken at $90^{\circ}$ intervals in each quadrat and the mean proportion of open canopy was calculated. Simpson's index of diversity 1-D was calculated for all quadrats and median species richness, evenness and diversity 
was calculated for all sites and compared using a Kruskal-Wallis test. Post hoc pairwise comparisons of plant diversity among sites were conducted using a Dunn's multiple interactions test using GraphPad InStat v. 3.10 statistical software (GraphPad Software inc., 2009).

\subsubsection{Correlation between nest density, size and distribution and habitat}

Pairwise correlations for all combinations between $P$. advenus nest density, $P$. advenus nest size, $P$. advenus nest distribution, $V$. vulgaris nest density, honeydew availability and plant species diversity were conducted using Spearman's rank correlation test using PASW 18.0.0 statistical software (SPSS Inc., 2010).

\subsection{Results}

\subsubsection{Species composition}

Ant species composition varied among sites. Prolasius advenus nests were found in every quadrat at all sites and were significantly more abundant than those of any other species. Lake Rotoiti had the greatest ant diversity comprised as it was of four species; P. advenus, Amblyopone saundersi, Huberia striata and H. brounii. Lake Rotoiti was the only site where $V$. vulgaris nests were found on the ground in any of the quadrats. Three ant species were found at Mt. Misery: P. advenus, $H$. striata and $H$. brounii. Two ant species were found in the quadrats at Pelorus Bridge $P$. advenus and Monomorium antarcticum. Spooner's Range also had two ant species present $P$. advenus and A. saundersi, the latter was represented by a single nest in one quadrat.

\subsubsection{Nest density}

Prolasius advenus nest density was greatest where wasps were most abundant. The mean $P$. advenus nest density was lowest at Spooner's Range (mean \pm S.E. $=5.6 \pm 1.02$ nests $100 \mathrm{~m}^{2}$ ) and greatest at the Lake Rotoiti wasps removed site (Mean \pm S.E. $=29.5 \pm 2.81$ nests $\left./ 100 \mathrm{~m}^{2}\right)$. If these results are extrapolated to nests $\mathrm{Ha}^{-1}$ densities they show that $P$. advenus nests at all sites outnumber $V$. vulgaris nests by a ratio of approximately 100:1. The results of the Kruskal-Wallis test indicated that median nest density varied significantly among sites $\chi^{2}(4, \mathrm{~N}=50)=36.64, \mathrm{P}$ $<0.001)$. The results of post-hoc Dunn's multiple comparison test indicated that the 


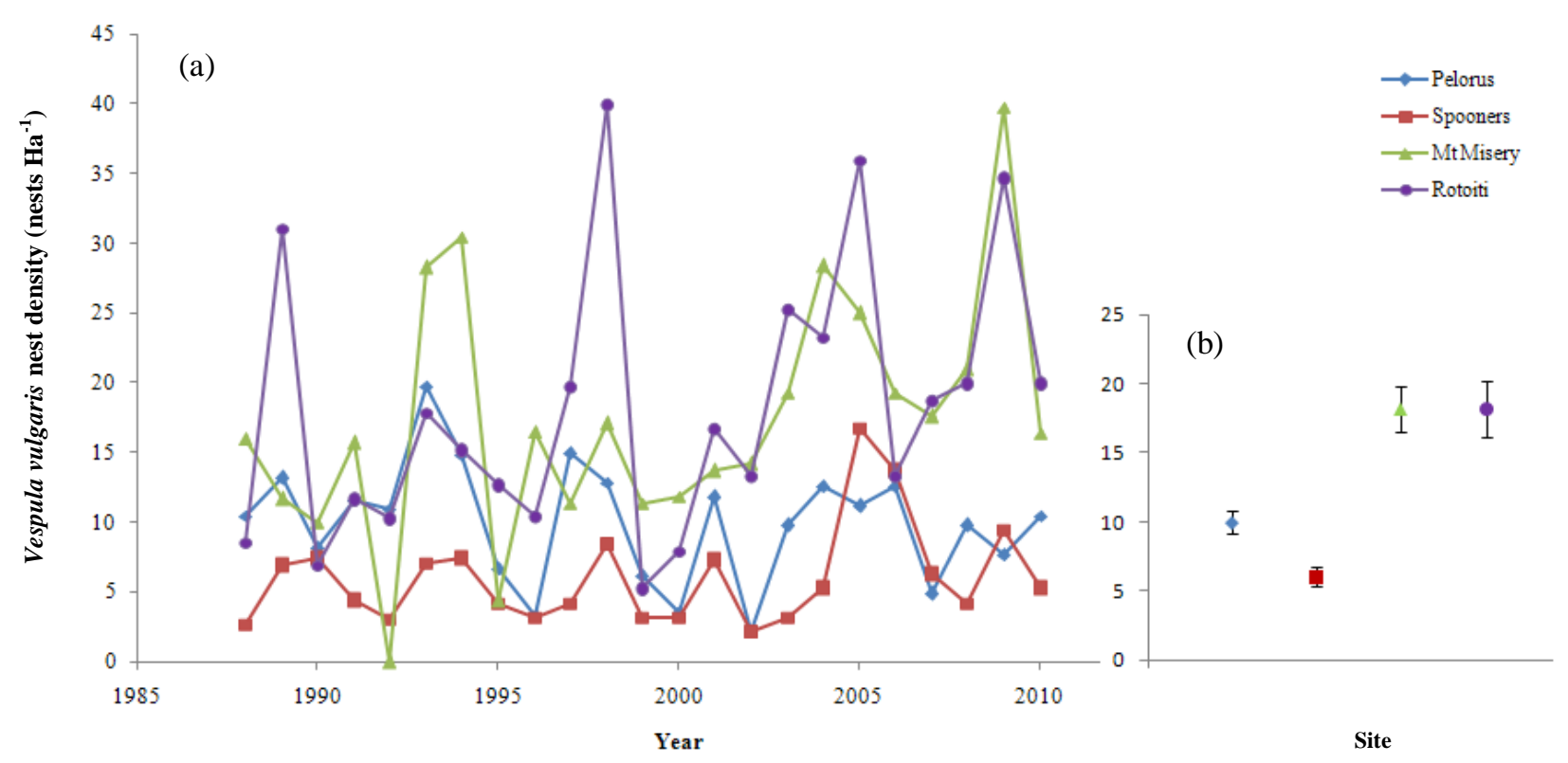

Figure 5. 1 Annual Vespula vulgaris nest density at four New Zealand South Island Nothofagus beech forest sites between 1988 and 2010(a) and. mean ( \pm S.E) density per site between 1988 and 2010(b).

median ant nest density at Lake Rotoiti wasps maintained was significantly greater $(\mathrm{P}<0.01)$ than at either of the low wasp density sites (Spooner's Range and Pelorus Bridge) (Figure 5.2). Similarly the median nest density at the other high wasp density site, Mt. Misery, was significantly greater $(\mathrm{P}<0.05)$ than either Pelorus Bridge or Spooner's Range. However, no significant difference $(\mathrm{P}>0.05)$ was found in the density of $P$. advenus nests between the Lake Rotoiti wasps maintained and wasp removed sites. No significant difference $(P>0.05)$ was observed between the two high wasp density sites (Lake Rotoiti wasps maintained and Mt. Misery) or between the two low wasp density sites Pelorus Bridge and Spooner's Range ( $\mathrm{P}>$ $0.05)$.

It is estimated that wasp poisoning reduces wasp density by approximately $70 \%$ (Duthie, 2011). At Lake Rotoiti the mean V. vulgaris nest density between 1988 and 2010 is 20 nests $\mathrm{Ha}^{-1}$. Based on the above estimate of poisoning efficiency this would suggest a mean wasp nest density of approximately 6 nests $\mathrm{Ha}^{-1}$, which is comparable to the lowest $V$. vulgaris nest density among the

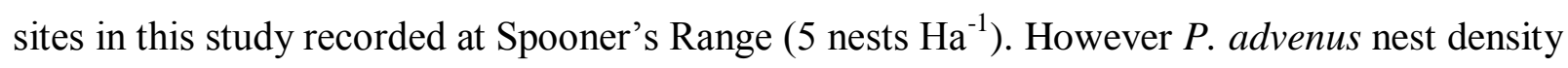


at the Lake Rotoiti wasps removed site was significantly $(\mathrm{P}<0.001)$ greater than either of the lower wasp density sites (Figure 5.2).

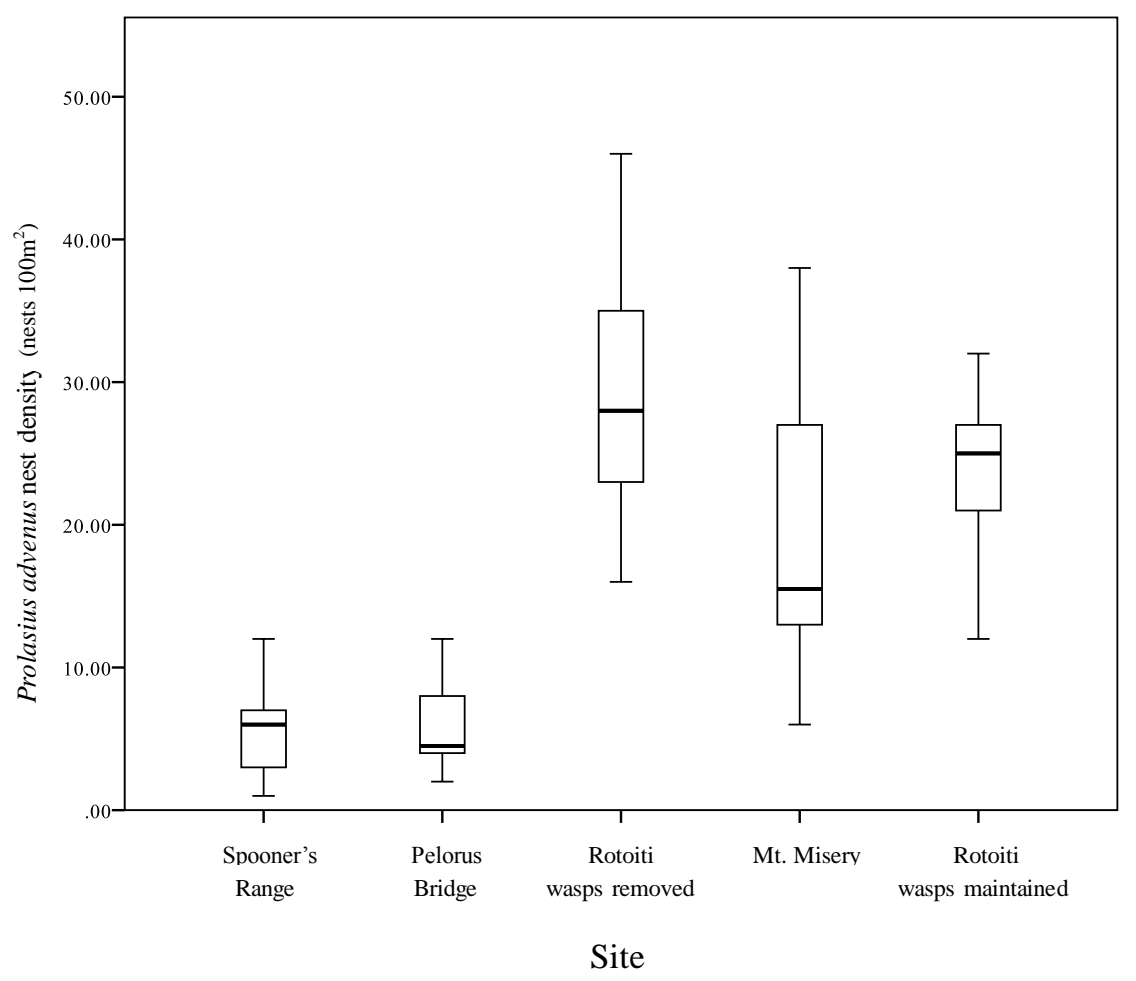

Figure 5.2 Prolasius advenus nest density distributions (nests $100 \mathrm{~m}^{2}$ ) in ten quadrats sampled at each of five New Zealand South Island Nothofagus beech forest sites arranged in order of increasing wasp nest density. Boxes represent the $25^{\text {th }}$ percentile, median and $75^{\text {th }}$ percentile. Whiskers represent sample minimum and maximum values per site.

\subsubsection{Nest distribution}

Based on the ratio of observed to expected nest distributions, $P$. advenus nests were found to be significantly $(\mathrm{P}<0.05)$ overdispersed at the Lake Rotoiti wasps maintained and wasps removed sites (Table 5.1). Four of the ten quadrats at Mt. Misery also showed significant overdispersal. At all of these sites, $P$. advenus nests were overdispersed relative to both their nearest conspecific and heterospecific neighbours suggesting the influence of intra- and inter-specific competition on nest distribution. The mean distance between nests and their nearest neighbours was smallest where wasps were most abundant, however wasp removal did not increase mean inter-nest 
Table 5.1 Nearest neighbour analysis of Prolasius advenus nest dispersion at five sites with varying wasp infestation. The value of $\mathrm{R}$ is the ratio of the observed and expected distance to nearest neighbouring nest. Values less than 1 indicate nest aggregation, values equal to 1 represent random nest distribution and numbers greater than 1 indicate over dispersal. Values of the $\mathrm{C}$ statistic, which tests the deviation of the observed inter-nest distance $\left(r_{O}\right)$ from the expected inter-nest distance $\left(r_{E}\right)$ under the assumption of randomness, are marked $* *$ are significant $(\mathrm{P}<0.001)$ and those marked NS do not differ significantly from the expected ratio.

\begin{tabular}{|c|c|c|c|c|c|c|c|}
\hline \multirow[t]{2}{*}{ Site } & \multirow{2}{*}{$\begin{array}{l}\text { Number } \\
\text { of nests }\end{array}$} & \multicolumn{2}{|c|}{$\begin{array}{c}\text { Distance to nearest } \\
\text { neighbour }(\mathrm{m})\end{array}$} & \multirow{2}{*}{$\begin{array}{l}\text { Mean } \\
r_{o}(\mathrm{~m})\end{array}$} & \multirow{2}{*}{$\begin{array}{l}\text { Mean } \\
r_{E}(\mathrm{~m})\end{array}$} & \multirow[t]{2}{*}{$\mathrm{R}$} & \multirow[t]{2}{*}{$\mathrm{C}$} \\
\hline & & Low & High & & & & \\
\hline $\begin{array}{l}\text { Rotoiti Wasps } \\
\text { Maintained }\end{array}$ & 225 & 1 & 3.6 & 1.353 & 0.999 & 1.213 & $2.233 * *$ \\
\hline $\begin{array}{l}\text { Rotoiti Wasps } \\
\text { Removed }\end{array}$ & 281 & 1 & 3.2 & 1.368 & 0.996 & 1.350 & $3.684 * *$ \\
\hline Pelorus Bridge & 66 & 1 & 8.0 & 2.065 & 0.965 & 1.143 & $0.067 \mathrm{NS}$ \\
\hline Spooner's Range & 64 & 1 & 10.6 & 3.469 & 0.547 & 1.294 & $0.920 \mathrm{NS}$ \\
\hline Mt. Misery & 204 & 1 & 3.6 & 1.315 & 1.000 & 1.136 & $1.360 \mathrm{NS}$ \\
\hline
\end{tabular}

distances. A significant difference was observed in the mean distance to the nearest neighbouring nest among sites $(\mathrm{F}(4,852)=48.66 ; \mathrm{P}<0.001)$. A post hoc Tukey test revealed the mean internest distance was significantly shorter $(\mathrm{P}<0.001)$ at the two high wasp density sites (Mt. Misery and Rotoiti wasps maintained) than at either of the two lower wasp density sites (Pelorus Bridge and Spooner's Range). There was no significant difference $(\mathrm{P}=0.998)$ observed in inter-nest distance between the Rotoiti wasps maintained and Rotoiti wasps removed sites. No significant difference was found between the mean distance to nearest neighbour between Mt. Misery and Rotoiti wasps maintained $(\mathrm{P}=0.999)$ and Rotoiti wasps removed sites $(\mathrm{P}=0.979)$. The mean inter-nest distance at Spooner's Range was significantly greater $(\mathrm{P}=0.001)$ than at Pelorus Bridge (Figure 5.3). 


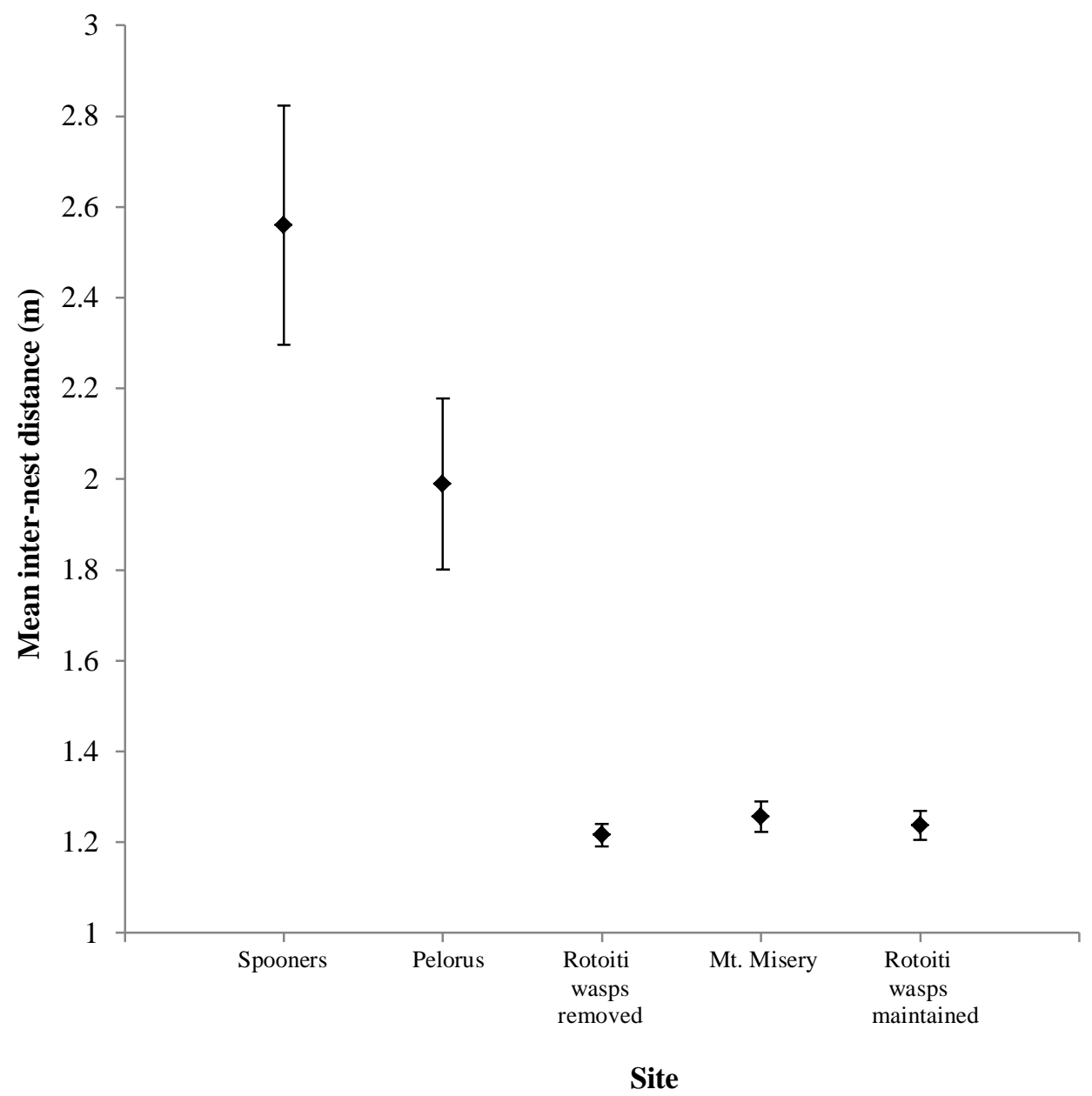

Figure 5.3 Mean ( \pm S.E) Prolasius advenus inter-nest distance (metres) at five New Zealand South Island Nothofagus beech forest sites arranged in order of increasing wasp nest density.

\subsubsection{Connectedness of nests}

All the nests opened to mark workers at both the Rotoiti wasps maintained and wasps removed sites and at the Mt. Misery site were abandoned within 24 hrs. One nest at the Rotoiti wasps maintained site had a small midden outside it comprising 27 fluorescent workers. No marked workers (alive or dead) were observed in any of the surrounding nests, many of which were also abandoned. No marked workers were located foraging around the nests that had been marked. For this reason the marking of ants was not repeated at Pelorus Bridge or Spooner's Range. 


\subsubsection{Nest size}

Prolasius advenus nest size (number of individuals per nest) varied greatly both within and among sites ranging from 170 to 26,216 individuals per nest. The lowest mean nest size (number of individuals per nest) was recorded at the Rotoiti wasps maintained site (1989.3) and the highest at Spooner's range (6622.0). No significant difference was observed in the median nest size among sites $\left(\chi^{2}(4, \mathrm{~N}=50)=5.05, \mathrm{P}=0.282\right)$ (Figure 5.4 a). However, analysis of the coefficient of variation showed a clear distinction between nest size variation in high and low wasp density areas. Little variation was found in nest size at the two high wasp density sites compared to the variation observed at the two lower wasp density sites. Variation in nest size was greater at Lake Rotoiti after wasp removal than at the Lake Rotoiti wasps maintained site (Figure 5.4 b).

\subsubsection{Honeydew availability}

Honeydew productivity inferred by sooty mould biomass was greatest where wasps and ants were most abundant and least abundant where there were fewer wasps and ants. The values of the honeydew index varied significantly $\left(\chi^{2}(4, \mathrm{~N}=50)=18.71, \mathrm{P}<0.001\right)$ among sites. The results of a post Hoc Dunn's multiple comparison test indicated the median value of the honeydew index was significantly lower at Spooner's Range than at Mt. Misery $(\mathrm{P}<0.05)$ or Lake Rotoiti wasps removed $(\mathrm{P}<0.05)$ sites. No significant difference $(\mathrm{P}>0.05)$ was found between any of the other sites (Figure 5.5). 
Chapter Five - Spatial Distribution

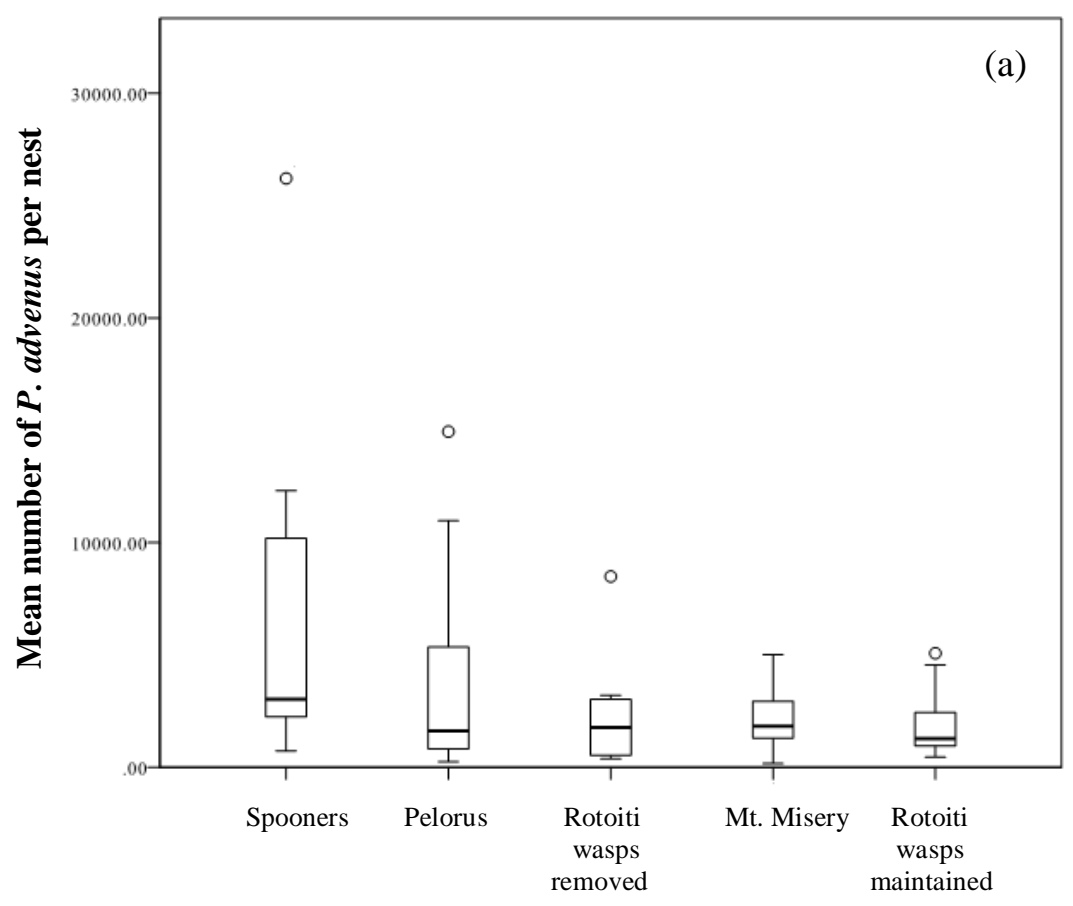

Site

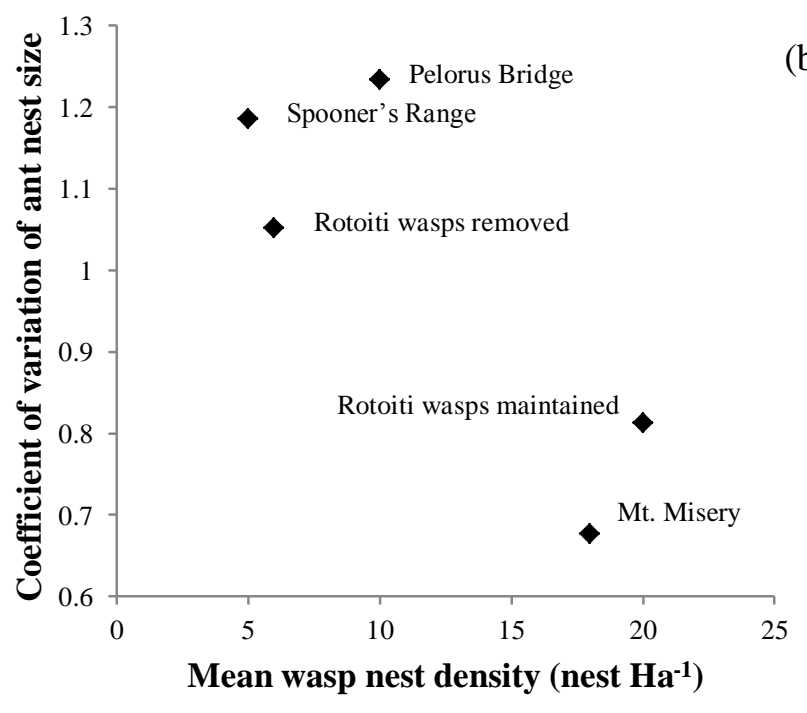

(b)

Figure 5.4 (a) Prolasius advenus nest size distributions of ten nests sampled from each of five New Zealand South Island Nothofagus beech forest sites arranged in order of increasing wasp nest density. Boxes represent the $25^{\text {th }}$ percentile, median and $75^{\text {th }}$ percentile. Whiskers represent sample minimum and maximum values per site. Open circles represent outliers. (b) The coefficient of variation of nest size distribution at the same five sites with increasing wasp density. 


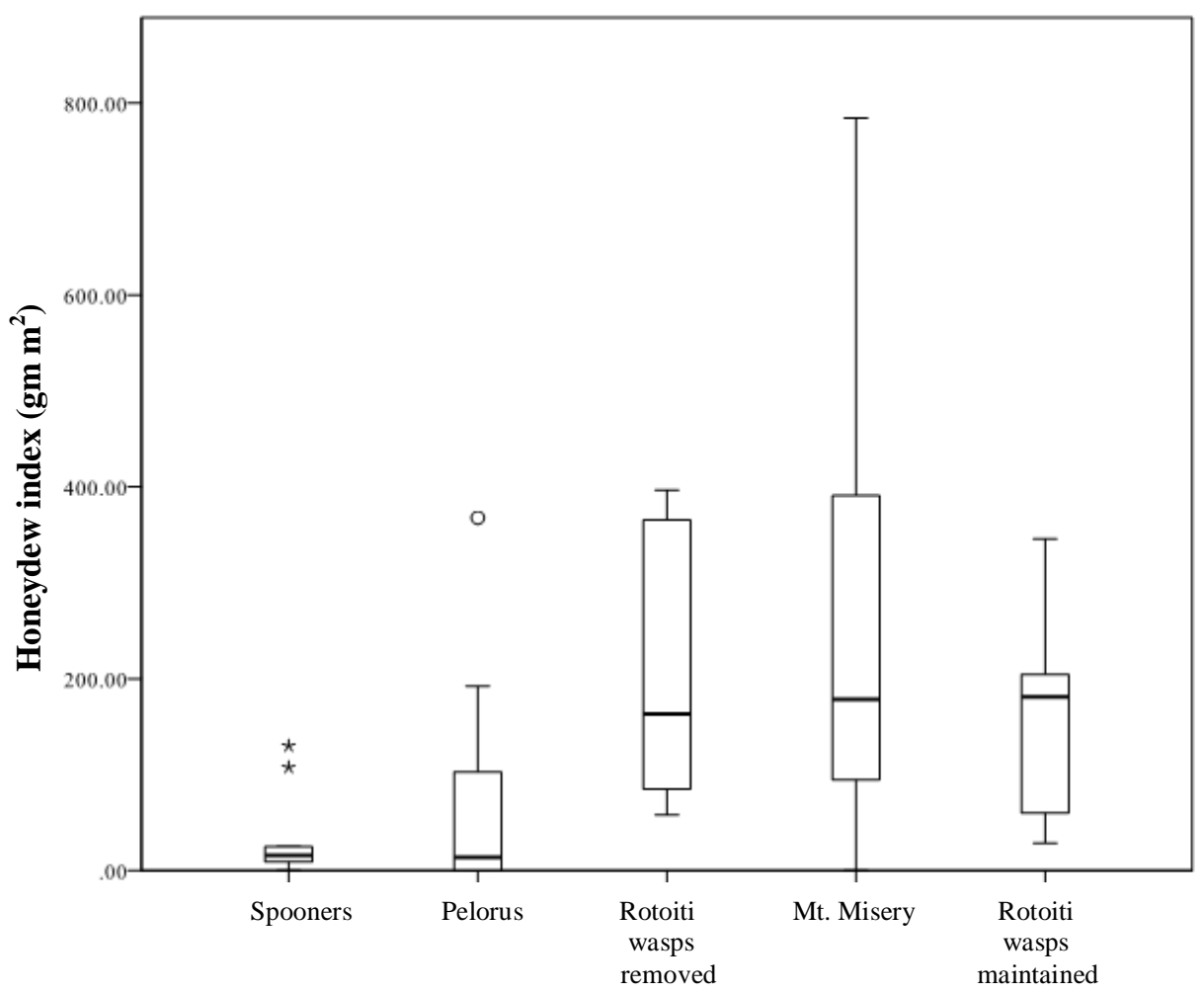

Site

Figure 5.5 Index of honeydew abundance based on the percentage of sooty mould ground cover and biomass per $\mathrm{cm}^{3}(\mathrm{gm})$ at five New Zealand South Island Nothofagus beech forest sites arranged in order of increasing wasp density Boxes represent the $25^{\text {th }}$ percentile, median and $75^{\text {th }}$ percentile of the distribution. Whiskers represent sample minimum and maximum values per site. Outliers are represented by stars (Spooner's Range) and open circles (Pelorus Bridge).

\subsubsection{Habitat diversity}

Wasp and $P$. advenus nest density was lower in sites with higher plant diversity. Plant diversity based on Simpson's index of diversity 1 -D was found to vary significantly among sites $\left(\chi^{2}(4, \mathrm{~N}\right.$ $=50)=24.51, \mathrm{P}<0.001)$. Plant species richness and evenness was found to be greater at the two lower wasp density sites, Spooner's Range and Pelorus Bridge compared to Lake Rotoiti and Mt. Misery (Table 5.2). The results of a post Hoc Dunn's multiple comparison test indicated that plant diversity at Spooner's range was significantly greater than at Lake Rotoiti wasps maintained ( $\mathrm{P}<0.001)$, Lake Rotoiti Wasps removed $(\mathrm{P}<0.010)$ and Mt. Misery $(\mathrm{P}<0.050)$, but did not differ from Pelorus Bridge ( $\mathrm{P}>0.05)$. None of the other sites differed (Figure 5.6). The canopy at all sites except Pelorus Bridge entirely comprises mature Nothofagus spp. Two of 
the ten quadrats surveyed at Pelorus Bridge had no beech present and the canopy comprised a combination Belschmidia tawa and Dacrydium cupressinum. The canopy in the remaining eight quadrats comprised entirely of Nothofagus spp.

Table 5.2 Plant species richness, evenness of each species contribution to the overall array and diversity in the canopy, understory and at ground level in five New Zealand South Island Nothofagus forests

\begin{tabular}{lccc}
\hline \multicolumn{1}{c}{ Site } & Species richness & Evenness & Simpson's 1-D \\
\hline Spooner's Range & 14 & 0.89 & 0.89 \\
Pelorus Bridge & 16 & 0.81 & 0.86 \\
Rotoiti wasps removed & 12 & 0.61 & 0.68 \\
Mt. Misery & 12 & 0.70 & 0.75 \\
Rotoiti wasps maintained & 10 & 0.53 & 0.58 \\
\hline
\end{tabular}

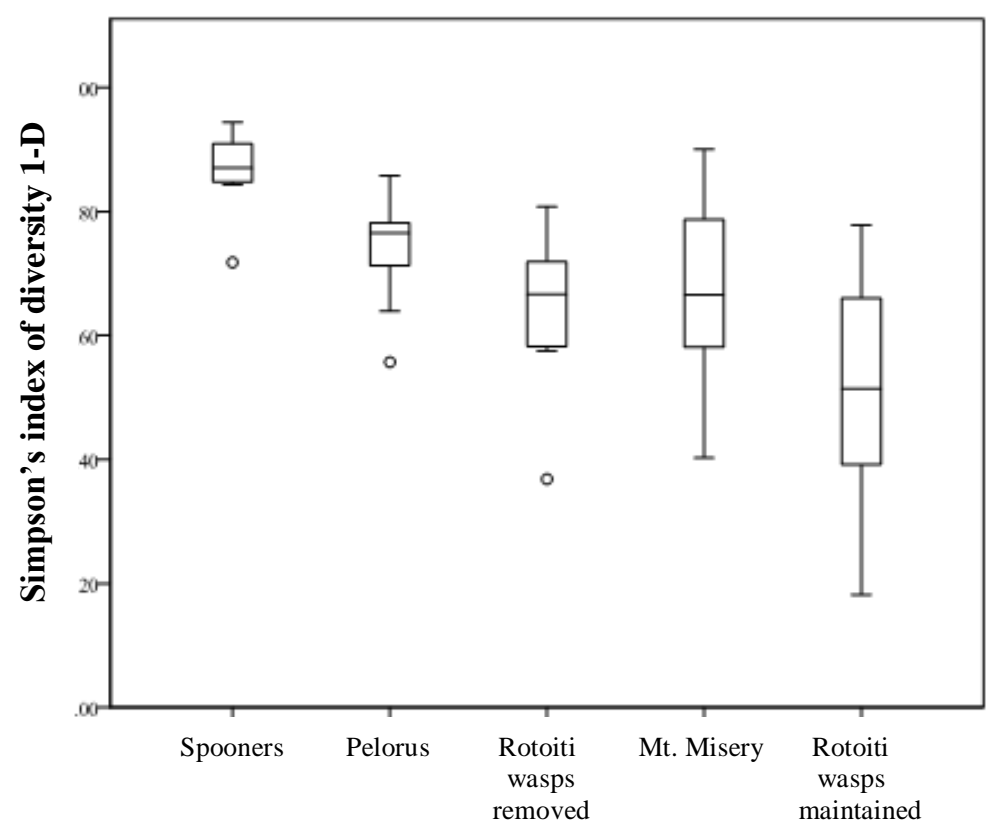

Site

Figure 5.6 Variation in plant species diversity based on Simpson's index of diversity (1-D) at five South Island Nothofagus forest sites arranged in order of increasing wasp density. Boxes represent the $25^{\text {th }}$ percentile, median and $75^{\text {th }}$ percentile of the diversity distribution. Whiskers represent sample minimum and maximum values per site. Outliers are represented by open circles. 
The relative proportion of mature honeydew producing Nothofagus fusca and N. solandri and non honeydew producing $N$. menziesii that made up the canopy varied significantly among sites. There was significant variation in the relative proportion of Nothofagus fusca $(\mathrm{F}(4,49)=6.113$, $\mathrm{P}=0.001), N$. menziesii $(\mathrm{F}(4,49)=9.932, \mathrm{P}<0.001)$, and $N$. solandri $(\mathrm{F}(4,49)=4.601, \mathrm{P}=$ 0.003) comprising the canopy at each site (Figure 5.7). A post hoc Dunnet's H3 test for unequal variances indicated that the proportion of $N$. fusca in the canopy was significantly $(\mathrm{P}<0.050)$ lower at the Lake Rotoiti wasps maintained site than at any of the other sites except Lake Rotoiti wasps removed and that the proportion $N$. menziesii, which is rarely infested by honeydew producing scale insects, was significantly greater at the site than either Pelorus Bridge or Spooner's Range, but did not differ significantly from Lake Rotoiti Wasps removed or Mt. Misery. Nothofagus solandri was not found at Mt. Misery or Spooner's Range and did not differ significantly $(\mathrm{P}>0.050)$ in the proportion of the canopy comprised at Lake Rotoiti wasps removed, Lake Rotoiti wasps maintained or Pelorus Bridge. No significant difference was observed in the percentage of open canopy among sites $(F(4,49)=1.760, \mathrm{P}=0.154)$, which ranged between $7.774 \pm 2.413 \%$ at Pelorus Bridge and $10.946 \pm 3.369 \%$ at Lake Rotoiti wasps maintained.

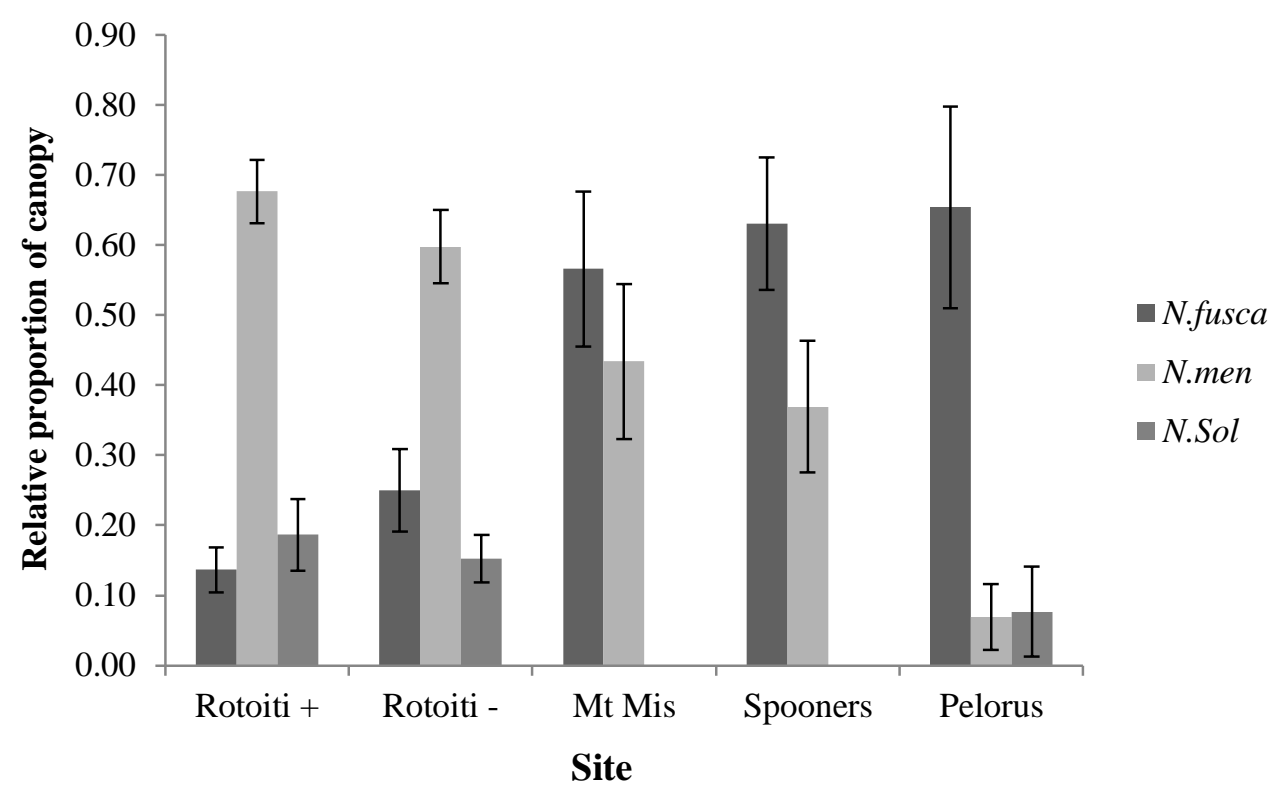

Figure 5.7 The mean $( \pm$ S.E) relative proportion of the canopy made up by mature honeydew rich Nothofagus fusca, and N. solandri and honeydew poor N. menziesii trees at five New Zealand South Island sites with varying wasp density. 
The understory at all sites was simple and consisted mainly of juvenile Nothofagus spp. and shrubs including Coprosma spp., Pseudopanax spp., Leptecophylla juniperina, Leucopogon fasciliatus and Griselinia littoralis at Lake Rotoiti and Mt. Misery. In addition to these species tree ferns (Dicksonia squarosa and Cyathea dealbata) contributed a significant portion of the understory composition at the two lower wasp density sites Spooner's Range and Pelorus Bridge.

Ground cover at all sites was predominantly leaf litter with between $3.7 \pm 2.7 \%$ (Spooner's Range) and $18 \pm 12.3 \%$ (Lake Rotoiti wasps maintained) moss cover. Crown ferns Blechnum discolor were also present at some sites and contributed $12.1 \% \pm 6.1 \%$ ground cover at Mt. Misery, $5 \% \pm 1.9 \%$ at Spooner's Range and $4.5 \% \pm 3.2 \%$ at Pelorus Bridge.

\subsubsection{Correlation between nest density size and distribution and habitat}

Of the thirty possible pairwise correlations tested between $P$. advenus nest density, $P$. advenus nest size, $P$. advenus nest distribution, $V$. vulgaris nest density, honeydew availability and plant species diversity, only three were found to be significant: $P$. advenus nest density was found to decrease with increasing plant diversity $(\rho=-0.900, P=0.037), P$. advenus nest size was found to increase significantly ( $\rho=0.900, P=0.037)$ with increasing plant diversity and decrease significantly $(\rho=-0.900, P=0.037)$ with increasing wasp density. 


\subsection{Discussion}

The results of this study indicate that the brown bush ant $P$. advenus is the most abundant ant species in all of the southern beech forests sites examined. Bush ant nest densities were significantly higher where common wasps were most abundant compared to sites where wasps occurred at lower density. However, a significant negative correlation was observed between wasp abundance and $P$. advenus nest size. Furthermore nest size was found to vary less where wasp densities were highest, which may indicate a negative influence of wasps that results in reduced longevity of $P$. advenus nests. Where wasps were removed by poisoning ant nest densities remained higher than at low wasp density sites and variation in nest size was found to be greater than where wasps persisted at high density. The spatial distribution of nests was overdispersed where wasps were most abundant, which is consistent with distributions observed under high levels of competition in other taxa. Honeydew abundance was lower where both wasps and ants were least abundant than where they were most abundant, but did not differ significantly among other sites. Ant densities were lower at sites where plant diversity was higher, possibly because of a lack of suitable nest sites.

Prolasius advenus nest density was greatest at sites where wasps were most abundant. However, the ten year wasp poisoning programme had no significant effect on $P$. advenus nest density. It is likely this result indicates that the relationship between high densities of invasive wasps and ants is not causal but rather that a common factor allows both species to attain high population densities at Lake Rotoiti and Mt. Misery. Both sites have abundant honeydew resources which have been suggested to be a key factor facilitating the high nest densities of wasps (Barlow et al., 2002). Honeydew is also associated with numerical dominance in many ant species (Brightwell et al., 2010) providing a perennial carbohydrate resource that fuels foraging (Hölldobler and Lumsden, 1980) and facilitates colony growth (Porter, 1988). However, no significant difference was observed between honeydew availability at Pelorus Bridge, where both $P$. advenus and $V$. vulgaris nest densities were comparatively low, and Lake Rotoiti and Mt. Misery where both species were more abundant. This result suggests that factors additional to honeydew availability, such as habitat heterogeneity may influence nest density of $P$. advenus.

Environmental heterogeneity may affect ant nest distribution (Schooley and Wiens, 2003). Comparatively high nest densities of both $P$. advenus and V. vulgaris were observed at Mt. 
Misery. Nest distribution of $P$. advenus was found to be significantly overdispersed in four of the ten quadrats sampled at that site, which might be expected where competition is high. However, nest distribution in the remaining six quadrats was apparently random. A significant negative correlation was observed between nest density and plant diversity. With the exception of two quadrats at Pelorus Bridge where the canopy was not dominated by Nothofagus spp., the majority of variation in plant diversity observed was the result of pteridophytes in the understory and on the forest floor. In contrast to Lake Rotoiti, the ground cover at Mt. Misery included a large component of patchily distributed Blechnum discolor crown ferns, which appear to preclude $P$. advenus from nesting. Thus, it seems likely that in addition to resource availability habitat suitability also determines P.advenus nest distribution at this site. However, the presence of high densities of a competitor for such resources may also affect $P$. advenus nest distribution.

Viewed in combination with reduced inter-nest distance and smaller nest sizes, the increased nest density observed in areas heavily infested by common wasps is consistent with patterns commonly observed in polydomous colonies of other species (Debout et al., 2007).

Unfortunately the tendency for $P$. advenus to abandon nests that have been disturbed means that the crucial indicator of polydomy; the exchange of workers between nests could not be confirmed. However, molecular assignment tests of $P$. advenus workers indicated that only $31 \%$ of workers sampled at Lake Rotoiti could be assigned to the nest they were collected from (Chapter 4). This result indicates that intra nest relatedness is low and suggests that exchange of workers between nests may indeed take place at that site. Common wasps impose environmental constraints on $P$. advenus by a combination of predation (Harris, 1991) and competition (Grangier and Lester, 2011 and Duthie, 2011). These constraints are comparable to the high cost of dispersal (Bourke and Franks, 1995) and inter-specific competition (Traniello and Levins, 1986) that have been suggested to promote polydomous colony distribution in other species. Observed at a larger scale, the high densities of $P$. advenus nests at Lake Rotoiti may reflect aggregation at the nest level in response predation.

At a finer scale $P$. advenus nests were found to be significantly overdispersed in all quadrats at both the Rotoiti wasps removed and wasps maintained sites. Regular spacing of nests has been suggested to mitigate the effects of both intra- (Cushman et al., 1988) and inter-specific competition (Solida et al., 2010). Wasps have clearly been demonstrated to compete with $P$. 
advenus for food resources (Grangier and Lester, 2011 and Duthie 2011). However, the nest distribution at Lake Rotoiti appears to have remained overdispersed after ten years of wasp removal. As $P$. advenus nests are also at high density at this site the observed overdispersed distribution may serve to reduce overlap of conspecific foragers from unrelated neighbouring colonies. Thus, it seems likely that a combination of intra- and inter-specific competition is driving the observed pattern.

Variance in nest size was lower where wasps were most abundant. This result may be indicative of either life history strategies that favour smaller colonies, or reduced longevity in the presence of high densities of wasps. In ants, nest size is strongly correlated with nest age (Hölldobler and Wilson, 1990 and Gordon and Wagner, 1997). Colony growth typically occurs in three phases: a founding stage, an ergonomic phase and a reproductive stage (Hölldobler and Wilson, 1990). Founding queens, produce a first clutch of nanitic workers from stored reserves amassed prior to leaving the natal nest. The first brood of workers collect resources to enable the queen to produce a second clutch. If the colony survives beyond the second worker brood it will enter a period of exponential growth before reaching an optimum size and entering the reproductive phase when sexually reproductive alate queens and males will be produced. Nests may continue to grow after maturity and have been reported to persist for as long as 40 years in some ant species (Chew, 1987). Elevated and persistent disturbance such as high levels of predation or competition, which reduce the probability of nest survival to the reproductive phase may select for colonies that are smaller and reach maturity faster (Kaspari and O'Donnell, 2003 and Linksvayer and Janssen, 2009). The common wasp has been demonstrated to reduce honeydew availability by more than 90\% (Beggs, 2001) as well as competing with the species for food resources (Grangier and Lester, 2011) and is also a significant predator of dispersing alate queens (Harris, 1991). In combination these factors may favour smaller nests that mature more rapidly.

Alternatively, the combination of predation and competition by high densities of invasive wasps may simply reduce nest longevity. A significant negative correlation was observed between $P$. advenus nest size and $V$. vulgaris nest density. Although the results of this study indicated no significant difference in $P$. advenus nest size among high and low wasp density sites the trend was for nests to be smaller where there were more wasps. The coefficient of variation indicated variation in nest size was greater where wasps were less abundant. The absence of large nests 
comparable in size to those observed at the lower wasp density site suggests that colony growth may be arrested or survival reduced by a combination of competition and predation pressure exerted by invasive common wasps. Furthermore when wasps were removed by poisoning at Lake Rotoiti nest size variation was found to be greater than where wasps persisted at the same site and comparable to the two lower wasp density sites. This may be indicative of increased survivorship of $P$. advenus nests where wasps are less abundant.

\subsubsection{Conclusions}

The results of this study indicate that nest densities of the New Zealand endemic ant $P$. advenus are highest where the invasive common wasp is most abundant, indeed ant nests outnumber wasp nests by approximately 100:1; this did not support my hypothesis that ant nest density would be reduced where wasps were at high abundance. On first inspection, the combination of abundant honeydew resources and suitable nest sites at some sites appears to support the presence of both species at high density. However, closer examination indicates that the additional competitive pressure the wasp exerts may subtle detrimental effects on the bush ant. The spatial distribution of $P$. advenus nests where both the wasps and ants were most abundant was significantly overdispersed, potentially indicating a combination of intra- and inter-specific competition for resources. Furthermore, nest size distributions were found to vary less in the presence of high densities of wasps, which arguably indicates reduced nest longevity in response to this additional competition. When wasps were removed by poisoning over a ten year period variation in P.advenus nest size was greater and more comparable to areas where wasps are less abundant. These results suggest that even in the presence of abundant resources and nest sites a combination of intra-specific competition, and competition and predation pressure exerted by a novel invader can alter the distribution of recipient species. The apparent detrimental effects of high densities of the invasive wasp on $P$. advenus populations observed in this study would not have been detected were abundance based on nest density the only parameter measured. 


\subsection{References}

Andrewes , C. (1969) The lives of wasps and bees. Chatto and Windus, London. 204pp

Barlow, N.D., Beggs, J.R. and Barron, M.C. (2002) Dynamics of common wasps in New Zealand beech forests: a model of density dependence and weather. The Journal of Animal Ecology 71(4): 663-671

Beggs, J. (2001) The ecological consequences of social wasps (Vespula spp.) invading an ecosystem that has an abundant carbohydrate resource. Biological Conservation 99: 17-28.

Beggs, J.R., Toft, R.J., Malham, J.P., Rees, J.S., Tilley, J.A.V., Moller, H. and Alspach, P. (1998) The difficulty of reducing introduced wasp (Vespula vulgaris) populations for conservation gains. New Zealand Journal of Ecology 22(1): 55-63

Beggs, J. R. and Wilson, P. R. (1991) The kaka Nestor meridionalis, a New Zealand parrot endangered by introduced wasps and possums. Biological Conservation 56: 23-38

Beggs J.R. and Wardle, D.A. (2006) Keystone species: competition for honeydew among exotic and indigenous species. In Allen, R.B.and Lee, W.G. editors. Biological invasions in New Zealand. Springer, Berlin, pp. 281-294

Bevacqua, D., Andrello, M., Melia, P., Vincenzi, S., De Leo, G. A. and Crivelli, A. J. (2011) Density-dependent and inter-specific interactions affecting European eel settlement in freshwater habitats Hydrobiologia 671: 259-265

Bourke, A. F. G. and Franks, N. R. (1995) Social evolution in ants. Princeton University Press, Princeton, New Jersey: 529pp

Brightwell, R.J., Bambara, S.B. and Silverman, J. (2010) Combined effect of hemipteran control and liquid bait on Argentine ant populations. Journal of Economic Entomology 103(5): 17901796

Chew, R.M. (1987) Population dynamics of colonies of three species of ants in desertified grassland, Southeastern Arizona, 1958-1981. American Midland Naturalist 118: 177-188

Clark, P. J. and Evans F.C. (1954) Distance to nearest neighbour as a measure of spatial relationships in Populations. Ecology 35(4): 445-453

Cushman, J.H., Martinsen, G.D., and Mazeroll, A.I. (1988) Density- and size-dependent spacing of ant nests: evidence of intraspecfic competition. Oecologia 77: 522-525

Davies, N.B. (1978) Ecological questions about territorial behaviour.PP 317-350 In Krebs, J.B and Davies, N.B., editors Behavioral Ecology an Evolutionary Approach Sinauer Associates Inc. Sunderland Massachusetts, USA; 494pp

Debout, G., Schatz, B., Elias, M. and McKey, D. (2007) Polydomy in ants: what we know, what we think we know and what remains to be done. Biological Journal of the Linnean Society 90:319-348 
Don, W. (2007) Ants of New Zealand. Otago University Press, Dunedin, New Zealand: 239pp

Donovan, B.J., Howie, A.M.E. and Schroeder, N.C. (1992) Comparative characteristics of nests of Vespula germanica (F.) and Vespula vulgaris (L.) (Hymenoptera, Vespinae) from Christchurch city New Zealand. New Zealand Journal of Zoology 19: 61-71.

Duthie, C. (2011) Factors promoting coexistence between endemic ants and invasive wasps. Unpublished PhD thesis. Victoria University Wellington.

Gordon, D.M. (1992) How colony growth affects forager intrusion in neighbouring harvester ant colonies. Behavioural Ecology and Sociobiology 31: 417-427

Gordon, D.M. and Kulig, A.W. (1996) Founding, foraging, and fighting: colony size and the spatial distribution of harvester ant nests. Ecology 77(8): 2393-2409

Gordon, D.M. and Wagner, D. (1997) Neighbourhood density and reproductive potential in harvester ants. Oecologia 109(4): 556-560

Grangier, J. and Lester, P.J. (2011) A novel interference behaviour: invasive wasps remove ants from resources and drop them from a height. Biology Letters 7(5): 664-667

Grant, W.D. and Beggs, J. (1989) Carbohydrate analysis of beech honeydew. New Zealand Journal of Zoology 16: 283-288.

GraphPad InStat 3.10. (2009) GraphPad Software. Inc.

Hamilton, W. D. (1971). Geometry for the selfish herd. Journal of Theoretical Biology 31: 295311

Harris, R. (1991) Diet of the wasps Vespula vulgaris and V. germanica in honeydew beech forest of the South Island, New Zealand). New Zealand Journal of Zoology 18: 159-169

Harris, R.J. and Oliver, E.H. (1993) Prey diets and population densities of wasps Vespula vulgaris and Vespula germanica in a scrubland-pasture. New Zealand Journal of Ecology 15: 512

Hölldobler, B. and Lumsden, C.J. (1980) Territorial strategies in ants. Science 210(4471): 732739

Hölldobler, B. and Wilson, E.O. (1977) The number of queens: an important trait in ant evolution. Naturwissenschaften 64: 8-15

Hölldobler, B. and Wilson, E.O. (1990) The Ants. Harvard University Press, Cambridge, MA: $732 \mathrm{pp}$

Holway, D.A. and Case, T.J. (2000) Mechanisms of dispersed central-place foraging in polydomous colonies of the Argentine ant. Animal Behaviour 59(2): 433-441

Human, K. G. and Gordon, D. M. (1999) Behavioural interactions of the invasive Argentine ant with native ant species. Insectes Sociaux 46: 159-163 
Johnson, L.K., Hubbell, S.P. and Feener Jnr., D.H. (1987) Defence of food supplies by eusocial colonies. American Zoologist 27: 347-358

Kaspari, M. and O'Donnell, S. (2003) High rates of army ant raids in the neotropics and implications for ant colony and community structure. Evolutionary Ecology Research 5: 933-939

Keller, L. (1995) Social life: the paradox of multiple queen colonies. Trends in Ecology and Evolution 10: 335-360

Levins, S. and Traniello, J. E. A. (1981). Territoriality, nest dispersion, and community structure in ants. Psyche 88: 265-319

Linksvayer, T. A. and Janssen, M.A. (2009) Traits underlying the capacity of ant colonies to adapt to disturbance and stress regimes. Systems Research and Behavioural Science 26: 315-329

Lõrinczi, G. (2011) Density and spatial pattern of nests in sub-Mediterranean ground-dwelling ant communities (Hymenoptera: Formicidae). Community Ecology 12(1): 51-57

McColl, H.P. (1975) The invertebrate fauna of the litter surface of a Nothofagus truncata forest floor, and the effect of microclimate on activity. New Zealand Journal of Zoology 2(1): 15-34

McNatty A., Abbott, K.L. and Lester, P.J. (2009) Invasive ants compete with and modify the trophic ecology of hermit crabs on tropical islands. Oecologia 160: 187-194

Mercado, R.J., Siegert, N.W., Liebhold, A.M. and McCullough, D.G. (2011) Influence of foraging behaviour and host spatial distribution on the localised spread of the emerald ash borer, Agrilus planipennis. Population Ecology 53: 271-285

Moller, H. and Tilley, J.A.V. (1989) Beech honeydew: seasonal variation and use by wasps, honey bees, and other insects. New Zealand Journal of Zoology 16: 289-302

Moller, H., Tilley, J.A.V., Thomas, B.W. and Gaze, P.D. (1991) Effect of introduced social wasps on standing crop of honeydew in New Zealand beech forests. New Zealand Journal of Zoology 18: 171-179

Morales, C.F., Hill, M.G. and Walker, A.K. (1988) Life history of the sooty beech scale (Ultracoelostoma assimile) (Maskell), (Hemiptera:Margarodidae) in New Zealand Nothofagus forests. New Zealand Entomologist 11: 24-38

Orians, G.H. and Pearson, N.E. (1979) On the theory of central place foraging. PP 155-177. In Horn E.M., Stairs, G.R. and Mitchell, R.D., editors. Analysis of Ecological Systems. Ohio State University Press, Columbus, Ohio, USA:312pp

PASW 18.0.0 (2010) SPSS Inc., Chicago.

Pfeiffer, M. and Linsenmair, K.E. (1998) Polydomy and the organisation of foraging in a colony of the Malaysian giant ant Camponotus gigas (Hym. Form.). Oecologia 117: 579-590.

Porter, S.D. (1988) Effects of diet on the growth of laboratory fire ant colonies (Hymenoptera:Formicidae). Journal of the Kansas Entomological Society 62(2): 288-291 
Quinet, Y., de Biseau, J.C. and Pasteels, J.M. (1997) Food recruitment as a component of trunktrail foraging behaviour of Lasius fulginosus (Hymenoptera: Formicidae). Behavioural Processes 40: $75-83$.

Rowles, A. D. and O'Dowd, D. J. (2007) Interference competition by Argentine ants displaces native ants: implications for biotic resistance to invasion. Biological Invasions 9: 73-85.

Scharf, I., Fischer-Blass, B. And Foitzik, S. (2011) Spatial structure and nest demography reveal the influence of competition, parasitism and habitat quality on slavemaking ants and their hosts. BMC Ecology 11(9): 1-13.

Schoener, T.W. (1979) Generality of the size-distance relation in models of optimal feeding. American Naturalist 114: 902-914.

Schooley, R.L. and Wiens, J.A. (2003) Spatial patterns, density dependence, and demography in the harvester ant, Pogonomyrmex rugosus, in semi-arid grasslands. Journal of Arid Environments 53: $183-196$.

Smith, C.E. (1969) A morphological and behavioural study of the ants Amblyopone saundersi Forel and Prolasius advena Fr. Smith (Hymenoptera: Formicidae). Unpublished BSc(Hons) thesis, University of Otago, Dunedin

Solida, L., Scalisi, M., Fanfani, A., Mori, A. and Grasso, D.A (2010) Interspecific space partitioning during the foraging activity of two syntopic species of Messor harvester ants. Journal of Biological Research 13: 3-12

Thomas, C. D., Moller, H., Plunkett, G. M. and Harris, R. J. (1990) The prevalence of introduced Vespula vulgaris wasps in a New Zealand beech forest community. New Zealand Journal of Ecology 13: 63-72

Thomas M.L., and Framenau, V.W. (2005) Foraging decisions of individual workers vary with colony size in the greenhead ant Rhytidoponera metallica (Formicidae, Ectatomminae). Insectes Sociaux 52: 26-30

Toft, R.J. and Beggs, J.R. (1995) Seasonality of crane flies (Diptera:Tipulidae) in South Island beech forest in relation to the abundance of Vespula wasps (Hymenoptera: Vespidae). New Zealand Entomologist 18: 37-43

Tosh, C.R. (2011) Which conditions promote negative density dependent selection on prey aggregations? Journal of Theoretical Biology 281: 24-30

Traniello, J.F.A. and Levins, S.C. (1986) Intra- and intercolony patterns of nest dispersion in the ant Lasius neoniger: correlations with territoriality and foraging ecology. Oecologia 69(3): 413419

Wardhaugh, C.W., Blakekly, T.J., Greig, H., Morris, P.D., Barnden, A., Rickard, S., Atkinson, B., Fagan, L.F., Ewers R.M. and Didham, R.K. (2006) Vertical stratification in the spatial distribution of the beech scale insect (Ultracoelostoma assimile) in Nothofagus tree canopies in New Zealand. Ecological Entomology 31: 185-195 
Chapter Six - General Discussion

Chapter Six

\section{General Discussion}




\subsection{Conclusions and synthesis}

Invasive species are frequently reported to alter native species' abundance and distribution and to effect their displacement or extinction by means of predation and competition. Recent studies have demonstrated that the common wasp Vespula vulgaris, which is invasive to New Zealand, displays significant dietary overlap with the endemic small brown bush ant Prolasius advenus (Duthie, 2011), competes with it for food resources (Grangier and Lester, 2011), and preys on its dispersing queens (Harris, 1989 and Harris pers. com.). In this dissertation I examined the sublethal effects the invasive wasp has on the bush ant in terms of growth and morphology, behaviour and population genetics as well as abundance and spatial distribution. My results may be summarised as follows: in Chapter 2, I found that where wasps are most abundant P. advenus workers are smaller and display variation in the scaling relationships among body parts compared to where wasps are sparse. Different scaling relationships were found between the thorax and abdominal segments of $P$. advenus workers from high and low wasp density sites. The results of Chapter 3 showed that where wasps occur at high density $P$. advenus workers forage predominantly diurnally compared to low wasp density sites where foraging is predominantly nocturnal. I also found that $P$. advenus workers display size correlated task allocation where wasps are most abundant. Larger workers were found to forage for honeydew on the trunks of Nothofagus trees infested with Ultracoelostoma spp. scale and also to tend brood whereas smaller workers are active in the leaf litter presumably collecting invertebrate prey. In Chapter 4, I presented evidence of a genetic bottleneck in $P$. advenus populations from sites where the predatory wasps have been present at consistently high densities for more than twenty years. Evidence of genetic bottleneck was also found at one low wasp density site that had become isolated due to deforestation and cultivation of exotic pine forestry. Low assignment of workers to the nests they were collected from in high wasp density sites was suggestive of exchange of workers among nests potentially indicating modified nest structure in the presence of high densities of wasp. An assessment of the broader population genetics of the P. advenus from the seven study sites found that the sampled sites could be broadly divided into distinct north eastern and south western populations with evidence of either some admixture or historical divergence from a common population. In Chapter 5, P. advenus nest densities were highest where wasps were most abundant and lowest where both wasps and honeydew were least abundant and plant diversity was greatest. Prolasius advenus nests tended to be smaller and 
varied less in size, potentially indicating either reduced longevity of monodomous nests or that the bush ant forms polydomous colonies in these areas. The spatial distribution of ant nests was found to be overdispersed where wasp and ant densities are greatest indicating that a combination of intra- and inter-specific competition informs spatial distribution of nests.

The findings presented in this dissertation provide some new insights into the biology of a New Zealand endemic species that has previously been the subject of very little research. In addition, my results illustrate some of the finer scale effects that invasive species may have on recipient taxa over a comparatively short period of time. These effects are evident in terms of altered growth, behaviour, genetic diversity and spatial distribution. What the long term implications of these effects are for the fitness and persistence of $P$. advenus is uncertain, however, in this chapter I suggest that these effects have the potential to impose significant long-term costs to the species.

In ants, size is frequently correlated with foraging efficiency (Braendle et al., 2003; Kay and Rissing, 2005; Tanner, 2008). Smaller workers are typically better at discovering resources, but are less able to defend them from competitors (Kay and Rissing, 2005; Arnan et al., 2011). Furthermore, smaller individuals may experience increased handling time of larger prey items (Wu et al., 2011) and greater energetic costs in terms of size to load ratios (Arnan et al., 2011). Smaller workers in other ant species are shorter lived than larger workers and measures of their respiration rate indicate they are more costly for a nest to maintain (Porter and Tschinkel, 1985). My results show that $P$. advenus workers are smaller in areas where wasp densities are consistently high. As wasps in Nothofagus beech forests reduce the standing crop of honeydew by more than $90 \%$ (Beggs et al., 1998) as well as reducing the availability of potential invertebrate prey species (Harris and Oliver, 1993), the observed reduction in P. advenus worker size may be a result of reduced resource availability. Such size reduction where resources are limited has been demonstrated in numerous other species (Wheeler and Buck, 1992; Mirth and Riddiford, 2007; Sorvari and Hakkarainen, 2009). If the observed reduction in P. advenus worker size is accompanied by a reduction in longevity, reduced foraging efficiency, and increased maintenance costs demonstrated in small workers of other species then there is the potential for it to impose a fitness cost to colonies or to reduce the colony lifespan. 
Ant species with smaller workers may increase their competitive ability by numerical dominance and aggression (Human and Gordon, 1995; Rowles and O’Dowd, 2007; Blight et al., 2010). When present in higher numbers, $P$. advenus workers react aggressively toward wasps at food resources (Duthie, 2011). However, such aggressive interactions can be costly in terms of energetic loss relative to the energetic gain from a food resource (Schoener, 1974). Workers engaged in conflict with wasps are expending energy rather than gaining it by collecting food. There is also the potential for workers to be lost or injured in aggressive competitive interactions (Tanner and Adler, 2008). Wasps aggressively remove $P$. advenus from food resources by physically carrying and dropping them away from the food (Grangier and Lester, 2011). This behaviour arguably increases the risk of injury to ant workers.

Temporal niche partitioning can mitigate the effects of competition if resource availability is renewed between feeding times (MacArthur and Levins, 1967). In southern beech forest honeydew is produced throughout the diel cycle and productivity has been found to be greatest at night (Kelly et al., 1992). As V. vulgaris is active only diurnally (Thomas et al., 1990), I predicted that $P$. advenus would forage proportionally more nocturnally than diurnally where wasps were most abundant. However, rather than reducing the potential for costly competitive interaction with wasps by foraging more at night, I found that $P$. advenus workers forage as much or more by day than by night in the presence of high densities of wasps. Experiments with laboratory colonies of $P$. advenus found that when carbohydrate resources were restricted, forager abundance increased significantly (Grangier, unpublished.). Thus, the restriction of honeydew availability by wasps may offer a plausible explanation for the increased recruitment of diurnal $P$. advenus foragers observed at high wasp density sites. Increasing forager recruitment may negate the need for a temporal niche shift, but foraging in the presence of wasps likely incurs costs by diverting workers from other nest functions and in terms of reduced energetic gain and the potential for loss or injury of workers.

Larger workers may be better able to defend resources from wasps. Where wasps were present in high numbers I found that larger $P$. advenus workers were deployed to collect honeydew, potentially because they are better able to defend the resource from competitors. This need for defence may also represent a cost to the colony as the production of larger workers requires increased allocation of food resources during larval growth (Emlen and Nijhout, 2000; Mirth and 
Riddiford, 2007). However, worker deaths may be offset if the resources gained exceed the cost of competitive interactions (Hölldobler and Lumsden, 1980) suggesting that a cost-benefit trade off exists between resource acquisition and defence (Tanner and Adler, 2009). Further study is needed to determine whether the observed increase in diurnal foraging in the presence of high densities of wasps observed in this study represents a net cost or benefit to $P$. advenus in terms of energetic gain relative to energy lost in aggressive interactions.

My results in Chapter 5 indicated that $P$. advenus nests in areas that are heavily infested with wasps tend to be smaller than those where there are fewer wasps and also display significantly less size variation. Reduction in the quality and availability of food resources is a key factor that limits colony growth (Kay et al., 2006). Typically, protein derived from arthropod prey is essential for brood production (Porter, 1988), however limitation of carbohydrate, which fuels worker activity, has also been demonstrated to inhibit colony growth in laboratory colonies of the fire ant Solenopsis invicta by $60 \%$ compared with colonies allowed free access to carbohydrate resources (Porter, 1988). Previous work has demonstrated a significant overlap in the diet of $P$. advenus and V. vulgaris (Duthie, 2011) as well as interference competitive interactions at food resources (Lester and Grangier, 2011). Furthermore, V. vulgaris severely reduces honeydew quality and availability (Moller and Tilley, 1989) and is a major predator of macro-invertebrates (Harris, 1991). The trend for P. advenus nests to be smaller and for reduced variation in nest size observed where wasps are most abundant is suggestive of a reduction in nest growth and longevity. Whether this reduction is associated with reduced forager efficiency resulting from smaller worker sizes observed in Chapter 2 or reflects a cost imposed by increased competitive interactions with wasps observed in Chapter 3 is uncertain. However, a reduction in nest size and growth in the presence of high densities of wasps may have long term implications for the fitness and persistence of $P$. advenus colonies.

For most ant species, nest size typically increases over time until it reaches an optimum point, after which the queen or queens begin to produce sexual offspring (Asano and Cassill, 2011). However, while the production of reproductive offspring tends to be seasonal, queens produce sterile workers throughout the year, which enables the nest to acquire greater nutrient reserves (Oster and Wilson, 1978). Furthermore, a large reserve of workers has been shown to increase the probability of queen survival over winter, acts as a buffer against losses incurred by 
environmental change and facilitates increased foraging ability in case of resource shortage (Cassill, 2002; Asano and Cassill, 2011). Thus a smaller nest may have a compromised ability to secure resources, which may result in the production of smaller workers as observed in Chapter 2. Smaller nests have also been shown to have decreased interference competitive ability in interspecific conflict compared to larger nests (Palmer, 2004). The tendency for P. advenus to forage proportionally more diurnally in the presence of high densities of wasps observed in Chapter 3 increases the potential for competitive interactions between the two species. As these ants likely come from smaller nests it is possible that engaging large numbers of workers in competitive conflict may come at the cost of other nest functions.

Competitive interactions may be reduced to some extent by an overdispersed nest distribution. Overdispersal of nests reduces forager overlap by positioning nests as far apart as is possible in a given area (Davies, 1978; Levins and Traniello, 1981). My results in Chapter 5 indicated that the distribution of $P$. advenus nests was overdispersed relative to their intra- and inter- specific neighbours in areas where both ants and wasps were most abundant. However, as the foraging radius of V. vulgaris may be as great as four kilometres (Beggs et al., 1998) it seems likely that the positioning of $P$. advenus nests relative to those of wasps will have little if any impact on foraging overlap between the two species. The observed overdispersed distribution of $P$. advenus nests could, however, potentially reduce the overlap of $P$. advenus foragers from different colonies. The overdispersed distribution of $P$. advenus nests may be the result of reduced food availability since the arrival of the wasps as a reduction in intra-specific competition may indirectly reduce the impact of inter-specific competition with wasps.

Alternatively, the spatial distribution observed in the high wasp density sites may be indicative of polydomous colony formation where nest boundaries are relaxed and there is free exchange of workers between nests. Polydomous colonies facilitate dispersed central place foraging, minimising the costs of central place foraging such as aggressive competitive interactions and, by positioning of the nest in close proximity to stable resources, the cost of resource transport (Debout et al., 2007). The high density of nests, coupled with reduced inter-nest distances and smaller less variable nest sizes is consistent with polydomous distribution. While I attempted to confirm the exchange of workers between nests by marking ants with paint, P.advenus' tendency to abandon their nests when they were disturbed meant I was unsuccessful. However, the 
comparatively low assignment of $31 \%$ of workers to the nest from which they were collected observed in Chapter 4 may be indicative of the relaxed nest boundaries and exchange of workers typical of polydomous colonies. Polydomy is a facultative trait induced by competition and a high cost of dispersal and single species may form either monodomous or polydomous colonies dependent on the strength of these environmental pressures (Bourke and Franks, 1995). Winged Formicidae form more than $25 \%$ of $V$. vulgaris' diet when the wasp is at peak abundance (Harris, 1991). Given that $P$. advenus was found to be the most abundant ant species in all of my study the sites it is likely that a large proportion of this is comprised of $P$. advenus alate queens, which arguably represents a high dispersal cost that may be mitigated by reduced dispersal and polydomous colony foundation.

High levels of predation can ultimately result in a reduction in effective population size. This reduced population size may result in a loss of allelic diversity and heterozygosity (Nei et al., 1975; Gasc et al., 2010). The results of Chapter 4 indicated that a significant genetic bottleneck had occurred in P. advenus populations in areas where wasps are most abundant. As winged ants comprise a large proportion of V. vulgaris' diet (Harris, 1991) and the peak abundance of the wasp coincides with the nuptial flight of $P$. advenus (Toft and Rees, 1998; Don, 2007), I suggest that high levels of predation by wasps is the most parsimonious explanation of these results. Such a reduction in genetic diversity has potential long term implications for the fitness of these $P$. advenus populations. Reduced populations are more susceptible to further loss of alleles by means of genetic drift (Allendorf and Luikart, 2007); particularly where gene flow is limited by predation. Loss of genetic diversity has the potential to reduce pathogen resistance, decrease adaptive potential and to result in loss of fitness associated with inbreeding depression (Charlesworth and Charlesworth, 1987; Hitchings and Beebee, 1988; Ugelvig et al., 2010).

Populations living at high density are at greater risk from the spread of pathogens (Elliot and Hart, 2010). In Chapter 5 I found that P. advenus nests were at extremely high density in areas of where wasps were most abundant. These ant populations have the potential to be particularly susceptible to the transmission of parasites and disease as the results of Chapter 4 indicated they also display significantly reduced genetic diversity. A recent study found that $P$. advenus workers collected from high density populations are infested with nematode parasites (BrentonRule and Lester, unpublished). It is possible that such susceptibility to disease and parasites 
could reduce the lifespan of nests, which may be reflected by the reduced nest size variation observed in those populations in Chapter 5.

The genetic diversity of ant colonies can be viewed both at the individual level (homozygosity) and at the nest level (relatedness among individuals) (Ugelvig et al., 2010). The P. advenus populations examined in Chapter 4 all displayed significant heterozygote deficit, which is likely

indicative of a combination of limited dispersal, population substructure and non-random mating, typical of polygynous nests (Pamilo et al., 1997; Peeters and Ito, 2001; Ruppell et al., 2001; Gyllenstrand and Seppa, 2003; Mäki-Petäys et al., 2005). Indeed, similar results of heterozygote deficit have been reported in several other polygynous ant species (Chapuisat et al., 1997; Pamilio et al., 1997; Chapuisat and Keller 1999; Ross 2001). Several hypotheses have been suggested to explain the advent of polygyny in ants. Perhaps foremost among these is that polygyny mitigates the effects of high dispersal costs imposed by predation, patchy resource distribution and high levels of competition (Bourke and Franks, 1995). I suggest these conditions are typical of the post-wasp invasion honeydew beech forest sites in this study and that the polygynous nature of $P$. advenus nests may contribute in some part to the observed heterozygote deficit.

\subsection{Future research directions}

This thesis focused on the non-lethal effects of an exotic wasp invasion on an endemic ant. Both species forage for honeydew and prey on macro-invertebrates in the Nothofagus beech forests. Vespula vulgaris has been demonstrated to severely limit honeydew availability (Moller and Tilley, 1989; Beggs et al., 1998) and imposes significant interference competitive pressure on $P$. advenus (Grangier and Lester, 2011), as well as being a predator of the ant's sexual caste (Harris, 1991). I have presented evidence that suggests invasive wasp thus impact on several areas of the ant's biology including its morphology, behaviour, genetic variation, spatial distribution and longevity. Yet, contrary to the Gause (1932) principle of competitive exclusion, $P$. advenus persists at nest high densities in the presence of high abundances of the invasive wasp.

My results provide a baseline of morphological variation, population density and genetic diversity data for an endemic ant in areas of varying invasive wasp density. Long-term ongoing monitoring of both ants and wasps repeating aspects of this work would be useful in providing 
evidence of the more subtle detrimental effects invasive species may have on recipient taxa and in cataloguing their potential for effecting population declines and loss of genetic diversity. Such ongoing monitoring would be particularly interesting in those populations that have become isolated by anthropogenic habitat fragmentation to examine the synergistic effects of more than one novel environmental stressor on an abundant and ecologically dominant native species.

It would be helpful in understanding whether the allometric scaling of the gaster serves any ecological function to determine whether the crop and/or poison gland scale isometrically with the gaster. Furthermore, a recent study has confirmed experimentally that $P$. advenus workers can produce male offspring and there appears to be evidence that this occurs in field populations (Grangier, unpublished). Worker reproduction has been demonstrated in other species (Bourke and Franks , 1995; Walin et al., 1998; Helanterä and Sundström, 2005) and has been shown to be positively correlated with worker size in Cataglyphis cursor (Clemencet et al., 2008) and it would be interesting to see whether there is a relationship between gaster size and reproductive ability.

A limiting factor in this study was my inability to get $P$. advenus to reproduce in captivity despite trying numerous different diets, artificial nest types and temperature and humidity regimes. Experimental manipulation of food availability to examine the effect of protein and/or carbohydrate restriction on growth and scaling relationships whilst controlling for environmental factors such as temperature and humidity would have been invaluable. Future studies in this area might utilise food supplementation in the field. However, I experienced similar difficulty in finding an artificial nest that $P$. advenus would not abandon in the field during my early attempts at reciprocal transplant experiments. Further experimentation is needed to solve these fundamental problems before addressing experimental manipulation of food availability.

Further study is also needed to establish the cost to the colony of increased competitive interactions resulting from foraging concurrently with wasps. Theory predicts that such interactions are costly to central place foragers and that where spatial and resource use overlaps the competitively superior species should displace the inferior competitor. However this is clearly not the case with $P$. advenus and $V$. vulgaris. To better understand the benefits of size correlated task allocation, experimental manipulation of workers grouped by size and placed under differing levels and types of resource stress would be valuable. It would also be helpful to 
examine the effects of deployment of additional workers on other nest functions and to measure the effect on reproductive output under experimental conditions.

Heterozygote deficiency is common in diploid outcrossing populations. Ant breeding systems are typically more complex and allele frequencies may be affected by a number of factors such as the number of reproductive queens per nest, the number of matings per queen, worker reproduction, ploidy of males and assortive mating to name but a few. There is experimental evidence that queenless $P$. advenus workers produce male offspring and dissections of workers from queen-right colonies dissected immediately after collection indicate they may also produce males in naturally occurring nests (Grangier, unpublished). A detailed molecular study of $P$. advenus' mating system would be extremely helpful in disentangling the peculiarities of $P$. advenus' breeding system from other potential causes of heterozygote deficit observed, such as population substructure, dispersal dynamics and non-random mating. In addition dissections of queen spermathecae to examine for evidence of polyandry, and flow cytometry of males to establish ploidy would truly delineate the mating system. Fine scale molecular assignment testing to nests and analysis of inter-nest relatedness in areas where $P$. advenus nest densities are high would be helpful in understanding the species dispersal dynamics. Furthermore, such assignment testing would be helpful in establishing whether there is exchange of workers between nests to examine further the possibility that $P$. advenus forms polydomous colonies.

It would also be useful in testing for polydomous nest structure to be able to observe the movements of workers among nests in the field. To this end further experimentation is needed to establish a successful means of marking large numbers of workers. This may be in the form of paint application to opened nests or through means such as radioactively labelled food or by use of experimental colonies and strategically placed food resources.

\subsection{General conclusions}

Invasive species exert considerable negative influence on recipient species by means of competition and predation. The effects of competition are typically sub-lethal (Davis, 2003); however they are most frequently reported in terms of displacement and loss of abundance of recipient taxa. In this dissertation I examined the sub-lethal impact of an invasive wasp on a New Zealand endemic ant species, and my results indicate that interactions with invasive species may have more subtle effects on recipient taxa. The restriction of resources by a novel competitor 
may result in reduced growth and altered scaling relationships. In response to exotic competitors, recipient species may modify their foraging behaviour, exploit less profitable environments or engage in potentially costly aggressive interactions. Furthermore, the addition of new competitors to existing intra-specific interactions may result in altered spatial distribution and reduced longevity of native species. In addition, invasive predators may reduce the effective population size of native species and diminish their genetic diversity, particularly in isolated populations or those that are poor dispersers. These are potential impacts of exotic species that would not necessarily be reflected in commonly reported assessments of presence or absence. However, while subtle, these effects may have longer term implications for fitness and longevity by indirect means. Potential mechanisms include impaired resource gathering and defensive efficiency resulting from reduced size, energetic costs imposed by increased competitive activity and an increased risk of damage or injury from aggressive interactions. Furthermore, the loss of genetic diversity resulting from intense predation has the potential to impose costs including lack of resistance to pathogens, loss of adaptive potential and reduced fitness due to inbreeding depression.

This thesis highlights some potential impacts of invasive species on the morphology, behaviour population genetics and spatial distribution of recipient taxa that may applicable across a broader range of taxa. In addition this dissertation provides some new insights into the biology of an abundant and ecologically dominant New Zealand endemic species, which has previously received little attention. 


\subsection{References}

Allendorf, F.W. and Luikart, G. (2007) Conservation and the genetics of populations. Wiley Blackwell Publishing: 642pp

Arnan, X., Ferrandiz-Rovira, M., Pladevall, C. and Rodrigo, A. (2011) Worker sze -related task partitioning in the foraging strategy of a seed -harvesting ant species. Behavioural Ecology and Sociobiology 65: 1881-1890

Beggs, J.R., Toft, R.J., Malham, J.P., Rees, J.S., Tilley, J.A.V., Moller, H. and Alspach, P. (1998) The difficulty of reducing introduced wasp (Vespula vulgaris) populations for conservation gains. New Zealand Journal of Ecology 22(1): 55-63

Bourke, A.F.G. (1988) Worker reproduction in the higher eusocial Hymenoptera. The Quarterly Review of Biology 63(3): 291-311

Bourke, A. F. G. and Franks, N. R. (1995) Social evolution in ants. Princeton University Press, Princeton, New Jersey: 529pp

Braendle, C., Hockley, N., Brevig, T., Shingleton, A. W. and Keller, L. (2003) Size-correlated division of labour and spatial distribution of workers in the driver ant, Dorylus molestus. Naturwissenschaften 90: 277-281

Chapuisat, M., Goudet, J. and Keller, L. (1997) Microsatellites reveal high population viscosity and limited dispersal in the ant Formica paralugubris. Evolution 51(2): 475-482

Chapuisat, M. and Keller, L. (1999) Extended family structure in the ant Formica paralugubris: the role of the breeding system. Behavioural Biology and Sociobiology 46(6): 405-412

Cleméncet, J., Rome, Q., Fédérici, P. and Doums, C. (2008) Aggretions and size related fecundity of queenless workers in the ant Cataglyphis cursor. Naturwissenschaften 95: 133-139

Davies, N.B. (1978) Ecological questions about territorial behaviour.PP 317-350 In Krebs, J.B and Davies, N.B., editors Behavioral Ecology an Evolutionary Approach Sinauer Associates Inc. Sunderland Massachusetts, USA; 494pp

Davis, M.A. (2003) Biotic globalization: does competition from introduced species threaten biodiversity? Bioscience 53(5): 481-489

Don, W. (2007) Ants of New Zealand. Otago University Press, Dunedin, New Zealand: 239pp

Duthie, C. (2011) Factors promoting coexistence between endemic ants and invasive wasps. Unpublished $\mathrm{PhD}$ thesis. Victoria University Wellington

Elliot, S.L. and Hart, A.G. (2010) Density-dependent prophylactic immunity reconsidered in the light of host group living and social behaviour. Ecology 91 (1): 65-72 
Emlen, D.J. and Nijhout, H.F. (2000) The development and evolution of exaggerated morphologies in insects. Annual Review of Entomology 45: 661-708

Gasc, A., Duryea, M.C., Cox, R.M., Kern, A. and Calsbeek, R. (2010) Invasive predators deplete genetic diversity of island lizards. PloS One 5(8): 1-4

Grangier, J. and Lester, P.J. (2011) A novel interference behaviour: invasive wasps remove ants from resources and drop them from a height. Biology Letters 7(5): 664-667

Gyllenstrand, N. and Seppa, P. (2003) Conservation genetics of the wood ant, Formica lugubris, in a fragmented landscape. Molecular Ecology 12: 2931-2940

Harris, R. (1989) An entrance trap to sample foods of social wasps (Hymenoptera: Vespidae). New Zealand Journal of Zoology 16: 369-371

Harris, R. (1991) Diet of the wasps Vespula vulgaris and V. germanica in honeydew beech forest of the South Island, New Zealand). New Zealand Journal of Zoology 18: 159-169

Harris, R.J. and Oliver, E.H. (1993) Prey diets and population densities of wasps Vespula vulgaris and Vespula germanica in a scrubland-pasture. New Zealand Journal of Ecology 15: 512

Helentarä, H. and Sundström, L. (2005) Worker reproduction in the ant Formica fusca. Journal of Evolutionary Biology 18(1); 162-171

Hölldobler, B. And Lumsden, C.J. (1980) Territorial strategies in ants. Science 210(4471):732739

Human, K. G. and Gordon, D. M. (1999) Behavioural interactions of the invasive Argentine ant with native ant species. Insectes Sociaux 46: 159 - 163

Kay, A. and Rissing, S.W. (2005) Division of foraging labour in ants can mediate demands for food and safety. Behavioral Ecology and Sociobiology 58: 165 - 174

Kay, A.D., Rostampour, S. and Sterner, A.W. (2006) Ant stoichiometry: elemental homeostasis in stage-structured colonies. Functional Ecology 20: 1037-1044

Kelly, D., Sterling, D.J., Hunt, G.R., Newell, C.L. and Jarvis, C.E. (1992) Honeydew standing crop and production over 24 hours in Nothofagus solandri forest in Canterbury. New Zealand Journal of Ecology 16(2): 69-75

Levins, S. and Traniello, J. E. A. (1981). Territoriality, nest dispersion, and community structure in ants. Psyche 88: 265-319

MacArthur, R.H. and Levins R. (1967) The limiting similarity, convergence, and divergence of coexisting species The American Naturalist 101(921): 377-385

Mirth, C.K. and Riddiford, L.M. (2007) Size assessment and growth control: how adult size is determined in insects. Bioessays 29(4): 344-355 
Moller, H. and Tilley, J.A.V. (1989) Beech honeydew: seasonal variation and use by wasps, honey bees, and other insects. New Zealand Journal of Zoology 16: 289-302

Palmer, T.M. (2004) Wars of attrition: colony size determines competitive outcomes in a guild of African acacia ants. Animal Behaviour 68: 993-1004

Pamilo, P., Gertsch, P., Thoren, P. and Seppa, P. (1997) Molecular population genetics of social insects. Annual Review of Ecological Systematics 28: 1-25

Peeters, C. and Ito, F. (2001) Colony dispersal and evolution of the queen morphology in social Hymenoptera. Annual Review of Entomology 46: 601-630

Porter, S.D. (1988) Effects of diet on the growth of laboratory fire ant colonies (Hymenoptera:Formicidae). Journal of the Kansas Entomological Society 62(2): 288-291.

Porter, S.D. and Tschinkel, W.R. (1985) Fire ant polymorphism: the ergonomics of brood production. Behavioural Ecology and Sociobiology 16(4): 323-336

Rowles, A. D. and O'Dowd, D. J. (2007) Interference competition by Argentine ants displaces native ants: implications for biotic resistance to invasion. Biological Invasions 9: 73-85

Rüppell, O., Heinze, J. and Hölldobler, B. (2001) Complex determination of queen body size in the queen size dimorphic ant Leptothorax ruatulus (Formicidae: Hymenoptera). Heredity 87: 3340

Schoener, T.W. (1974) Resource partitioning in ecological communities. Science 185 (4145): 2739

Tanner, C.J. (2008) Resource characteristics and competition affect colony and individual foraging strategies of the wood ant Formica integroides. Ecological Entomology 33: 127-136

Tanner, C.J. and Adler, F.R. (2009) To fight or not to fight: context-dependent interspecific aggression in competing ants. Animal Behaviour 77: 297-305

Thomas, C. D., Moller, H., Plunkett, G. M. and Harris, R. J. (1990) The prevalence of introduced Vespula vulgaris wasps in a New Zealand beech forest community. New Zealand Journal of Ecology 13: 63-72

Toft, R.J. and Rees, J. (1998) Reducing predation of orb-web spiders by controlling common wasps (Vespula vulgaris) in a New Zealand beech forest. Ecological Entomology 23: 90-95

Ugelvig, L.V., Kronauer,D.J.C., Schrempf, A., Heinze, J. and Cremer, S. (2010) Rapid antipathogen response in ant societies relies on high genetic diversity. Proceedings of the Royal Society B 277: 2821-2828

Walin, L., Sundström, L., Seppa, P. and Rosengren, R. (1998) Worker reproduction in ants - a genetic analyisis. Heredity 81: 604-612 
Chapter Six - General Discussion

Wu, G.M., Barrette, M., Boivin, G., Brodeur, J., Giraldeau, L.A., and Hance, T. (2011)

Temperature influences the handling efficiency of an aphid parasitoid through body sizemediated effects. Physiological Ecology 40(3): 737-742 
Appendix

\section{Appendix}



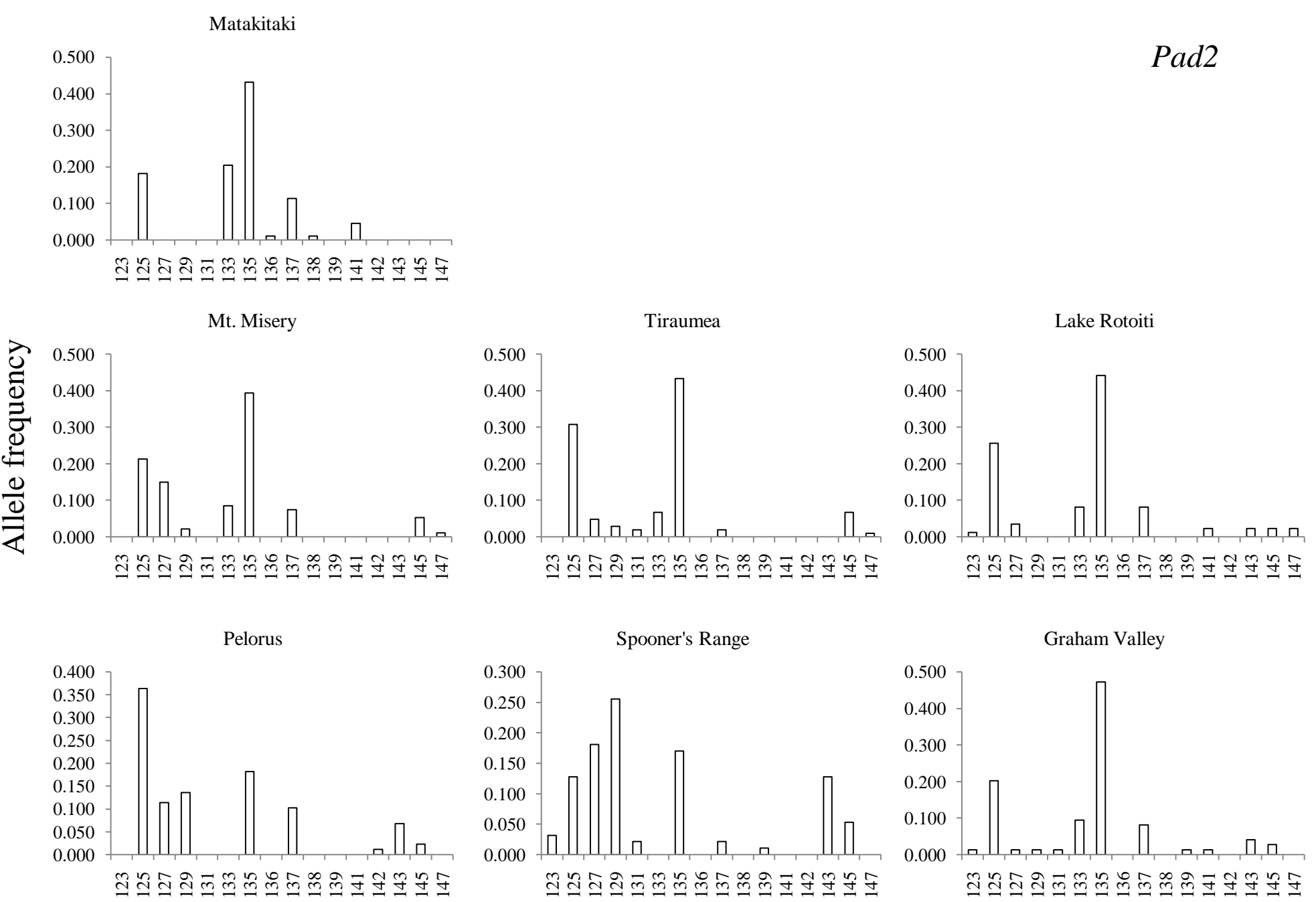

Allele size (basepairs)

Figure A.1 Allele frequency distributions in Prolasius advenus workers for locus Pad2 at each of seven New Zealand South Island Nothofagus beech forest sites with varying levels of infestation by the invasive common wasp Vespula vulgaris. 
Matakitaki
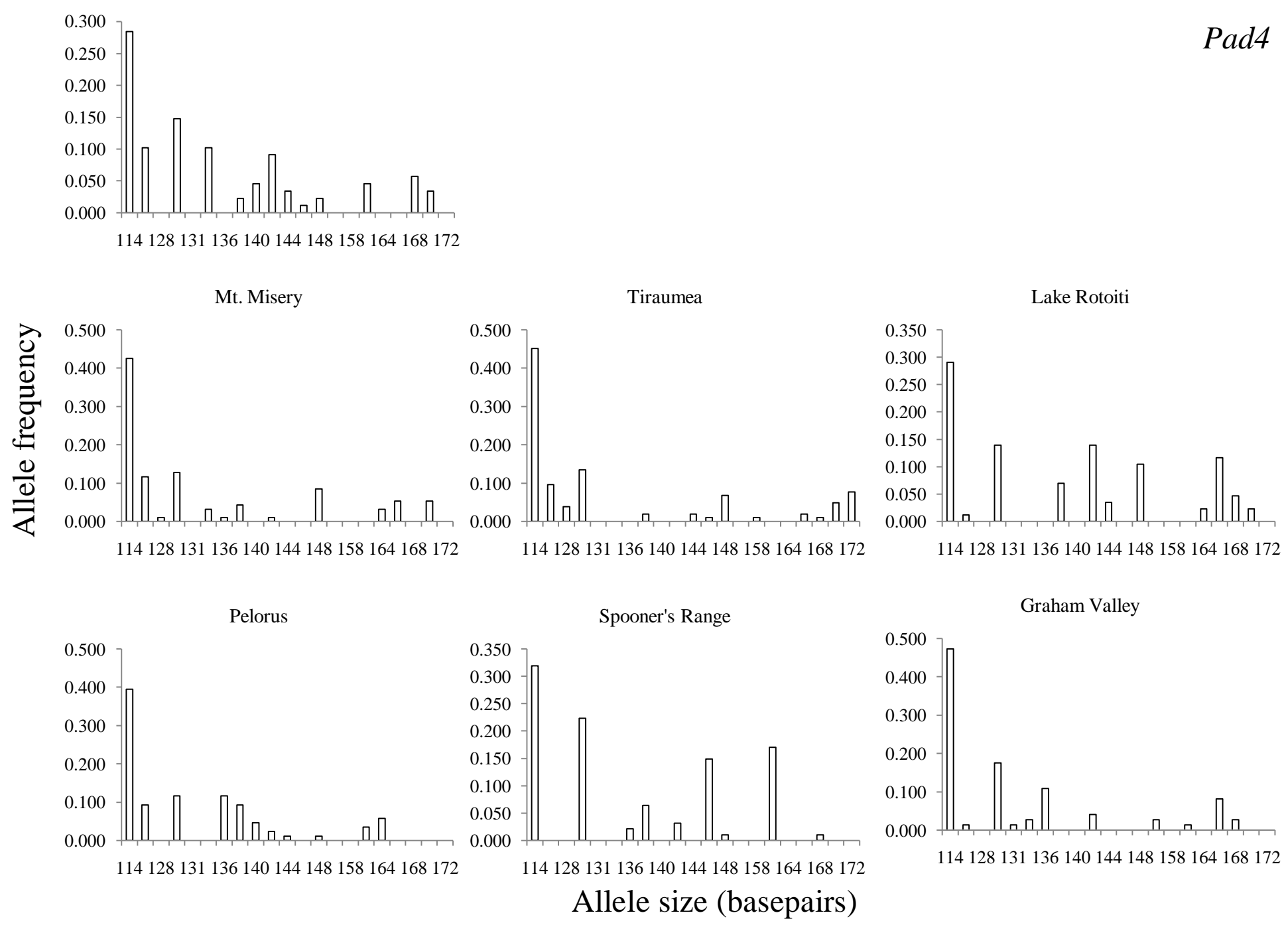

Figure A.2 Allele frequency distributions in Prolasius advenus workers for locus Pad4 at each of seven New Zealand South Island Nothofagus beech forest sites with varying levels of infestation by the invasive common wasp Vespula vulgaris. 
Matakitaki

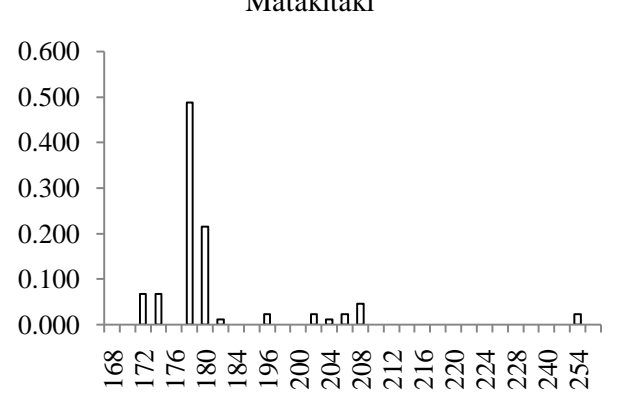

\section{Pad5}

Mt. Misery

Tiraumea

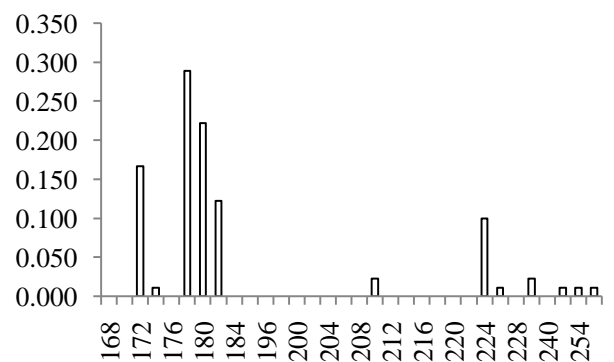

Spooner's Range
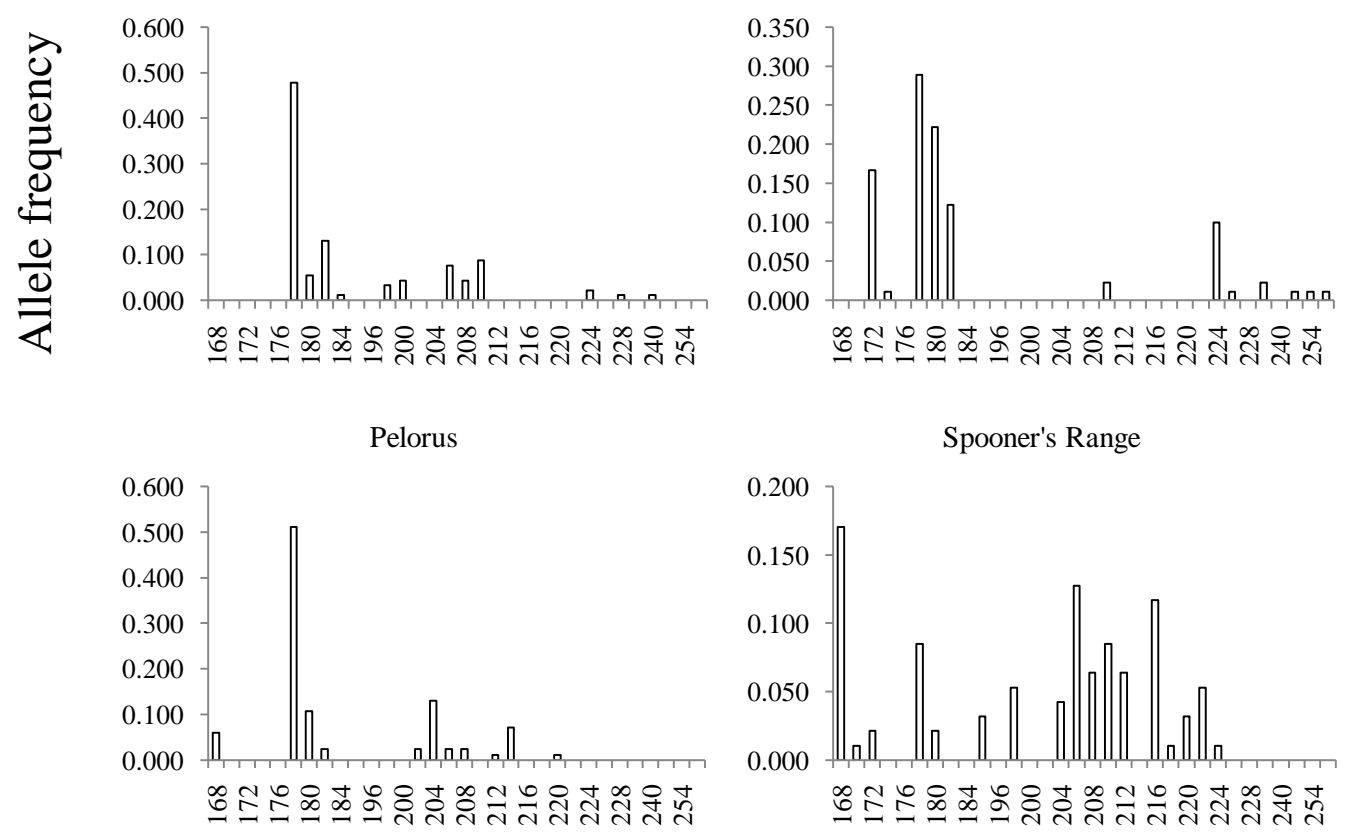

Allele size (basepairs)

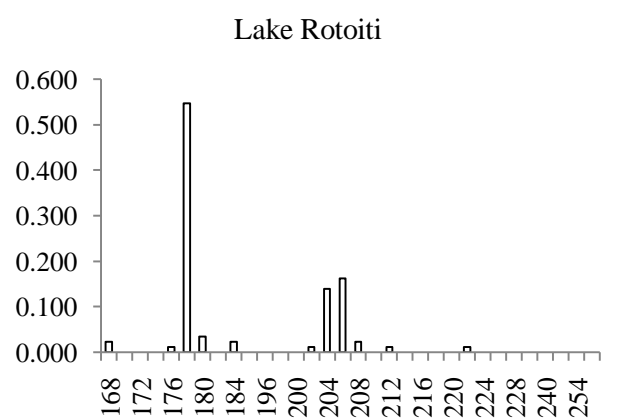

Graham Valley

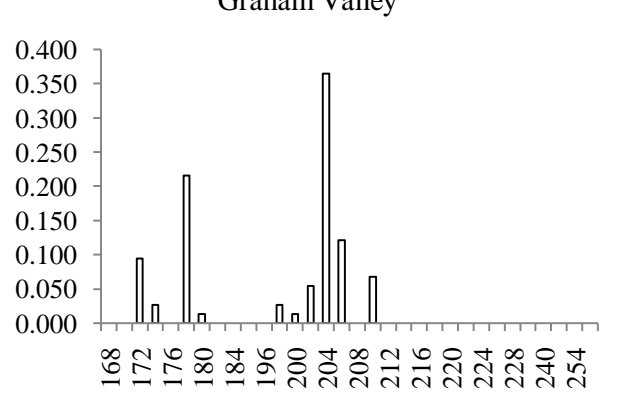

Figure A.3 Allele frequency distributions in Prolasius advenus workers for locus Pad5 at each of seven New Zealand South Island Nothofagus beech forest sites with varying levels of infestation by the invasive common wasp Vespula vulgaris. 


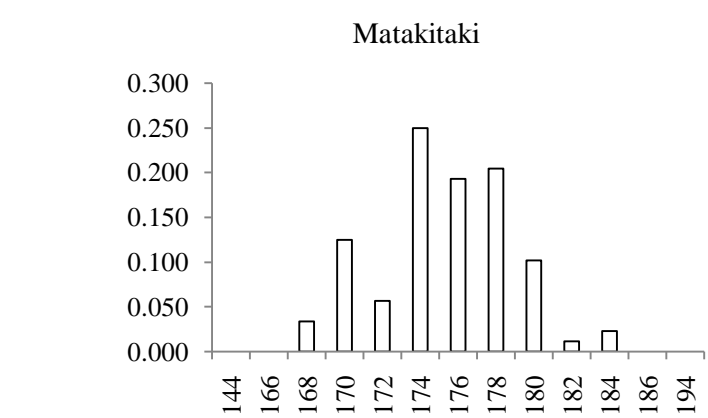

Pad9
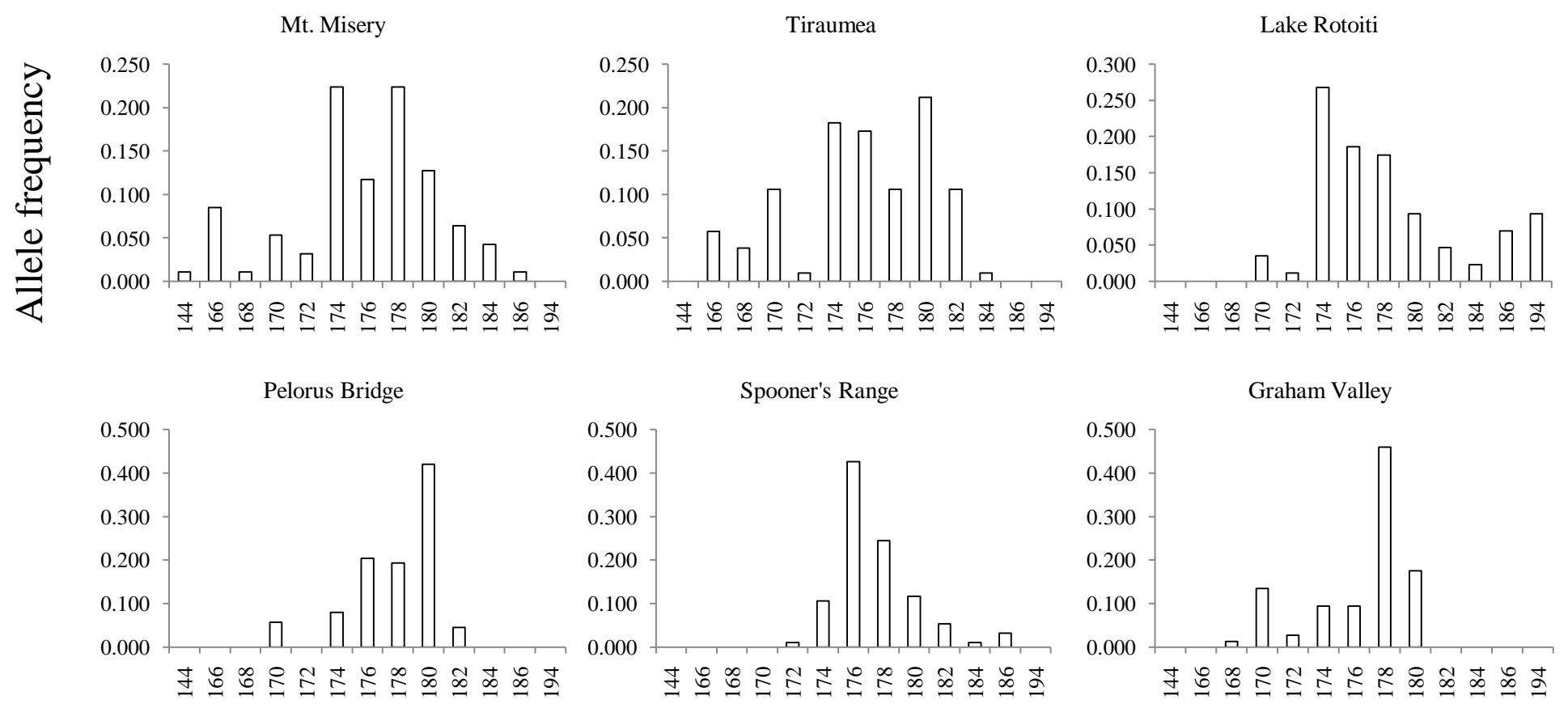

\section{Allele size (basepairs)}

Figure A.4 Allele frequency distributions in Prolasius advenus workers for locus Pad9 at each of seven New Zealand South Island Nothofagus beech forest sites with varying levels of infestation by the invasive common wasp Vespula vulgaris. 
Matakitaki

\section{Pad10}
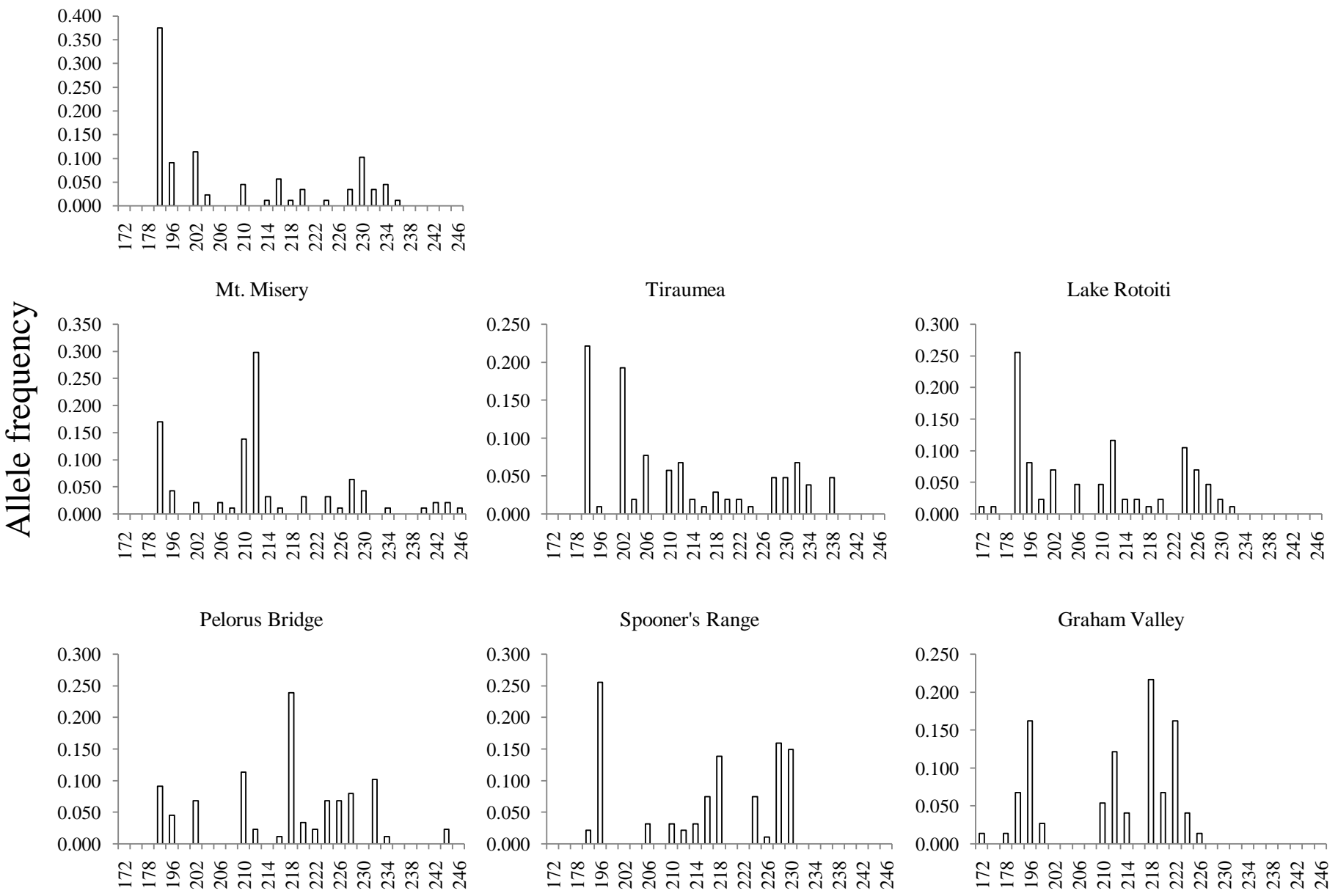

\section{Allele size (basepairs)}

Figure A.5 Allele frequency distributions in Prolasius advenus workers for locus Pad10 at each of seven New Zealand South Island Nothofagus beech forest sites with varying levels of infestation by the invasive common wasp Vespula vulgaris. 
Matakitaki

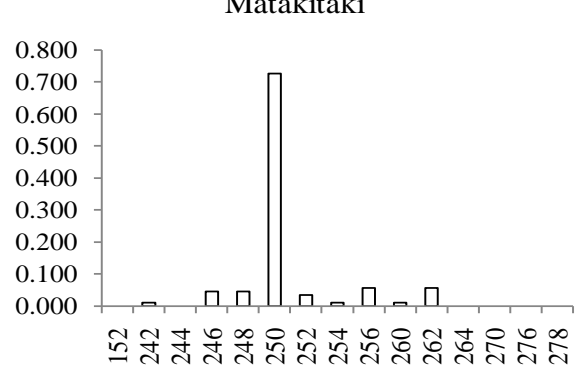

Mt. Misery
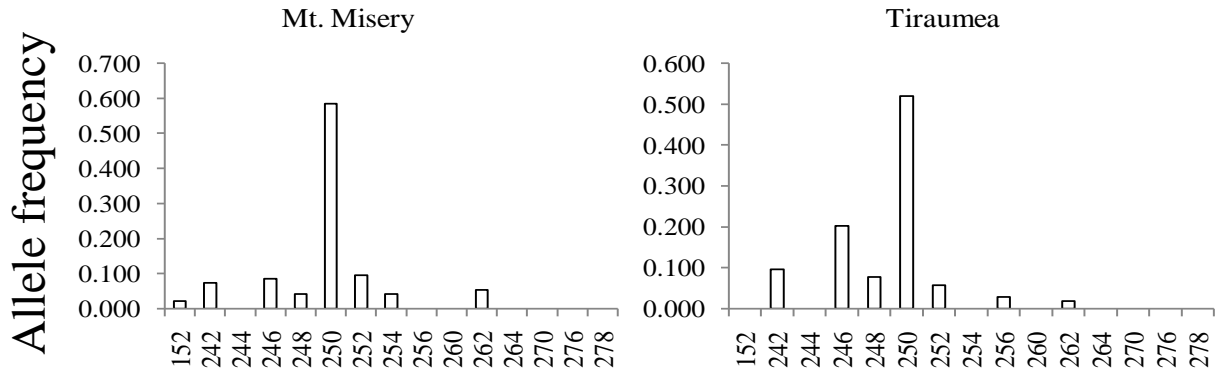

Pelorus Bridge

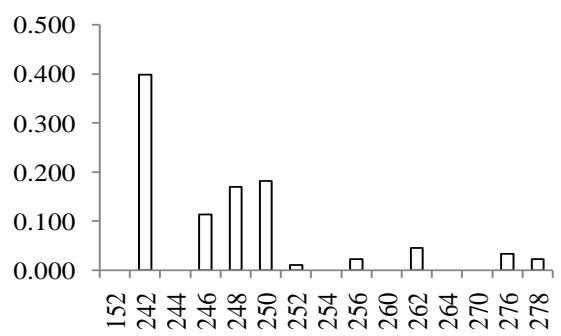

Spooner's Range

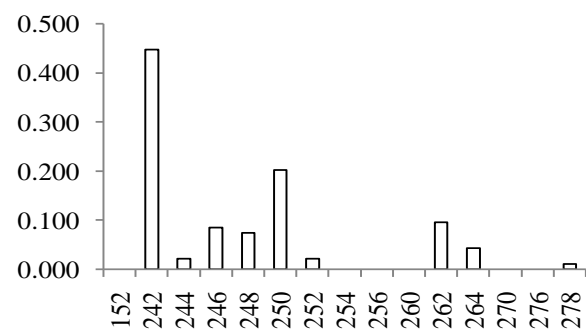

Pad15

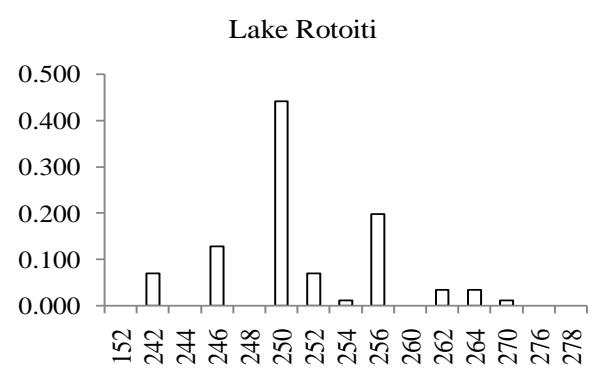

Graham Valley

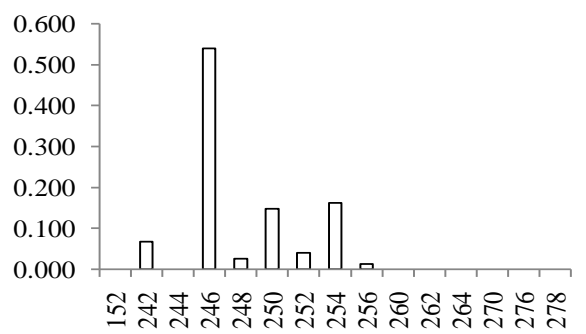

Allele size (basepairs)

Figure A.6 Allele frequency distributions in Prolasius advenus workers for locus Pad15 at each of seven New Zealand South Island Nothofagus beech forest sites with varying levels of infestation by the invasive common wasp Vespula vulgaris. 